\title{
Osteology, relationships, and functional morphology of Weigeltisaurus jaekeli (Diapsida, Weigeltisauridae) based on a complete skeleton from the Upper Permian Kupferschiefer of Germany
}

\author{
Adam C Pritchard ${ }^{\text {Corresp., } 1,2}$, Hans-Dieter Sues ${ }^{2}$, Diane Scott ${ }^{3}$, Robert R. Reisz ${ }^{3,4}$ \\ 1 Department of Paleontology, Virginia Museum of Natural History, Martinsville, Virginia, United States \\ 2 Department of Paleobiology, National Museum of Natural History, Smithsonian Institution, Washington, District of Columbia, United States \\ 3 Department of Biology, University of Toronto Mississauga, Mississauga, Ontario, Canada \\ 4 Dinosaur Evolution Research Centre and International Centre of Future Science, Jilin University, Changchun, China \\ Corresponding Author: Adam C Pritchard \\ Email address: adamcarlpritchard@gmail.com
}

Background. Weigeltisauridae is a clade of small-bodied diapsids characterized by a horned cranial frill, slender trunk and limbs, and a patagium supported by elongated bony rods. Partial skeletons and fragments are definitively known only from upper Permian (Lopingian) rocks in England, Germany, Madagascar, and Russia. Despite these discoveries, there have been few detailed descriptions of weigeltisaurid skeletons, and the homologies of many skeletal elements-especially the rods supporting the patagium-remain the subject of controversy. Materials \& Methods. Here, we provide a detailed description of a nearly complete skeleton of Weigeltisaurus jaekeli from the upper Permian (Lopingian: ?Wuchiapingian) Kupferschiefer of Lower Saxony, Germany. Briefly addressed by past authors, the skeleton preserves a nearly complete skull, postcranial axial skeleton, appendicular skeleton, and patagial supports. Through comparisons with extant and fossil diapsids, we examine the hypotheses for the homologies of the patagial rods. To examine the phylogenetic position of Weigeltisauridae and characterize the morphology of the clade, we integrate the material and other weigeltisaurids into a parsimony-based phylogenetic analysis focused on Permo-Triassic non-saurian Diapsida and early Sauria (61 taxa, 339 characters). Results. We recognize a number of intriguing anatomical features in the weigeltisaurid skeleton described here, including hollow horns on the post-temporal arch, lanceolate teeth in the posterior portion of the maxilla, the absence of a bony arch connecting the postorbital and squamosal bones, elongate and slender phalanges that resemble those of extant arboreal squamates, and patagial rods that are positioned superficial to the lateral one third of the gastral basket. Our phylogenetic study recovers a monophyletic Weigeltisauridae including Coelurosauravus 
elivensis, Weigeltisaurus jaekeli, and Rautiania spp. The clade is recovered as the sister taxon to Drepanosauromorpha outside of Sauria (=Lepidosauria + Archosauria).

Conclusions. Our anatomical observations and phylogenetic analysis show variety of plesiomorphic diapsid characters and apomorphies of Weigeltisauridae in the specimen described here. We corroborate the hypothesis that the patagial ossifications are dermal bones unrelated to the axial skeleton. The gliding apparatus of weigeltisaurids was constructed from dermal elements unknown in other known gliding diapsids. SMNK-PAL 2882 and other weigeltisaurid specimens highlight the high morphological disparity of Paleozoic diapsids already prior to their radiation in the early Mesozoic. 
1 Osteology, relationships, and functional morphology 2 of Weigeltisaurus jaekeli (Diapsida, Weigeltisauridae) 3 based on a complete skeleton from the Upper Permian 4 Kupferschiefer of Germany

Adam C. Pritchard ${ }^{1,2}$, Hans-Dieter Sues ${ }^{2}$, Diane Scott ${ }^{3}$, Robert R. Reisz ${ }^{3,4}$.

${ }^{1}$ Virginia Museum of Natural History, Martinsville, Virginia, United States of America 24112

$9 \quad{ }^{2}$ Department of Paleobiology, National Museum of Natural History, Smithsonian Institution,

10 Washington, DC, United States of America 20560

$11{ }^{3}$ Department of Biology, University of Toronto Mississauga, Mississauga, Ontario, Canada

12 M9A1X1

$13{ }^{4}$ Dinosaur Evolution Research Centre and international Centre of Future Science, Jilin

14 University, Changchun, China

15

16 Corresponding Author:

17 Adam C. Pritchard

1821 Starling Avenue

19 Martinsville, VA 24112

20 United States of America

21 Email address: adam.pritchard@vmnh.virginia.gov

22 


\section{Abstract}

24

25 - Background. Weigeltisauridae is a clade of small-bodied diapsids characterized by a horned

26 cranial frill, slender trunk and limbs, and a patagium supported by elongated bony rods. Partial

27 skeletons and fragments are definitively known only from upper Permian (Lopingian) rocks in

28 England, Germany, Madagascar, and Russia. Despite these discoveries, there have been few

29 detailed descriptions of weigeltisaurid skeletons, and the homologies of many skeletal

30 elements - especially the rods supporting the patagium-remain the subject of controversy.

31 - Materials \& Methods. Here, we provide a detailed description of a nearly complete skeleton

32 of Weigeltisaurus jaekeli from the upper Permian (Lopingian: ?Wuchiapingian)

33 Kupferschiefer of Lower Saxony, Germany. Briefly addressed by past authors, the skeleton

34 preserves a nearly complete skull, postcranial axial skeleton, appendicular skeleton, and

35 patagial supports. Through comparisons with extant and fossil diapsids, we examine the

36 hypotheses for the homologies of the patagial rods. To examine the phylogenetic position of

37 Weigeltisauridae and characterize the morphology of the clade, we integrate the material and

38 other weigeltisaurids into a parsimony-based phylogenetic analysis focused on Permo-Triassic

39 non-saurian Diapsida and early Sauria (61 taxa, 339 characters).

40

41

42

43

44

45

- Results. We recognize a number of intriguing anatomical features in the weigeltisaurid skeleton described here, including hollow horns on the post-temporal arch, lanceolate teeth in the posterior portion of the maxilla, the absence of a bony arch connecting the postorbital and squamosal bones, elongate and slender phalanges that resemble those of extant arboreal squamates, and patagial rods that are positioned superficial to the lateral one third of the gastral basket. Our phylogenetic study recovers a monophyletic Weigeltisauridae including 
46 Coelurosauravus elivensis, Weigeltisaurus jaekeli, and Rautiania spp. The clade is recovered

47 as the sister taxon to Drepanosauromorpha outside of Sauria (=Lepidosauria + Archosauria).

48 - Conclusions. Our anatomical observations and phylogenetic analysis show variety of

49 plesiomorphic diapsid characters and apomorphies of Weigeltisauridae in the specimen

50 described here. We corroborate the hypothesis that the patagial ossifications are dermal bones

51 unrelated to the axial skeleton. The gliding apparatus of weigeltisaurids was constructed from

52 dermal elements unknown in other known gliding diapsids. SMNK-PAL 2882 and other

53 weigeltisaurid specimens highlight the high morphological disparity of Paleozoic diapsids

54 already prior to their radiation in the early Mesozoic.

55

56 Introduction

57

58

The transition between the Paleozoic and Mesozoic eras involved a radical reversal of

fortunes for the Diapsida, the clade including all extant reptiles and birds. Diapsid fossils are

known from Permian strata around the globe, but they are less speciose than and vastly

outnumbered by nonmammalian synapsids and parareptiles. The subsequent Triassic Period saw

the emergence of many new diapsid clades and their rapid rise to abundance over the parareptiles and nonmammalian synapsids that survived the end-Permian extinction (Ezcurra et al., 2014;

64 Sues, 2020a).

Despite their relative rarity and limited species diversity, diapsids achieved a surprising morphological disparity long before they rose to prominence in the Mesozoic. Permian examples

67 of the group include lizard-like terrestrial forms (e.g., Gow, 1975; Carroll and Thompson, 1982; 
69 tails (e.g., Carroll, 1981; Currie, 1981a, 1982; Buffrénil and Mazin, 1989), and—by the very end

70 of the period-large-bodied carnivores (e.g., Sennikov, 1988; Ezcurra, 2016). Among the most

71 highly specialized of all known Permian diapsids are the Weigeltisauridae, a clade of diapsids

72 with frilled crania and specialized gliding adaptations. Herein, we describe a nearly complete

73 skeleton of a weigeltisaurid diapsid from the upper Permian (Lopingian: ?Wuchiapingian) of

74 Germany. The completeness of the specimen provides an opportunity to describe the osteology

75 of weigeltisaurid reptiles, contextualize the unique gliding apparatus in the clade, and revise the

76 phylogenetic placement of the group.

77

78 Geological Context

79

80

The specimen described here was found in the Kupferschiefer of Ellrich in the Mansfeld

mining district in Saxony-Anhalt of Germany (see Figure 7 of Paul, 2006). The Kupferschiefer

82

was deposited in a large marine basin extending from northern England (where it is known as the Marl Slate) far into Poland during the late Permian (Lopingian). The basin was located at a paleolatitude of about 15 to 20 degrees North and was bordered to the South by the Variscian mountains. The Kupferschiefer is a finely laminated marly shale that usually attains a thickness of less than one meter. When freshly exposed it is dark gray to black in color due to a high content of degraded organic carbon (Wedepohl, 1994). The Kupferschiefer contains significant amounts of copper (locally up to 3\% in Germany), lead, silver, and zinc and was mined from possibly Bronze Age times well into the last century. 
92 regions (Haubold and Schaumberg, 1985; Brandt, 1997; Sues, 2020b). It preserves few remains

93 of benthic organisms, which, along with an absence of bioturbation and a relatively high amount

94 of organic carbon, indicates deposition of the shale in anoxic deeper waters.

95 The Kupferschiefer Formation (T1) is the stratigraphically lowest unit of the Zechstein

96 Group. The age of this formation continues to be contentious. It is usually dated as early

97 Wuchiapingian based primarily on the presence of the conodont taxa Merrillina divergens and

98 Mesogondolella britannica in both the Kupferschiefer and the overlying Zechsteinkalk (Z1;

99 Szurlies, 2013). However, Hounslow and Balabanov (2018) noted that Merrillina divergens has

100 a much more extensive stratigraphic range (including strata dated as Changhsingian by other

101 means) and cautioned against its use as an index fossil. Denison and Peryt (2009) placed the

102 entire Zechstein Group in the Changhsingian based on strontium radioisotopic data. Furthermore,

103 Hounslow and Balabanov (2018) argued that the base of the Zechstein Group is in the oldest

104 portion of the Permian magnetochron LP2n.3n and thus the Kupferschiefer would be

105 Changhsingian in age.

106

107 History of Research

108

109

Weigelt (1930a) described much of the skeleton of an unusual reptile from the

110 Kupferschiefer of Eisleben in the Mansfeld region of Saxony-Anhalt (Germany). The famous

111 German paleontologist Otto Jaekel had purchased this specimen (now cataloged as SSWG 113/7

112 in the geological collections of the University of Greifswald), identified in a note as a "flying

113 reptile," along with some other fossils by from a dealer in 1913 (Fig. 1). Preoccupied with many

114 other projects, he never published on this fossil but prepared it himself. When Weigelt succeeded 
115 Jaekel as professor of geology and paleontology at the University of Greifswald he found the

116 specimen in the collections. He described it as a new taxon, Palaeochamaeleo jaekeli and

117 assigned it to Rhynchocephalia. Weigelt emphasized the distinctive casque formed by the

118 posterior portion of the cranium, which bore a striking resemblance to those in chamaeleonid

119 lizards. Associated with the skeleton were bundles of rod-like bones. Jaekel considered these

120 rods fin-rays of an overlying caudal fin of the actinistian fish Coelacanthus granulatus and

121 removed many of them during preparation to expose the reptilian skeleton.

122 Huene (1930) first drew attention to various similarities between Palaeochamaeleo

123 jaekeli and Coelurosauravus elivensis, which was briefly described by Piveteau (1926) from late

124 Permian strata of the Lower Sakamena Formation in Madagascar. He considered both taxa

125 closely related and interpreted them as very slender-limbed reptiles capable of climbing. He

126 quoted a letter from the British paleontologist D. M. S. Watson who had examined Piveteau's

127 specimens in 1927 and concluded that denticulated bones identified by Piveteau as lower jaws

128 were more likely parts of a chameleon-like cranial frill.

129

Kuhn (1939) noted that the generic nomen Palaeochamaeleo was preoccupied by De

130 Stefano (1903) and proposed the replacement name Weigeltisaurus. He also reinterpreted the

131 temporal region of the cranium as just having a single large temporal opening on either side

132 rather than the common diapsid condition with two openings suggested by Weigelt (1930a).

133 After several decades, interest in Weigeltisaurus and Coelurosauravus was reawakened

134 by the discovery of additional specimens of the former in Germany (Schaumberg, 1976, 1986)

135 and England (Pettigrew, 1979). Schaumberg noted the presence of numerous bony rods in the

136 new skeletons reported by him and argued that they were parts of the reptile's skeleton rather

137 than of overlying coelacanth fins. Independently, Carroll (1978) re-examined the material of 
138 Coelurosauravus elivensis reported by Piveteau (1926). He segregated one nearly complete

139 skeleton as a new taxon, Daedalosaurus madagascariensis. Carroll interpreted its long rod-like

140 bones as greatly elongated ribs and the new reptile as a glider.

141 Evans (1982) provided a detailed description of the well-preserved partial skeleton

142 referred to Weigeltisaurus jaekeli by Pettigrew (1979) from the Marl Slate of the Eppleton quarry

143 near Hetton-le-Hole in northeastern England. She also reviewed the then-known specimens of

144 Weigeltisaurus, Coelurosauravus, and Daedalosaurus. Correcting some of Carroll's

145 interpretations of skeletal features, Evans concluded that Daedalosaurus was a subjective junior

146 synonym of Coelurosauravus. She placed both Coelurosauravus and Weigeltisaurus in a family

147 Coelurosauravidae. Evans considered the trunk ribs bipartite, each composed of a short proximal 148 and a greatly elongated distal portion.

149 Following re-examination of the holotype of Weigeltisaurus jaekeli and identification of

150 another specimen, Evans and Haubold (1987) argued that this taxon was congeneric with

151 Coelurosauravus elivensis. This reallocation was subsequently widely accepted in the literature.

152 The authors also synonymized Gracilisaurus ottoi, based on disarticulated postcranial remains of

153 a small reptile from the Kupferschiefer of the Otto-Schacht (mine) in the Mansfeld region

154 (Weigelt 1930b), with Coelurosauravus jaekeli.

155 The exceptionally complete skeleton that forms the basis of this paper was found near

156 Ellrich in the Mansfeld region of Saxony-Anhalt (Germany) in 1992. It is preserved as part and

157 counterpart. A private collector acquired one of the slabs and later the Staatliches Museum für

158 Naturkunde Karlsruhe purchased the other. Frey et al. (1997) briefly discussed the nature of the

159 rod-like bones that supported a gliding membrane and explicitly noted that these structures were

160 neomorphs rather than parts of ribs. Schaumberg (1976) had hinted at this possibility but 
161 hesitated to state it explicitly. Schaumberg et al. (2007) provided additional information on the

162 Ellrich specimen and discussed the structure of the gliding apparatus.

In 2005, a Russian expedition prospecting late Permian lacustrine strata near the village

164 165

180

\section{Materials \& Methods}

182

183

\author{
Materials \& Methods
}

83 Systematic Paleontology

of Kul'chumovo in the Saraktashkii district of the Orenburg region (Russia) discovered a deposit of numerous mostly isolated but well-preserved bones referable to Weigeltisaurus-like reptiles. Bulanov and Sennikov (2006) identified a new genus Rautiania and divided it into two species based on differences among the cranial bones. Bulanov and Sennikov (2010) provided a detailed anatomical description additional material referable to Rautiania. Subsequently, these authors reexamined Coelurosauravus elivensis (Bulanov and Sennikov, 2015a) and Weigeltisaurus jaekeli (Bulanov and Sennikov, 2015b). They argued for maintaining a generic separation of these two taxa and noted that Weigeltisauridae Kuhn, 1939 has clear priority over Coelurosauravidae Evans, 1982. Like Kuhn (1939), Bulanov and Sennikov (2015a,b) reconstructed the temporal region of the cranium as having a single large temporal opening on either side. Finally, Bulanov and Sennikov (2015c) recognized an additional weigeltisaurid taxon, Glaurung schneideri, based on much of a skeleton including the skull found in the vicinity of Mansfeld and now housed in a private collection. Schaumberg et al. (2007) had previously briefly discussed this find, which they identified as Coelurosauravus sp. Glaurung schneideri differs from Weigeltisaurus jaekeli in various cranial features, especially the proportionately much broader parietals and squamosals. 
184

185 Diapsida Osborn, 1903

186 Weigeltisauridae Kuhn, 1939

187 Weigeltisaurus Kuhn, 1939

188

189 Type species: Weigeltisaurus jaekeli (Weigelt, 1930a)

190

191 SYNONYMIES

192 Palaeochamaeleo jaekeli Weigelt, 1930a.

193 Gracilisaurus ottoi Weigelt, 1930b.

194 Coelurosauravus jaekeli (Weigelt, 1930a).

195

196

197 Holotype: SSWG 113/7, complete skull, nearly complete forelimbs, partial hindlimbs, 198 articulated dorsal vertebrae, scattered patagials (many prepared away).

199

200 Referred specimen: SMNK-PAL 2882, nearly complete skull and skeleton preserved on a slab 201 (part only).

202

203 Stratigraphic occurrence: Kupferschiefer of Germany (Lopingian, Permian) and correlative 204 Marl Slate of England.

205 
206 Differential diagnosis: We herein list a number of characters that allow referral of SMNK-PAL

2072882 to Weigeltisaurus jaekeli and that differentiate the specimen from other named

208 weigeltisaurid taxa. In all listed characters, SMNK-PAL 2882 compares favorably with SSWG

209 113/7, the holotype of Weigeltisaurus jaekeli, and the diagnosis offered for the species by

210 Bulanov and Sennikov (2015b). A full revision of the taxonomy of European weigeltisaurids is

211 beyond the scope of this paper,

SMNK-PAL 2882 differs from Coelurosauravus elivensis in (1) presence of prominent

213 horns on dorsolateral surface of parietal (absent in C. elivensis), (2) jugal with anteroposteriorly

214 short, rapidly tapering anterior process (proportionally longer in C. elivensis), and, tentatively,

215 (3) ventral bases of anterior patagial ossifications with little-to-no inter-element spacing (widely

216 spaced in C. elivensis based on MNHN.F.MAP327).

SMNK-PAL 2882 differs from the material referred to Rautiania sp. in (1) premaxilla

218 with space for eight to nine teeth (more than ten teeth present in referred premaxillae of

219 Rautiania sp.), (2) lateral horn on quadratojugal proportionally shorter than all but the

220 dorsalmost squamosal horn (lateral horn on quadratojugal proportionally longer in Rautiania sp.)

221 SMNK-PAL 2882 differs from Rautiania alexandri in (1) possessing dorsoventrally

222 shallow and gradually tapering jugal facet on posterodorsal face of maxilla (proportionally

223 broader and more rapidly tapering in R. alexandri) and (2) bearing slender, tapering horns

224 separated by concave spaces on lateral surface of parietal (horns are dorsoventrally broader

225 without spaces in $R$. alexandri).

226 SMNK-PAL 2882 differs from Rautiania minichi in (1) possessing dorsoventrally

227 shallow and gradually tapering jugal facet on posterodorsal face of maxilla (proportionally

228 broader and more rapidly tapering in $R$. minichi). 
230 tapering horns on lateral surface of parietal (rugose margin present in G. schneideri), (2)

231 presence of slender lateral horns on lateral surface of squamosal, separated by distinct gaps

232 (broader horns without gaps in G. schneideri), and (3) presence of lateral horns on dorsalmost 233 portion of squamosal (dorsal horns absent in G. schneideri).

234

235 Overview and Preservation

236

237

SMNK-PAL 2882 is a nearly complete skeleton of Weigeltisaurus jaekeli (Fig. 2). Frey et al.

238 (1997) and Schaumberg et al. (2007) provided preliminary anatomical details of the specimen,

239 focusing on the anatomy of the skull and the homology of the patagial spars. The specimen is

240 preserved as part and counterpart on two separate slabs. Only the part has been accessioned in

241 the collections of the Staatliches Museum für Naturkunde Karlsruhe (as SMNK-PAL 2882). The

242 counterpart is held in a private collection and is inaccessible to scientific study.

243 The skull is preserved in ventral view (Fig. 3). Identifiable elements of the palate and

244 braincase are absent, such that the ventral surfaces of the rostrum and skull roof are exposed.

245 Much of the left mandibular ramus is also absent, although a tiny dentigerous portion of the

246 dentary and the postdentary complex are preserved around the level of the orbit. Much of the

247 skull is slightly disarticulated, and many bones remain three-dimensional and uncrushed. Our

248 observations of the skull in SMNK-PAL 2882 corroborate the reconstruction of the

249 Weigeltisaurus jaekeli skull in lateral view presented by Bulanov and Sennikov (2015b:Fig. 2).

250 Substantial segments of the vertebral column are missing in SMNK-PAL 2882 (Fig. 2).

251 Some cervical vertebrae are absent. Only a small number of dorsal vertebrae are preserved in 
252 lateral view. Two partial dorsal vertebrae are preserved in articulation posterior to the pectoral

253 girdle. A large gap separates these from the next segment, beginning at roughly $1 / 3$ the length of

254 the trunk region. These consist of a posterior half of a dorsal vertebra articulated to a series of

255 seven transversely compressed dorsal vertebrae. The second and seventh in the series are only

256 partially preserved, surrounded by an impression of the complete element.

257 The most complete portion of the vertebral column is the caudal series. The anteriormost

258 portion of the tail is covered by a sheet of appressed right patagial ossifications, followed by a

259 series of seven articulated caudal vertebrae. The mid-portion of this series is superficial to the

260 right tarsus. The subsequent two caudal vertebrae are preserved deep to proximal portion of the

261 right forearm, followed by a substantial segment of the tail preserved positioned deep to the

262 skull. The preserved tail terminates as a series of 23 posterior caudal vertebrae, which curves in

263 parallel to the curvature of the trunk region. A few probable chevrons are preserved as well.

264 The appendicular skeleton is largely complete in SMNK-PAL 2882, although the pectoral

265 and pelvic girdles are badly crushed. In our interpretation, the left scapulocoracoid is nearly

266 complete and exposed in lateral view. The anterior edge of the scapulocoracoid is framed by two

267 anteroposteriorly slender, curved rods of bone, which we interpret as the clavicle and cleithrum,

268 respectively. Both forelimbs are complete except for the carpal elements-which are not even

269 preserved as impressions - and the first digit of the left manus.

270 The pelvic region is exposed in dorsal view between two bundles of patagial spars. It is not

271 clear how much of the pelvic girdle is preserved, although both femora appear to remain in

272 articulation with their respective acetabula. The left hindlimb is complete except for all of the

273 tarsal elements and segments of each pedal digit. The proximal end of the right femur is exposed,

274 but the remainder is buried deep under a bundle of patagial spars. The right fibula is not 
275 preserved, and only the distal end of the right tibia can be seen, positioned deep under the

276 patagial spars and an articulated series of caudal vertebrae. The right tarsal bones are not

277 preserved, but the remainder of the right foot is nearly complete.

278 A large number of gastralia are preserved, framing the ventral portion of the trunk posterior 279 to the pectoral girdle and anterior to the pelvis. Some are preserved only as impressions, and an 280 accurate reconstruction of an individual segment is not feasible.

281 The most remarkable and noticeable bones present in SMNK-PAL 2882 are the patagial 282 ossifications: straight, slender bones that extend from the ventrolateral portion of the trunk. Some 283 of these represent the longest bones in the skeleton, being over four times the length of the left 284 femur. The left patagial ossifications are very incomplete. The distal ends of a bundle from the 285 anterior trunk region are preserved overlapping the posterior trunk vertebrae and the proximal 286 ends of the right patagial ossifications near the pelvis. The right patagial ossifications are nearly 287 complete, positioned deep to the preserved dorsal vertebral column. The posteriormost patagial 288 ossifications are tightly bundled together and anteroposteriorly short, making an accurate count 289 of the ossifications difficult.

290 It is plausible that the counterpart of SMNK-PAL 2882 preserves many of the missing bones. 291 Considering the phylogenetic and functional importance of the palate, braincase, carpus, and 292 tarsus, we encourage future paleontologists to pursue the specimen and bring it into a publicly 293 accessible museum collection for study. 
297 For the clade Neodiapsida Benton 1985, we employ the stem-based definition of Reisz et al. 298 (2011:3733) as "Youngina capensis Broom, 1914 [12] and all species more closely related to it 299 than to Petrolacosaurus kansensis Lane, 1945 [18]," in contrast to the node-based definition of 300 Laurin (1991) which used Younginiformes as a reference taxon. As noted by Bickelmann et al. 301 (2009) and Reisz et al. (2011), Younginiformes is likely a non-monophyletic grouping of non302 saurian diapsids. We note that this definition of Neodiapsida would incorporate a wide range of 303 non-traditional diapsids such as Parareptilia and Varanopidae under the phylogenetic hypotheses 304 of Laurin and Piñeiro (2017) and Ford and Benson (2019b). Future revisions to the definition of 305 Neodiapsida are encouraged.

306 The clade Avicephala Senter 2004 was defined by Senter (2004:261) as "all taxa more 307 closely related to Coelurosauravus and Megalancosaurus than to Neodiapsida." As our 308 definition of Neodiapsida would incorporate weigeltisaurids and drepanosauromorphs, a revised 309 definition is required. We herein redefine Avicephala as a stem-based taxon including all taxa 310 more closely related to Weigeltisaurus jaekeli Weigelt 1930 and Drepanosaurus unguicaudatus

311 Pinna 1979 than to Petrolacosaurus kansensis Lane 1945, Orovenator mayorum Reisz et al.

312 2011, Claudiosaurus germaini Carroll 1978, Youngina capensis Broom 1914, or Sauria

313 Macartney 1802 (sensu Gauthier et al. 1988). If future analyses strongly support the non-

314 monophyly of Avicephala relative to the other reference taxa listed, we recommend the 315 abandonment of the taxon.

316 Although Weigeltisauridae was first named by Kuhn (1939), no modern phylogenetic 317 definition for the clade has been offered. Kuhn (1969) defined the order Weigeltisauria and 318 family Weigeltisauridae based on a series of anatomical characters including the single temporal 319 fenestra, ornamented post-temporal arches, and an elongated internarial process of the 
320 premaxilla. To coincide with the intent of this definition we define Weigeltisauridae as a stem-

321 based taxon including Weigeltisaurus jaekeli Weigelt 1930 and all taxa more closely related to it

322 than Petrolacosaurus kansensis Lane 1945, Orovenator mayorum Reisz et al. 2011,

323 Drepanosaurus unguicaudatus Pinna 1979, Claudiosaurus germaini Carroll 1978, Youngina

324 capensis Broom 1914, and Sauria Macartney 1802 (sensu Gauthier et al. 1988).

325

326

Phylogenetic Methods

327

328

To explore the phylogenetic affinities of Weigeltisaurus jaekeli and Weigeltisauridae among

329

diapsid reptiles, we integrated new codings from SMNK-PAL 2882 into a modified phylogenetic

330

matrix based on the diapsid analysis from Pritchard and Sues (2019). This analysis represents a

331 downstream modification of earlier analyses presented in Pritchard and Nesbitt (2017) and

332 Pritchard et al. (2018). Changes to codings based on observations of new material and new

333 literature are noted in Appendix 1. Our modified matrix does not take into account modifications

334 suggested by Scheyer et al. (2020), which focused on the affinities of the saurian Colobops

335 noviportensis, as that is outside the scope of this work. Outside of additional codings for

336 weigeltisaurid taxa, the most substantial changes occur in the codings of Orovenator mayorum

337 based on the description of Ford and Benson (2019a).

338 Our analysis employs the araeoscelid diapsid Petrolacosaurus kansensis as an outgroup, as in 339 many prior studies of diapsid interrelationships (e.g., Dilkes, 1998; Ezcurra, 2016). We note that

340 numerous recent phylogenetic analyses recover some non-diapsid taxa as more closely related to

341 Neodiapsida than Araeoscelida. Laurin and Piñeiro (2017) presented a modification of the Laurin

342 and Reisz (1995) analysis in which Araeoscelida were recovered outside of a clade including 
343 Paleothyris, 'Younginiformes,' and Parareptilia. This analysis was heavily criticized by

344 MacDougall et al. (2018) who argued that Laurin and Piñeiro (2017) had used an outdated data

345 matrix and did not account for the substantial variation in temporal fenestration in Palaeozoic

346 amniotes (but see Laurin and Piñeiro, 2018). Ford and Benson (2019b) recovered Araeoscelida

347 as the outgroup of the clade Varanopidae + (Parareptilia + Neodiapsida). Although we do not

348 address these phylogenetic possibilities with the taxon sample in our analysis, none of these

349 results are incongruent with the use of araeoscelids as an outgroup to a clade including the 350 diapsid sample employed within.

351 Two new characters were added to describe possible apomorphies for Weigeltisauridae:

352

338) Premaxilla, anterodorsal process, contribution to anteroposterior length of rostrum: (0) contribution to anteroposterior length of rostrum subequal to that of alveolar process of premaxilla; (1) contribution to anteroposterior length of rostrum twice that of alveolar process of premaxilla.

This character describes the considerable elongation of the anterodorsal (= internarial) process of the premaxilla in known weigeltisaurids. This feature is evident in Weigeltisaurus jaekeli (SMNK-PAL 2882) and Rautiania spp. (Bulanov and Sennikov, 2010). In nearly all other diapsid reptiles, the contribution of the anterodorsal process to the length of the rostrum by the anterodorsal process is subequal to that of the tooth-bearing portion of the premaxilla.

363 Unfortunately, this character could not be coded for Coelurosauravus elivensis as no premaxillae 364 have been identified in the available material. Taxa coded as state " 1 " for Character 5, which 365 describes the presence or absence of an anterodorsal process, are coded as "“-" for this character. 
339) Postorbital, posterior process for articulation with squamosal: (0) present, contacting squamosal posteriorly; (1) absent, no contact between posterior portion of postorbital and

369 anterior portion of squamosal.

370

371

This character describes one of the most remarkable anatomical traits of known

372 Weigeltisauridae: the apparent absence of the upper temporal bar formed by the postorbital and 373 squamosal bones [here recognized in SMNK-PAL 2882 and by Bulanov and Sennikov (2010,

374 2015a, 2015b)]. As such, weigeltisaurids have a continuous, large temporal opening, extending

375 from the lower temporal bar ventrally to the medial elements of the skull roof dorsally. In all 376 other diapsids in this analysis for which the temporal region is completely known, the postorbital 377 extends posteriorly to contact the squamosal (e.g., Reisz, 1981; Gow, 1975; Modesto and Sues, 378 2004; Simões et al., 2018). Taxa coded as "1” for this character are coded as “-“" for Character 37951 , which describes the relative dorsoventral position of the upper temporal bar.

380 We also completely redefined Character 204 from the analysis by Pritchard and Sues (2019), 381 which initially described the presence or absence of bipartite dorsal ribs. This character was used 382 to describe the patagial ossifications of weigeltisaurids following the hypothesis by Evans 383 (1982). However, in light of the work of Schaumberg (1986), Frey et al. (1997), and the 384 anatomical observations described below, we consider these structures to be dermal ossifications 385 rather than part of the axial skeleton. The codings have not changed from prior iterations of this 386 analysis. Weigeltisaurus jaekeli and Coelurosauravus elivensis are coded as "present" for this 387 character. Rautiania spp. is coded as "?", as patagials have not been reported in the Russian 388 fossils. The new version of Character 204 reads as follows: 
204) Patagial ossifications (elongate bony spars positioned lateral/superficial to dorsal ribs:

391 (0) absent, (1) present.

392

393

We analyzed the matrix in TNT v 1.5 (Goloboff and Catalano, 2016). We used the traditional

394 search option with 10,000 replicates of Wagner trees followed by tree bisection and reconnection 395 (TBR), holding 10 trees per replicate. The best trees found were subjected to a final round of 396 TBR branch swapping. We used branch collapsing Rule 1 of Coddington and Scharf (1994), 397 collapsing all branches with a minimum length of 0 in any most-parsimonious tree.

398 Petrolacosaurus kansensis was designated as the outgroup for the analysis. We ran the 399 STATS.RUN script file to obtain the consistency and retention indices and the BREMER.RUN 400 script to obtain decay indices for the branches. This matrix is available on Morphobank 401 (www.morphobank.org) as Project 3656. Jackknife values were obtained in TNT by 10,000 402 replicates with a $20 \%$ character-removal probability per replicate; the values are presented for 403 each branch as frequency difference values.

404

405 Institutional Abbreviations

406

407 The following institutional abbreviations are use throughout the text and figure captions:

408 AMNH, American Museum of Natural History (New York, New York, USA); BP/1, 409 Evolutionary Studies Institute, University of the Witwatersrand (Johannesburg, South Africa);

410 CAS, California Academy of Sciences (San Francisco, California, USA) ; CM, Carnegie 411 Museum of Natural History (Pittsburgh, Pennsylvania, USA); FLMNH, Florida Museum of 
412 Natural History (Gainesville, Florida, USA); GR, Ruth Hall Museum of Paleontology (Abiquiu,

413 New Mexico, USA); IVPP, Institute of Vertebrate Paleontology and Paleoanthropology

414 (Beijing, China); MCSNB, Museo Civico Scienze Naturali Enrico Caffi (Bergamo, Italy); MCZ, 415 Museum of Comparative Zoology, Harvard University (Cambridge, Massachusetts, USA);

416 MFSN, Museo Friulano di Storia Naturale (Udine, Italy); MNHN, Muséum National d'Histoire

417 Naturelle (Paris, France); MPUM, Museo di Paleontologia Università degli Studi di Milano

418 (Milan, Italy); NHMUK, Natural History Museum of the United Kingdom (London, UK);

419 NMQR, National Museum Bloemfontein (Bloemfontein, South Africa); NSM, Nova Scotia

420 Museum (Halifax, Nova Scotia, Canada); PIMUZ, Paläontologisches Institut und Museum der

421 Universität (Zürich, Switzerland) PIN, Borissiak Paleontological Institute of the Russian

422 Academy of Sciences (Moscow, Russia); SAM, Iziko South African Museum (Cape Town,

423 South Africa); SMNK, Staatliches Museum fur Naturkunde Karlsruhe (Karlsruhe, Germany);

424 SSWG, Sektion Geologie, Universität Greifswald (Greifswald, Germany); TM, Ditsong

425 National Museum of Natural History (Pretoria, South Africa); TMM, Texas Memorial Museum

426 (Austin, Texas, USA); TWCMS, Sunderland Museum of Tyne \& Wear County Museums

427 (Sunderland, UK); UCMP, University of California Museum of Paleontology (Berkeley,

428 California, USA); VMNH, Virginia Museum of Natural History (Martinsville, Virginia, USA).

429

430 Results

431

432 Cranium

433 The premaxillae each consist of an alveolar process and an anterodorsal process. The left 434 premaxilla is complete and preserved in ventromedial view, whereas the right premaxilla only 
435 preserves the anterodorsal process. The alveolar process is triangular and anteriorly acuminate,

436 contributing to a sharply pointed rostrum. The preserved portion of the left alveolar process

437 preserves space for at least eight premaxillary teeth, although only the penultimate two teeth are

438 preserved in position. This compares favorably with the skull of the holotype of Weigeltisaurus

439 jaekeli (SSWG 113/7; Bulanov and Sennikov, 2015b) and is lower than the tooth count of 12 or

44013 in Rautiania spp. (PIN 5130/43; Bulanov and Sennikov, 2010). This indicates variability in

441 the premaxillary tooth count of Weigeltisauridae, although they compare well with the upper end

442 of the range of counts in early Neodiapsida. Low counts of three to five teeth occur in

443 Petrolacosaurus kansensis (Reisz, 1981), Orovenator mayorum (Ford and Benson, 2019a), and

444 Protorosaurus speneri (Gottmann-Quesada and Sander, 2009). Higher counts occur in

445 Gephyrosaurus bridensis (eight to 10 teeth; Evans, 1980) and Claudiosaurus germaini (up to 13

446 teeth in SAM-PK-8263; and Carroll, 1981).

447 The posterior margin of the alveolar process is concave where it would articulate with the

448 anterior process of the maxilla. Dorsal to the posterior part of the alveolar process, the premaxilla

449 contributes an anteroposteriorly elongate, anteriorly tapered margin to the external naris. There is

450 no posterodorsal process of the premaxilla, such that the maxilla forms much of the posterior

451 margin of the external naris. This narial conformation compares well with the holotype of

452 Weigeltisaurus jaekeli (SSWG 113/7; Bulanov and Sennikov, 2015b), Rautiania sp. (PIN

453 5130/44; Bulanov and Sennikov, 2010), and non-archosauromorph diapsids such as

454 Petrolacosaurus kansensis (Reisz, 1981) and the Tropidostoma Zone younginiform (SAM/PK

455 7710).

456 The anterodorsal process is twice the anteroposterior length of the alveolar process, a feature

457 common in weigeltisaurids (e.g., SSWG 113/7, PIN 5130/44). It extends posterodorsally from 
458 the anterior tip of the premaxilla. At the level of the posterior edge of the alveolar process, the

459 anterodorsal process of the premaxilla contacts the medial edge of the nasal. This contact extends

460 for the remainder of the anteroposterior length of the anterodorsal process. The anterodorsal

461 process exhibits a uniform transverse width throughout most of its anteroposterior length. The

462 process begins to taper transversely at the level of the sixth maxillary alveolus, tapering to a

463 point by the level of the ninth maxillary alveolus. Similarly elongate anterodorsal processes of

464 the premaxillae occur in the drepanosauromorph Megalancosaurus preonensis (e.g., Renesto and

465 Dalla Vecchia, 2005) and pterosaurs such as Eudimorphodon ranzii (e.g., Wild, 1978) and

466 Rhamphorhynchus (e.g., Bonde and Leal, 2015).

467 The nasals are partially preserved. The right element is nearly complete, whereas the left

468 preserves only the anterior tip and posterior articulation with the left frontal. They are rhomboid

469 in outline, with tapering anterior and posterior processes.

470 The anterior process is positioned at roughly the level of the first two maxillary alveoli. It

471 abuts the lateral margin of the anterodorsal process of the premaxilla throughout its length. The

472 lateral margin of the anterior process contributes the dorsomedial margin of the external naris.

473 The posterior edge of the anterior process of the nasal contacts the anterior margin of the dorsal

474 process of the maxilla, forming the posterior border of the external naris. We do not identify a

475 tubercle on the dorsolateral surface of the anterior process of the nasal as described by Bulanov

476 and Sennikov (2015b) in SSWG 113/7, but the structure may be remain embedded in matrix in

477 SMNK-PAL 2882.

478 Posterior to the external naris, the nasal remains unchanged in transverse width throughout

479 most of the remainder of its length. Medially, the nasal contacts the elongate anterodorsal

480 process of the premaxilla posteriorly to the level of the 11th maxillary alveolus. Posterior to this 
481 maxillary alveolus, the two nasals contact one another along the midline for the remainder of

482 their lengths. The ventral surface of the nasal is slightly concave.

483 Posterior to its contribution to the external naris, the lateral margin of the nasal contacts the

484 dorsal process of the maxilla. This contact is sigmoid, complementing curvatures on the

485 anterodorsal surface of the dorsal process of the maxilla. This contact ends at the level of the

486 fifteenth maxillary alveolus, where the anterior edge of the nasal posterior process sits.

487 The posterior process of the nasal tapers transversely throughout its length. Laterally, it

488 contacts the medial margin of the prefrontal. The contact between the nasal and the anterior

489 margin of the frontal is not clear on either side, but the nasal appears to lap dorsally over the

490 anterior tip of the frontal. The posterior margin of the nasal posterior process is straight and

491 transversely oriented.

492 The maxillae are nearly complete on both sides. Nearly all of the dentition is preserved in

493 situ on the left side, whereas the right maxilla has multiple gaps in its tooth row. The bone

494 consists of an alveolar portion that bears the teeth, a distinct anterior process, and a dorsal

495 process that forms much of the lateral surface of the snout.

496 Teeth are present throughout nearly the entire anteroposterior length of the maxilla. Both

497 maxillae preserve a short, edentulous region at the posterior tip of the alveolar process. The tooth

498 row extends posteriorly to roughly the anteroposterior midpoint of the orbit. Where it supports

499 the bases of the teeth, the maxilla is transversely thicker than is the dorsal process of the bone. A

500 distinct palatal process is absent.

501 There is a distinct anterior process of the maxilla that supports the first two maxillary teeth.

502 This process is concave anterodorsally where it contributes to the margin of the external naris.

503 The anterior process increases in height dorsoventrally further posteriorly, terminating where the 
504 maxilla contacts the anterolateral edge of the nasal. The dorsal process is a prominent, dorsally

505 convex, and transversely narrow structure that forms much of the lateral surface of the snout. It

506 increases in dorsoventral height back to the level of the 14th maxillary alveolus. Further

507 posteriorly, the dorsal process decreases in dorsoventral height to its posterior terminus.

508 The anterodorsal margin of the dorsal process of the maxilla bears a subtly sigmoid margin,

509 corresponding to a matching curvature on the lateral margin of the nasal. This sigmoid shape

510 occurs in other weigeltisaurid skulls (SSWG 113/7, MNHN.F.MAP327), and contrasts with the

511 simple convexity in other diapsids such as Youngina capensis (AMNH FARB 5561, BP/1 3859)

512 and Prolacerta broomi (BP/1 471; Modesto and Sues, 2004). The contact between the dorsal

513 margin of the maxilla and the ventrolateral margin of the nasal extends from the level of the

514 fourth through the 14th maxillary alveoli. A small notch in the dorsal margin of the maxilla is

515 present just posterior to the nasal contact, similar to that framing the preorbital fenestra noted in

516 SSWG 113/7 by Bulanov and Sennikov (2015b:Fig. 1). The dorsal process of the maxilla lacks a

517 distinct posterior concavity.

518 It is not clear how the maxilla contacted the lacrimal or jugal posteriorly, nor whether or not

519 the maxilla contributed to the margin of the orbit. The right maxilla preserves a subtle

520 posterodorsal embayment, which may mark the contact between the maxilla and the

521 anteroventral margin of the jugal. There is an anteroposteriorly short margin at the posterodorsal

522 edge of the dorsal process of the maxilla where it met the anterolateral edge of the dorsal process

523 of the prefrontal.

524 The prefrontals are preserved in articulation with the frontals and nasals on both sides (Fig

525 3). Both prefrontals are exposed in ventral view. The preserved portion of the bone is trapezoidal

526 with tapering anterior and posterior processes. The posterolateral margin of the prefrontal is 
527 marked by a prominent prefrontal boss, which contributes a substantial anterodorsal corner to the

528 orbit. The anterior and posterior processes are preserved on both sides, but the prefrontal boss is

529 only exposed on the right side. A passage for the nasolacrimal canal is not apparent in either

530 prefrontal of SMNK-PAL 2882.

531 The anterior process of the prefrontal is anteroposteriorly short. Based on the right prefrontal,

532 it may bifurcate at its anterior tip. The right anterior process appears to be positioned near its

533 anatomical position, situated between the posterodorsal corner of the dorsal process of the

534 maxilla laterally and the posterolateral corner of the nasal medially. The contact with the nasal

535 on the skull roof is anterolaterally oriented. The anterior process broadens posteriorly, reaching

536 the maximum transverse breadth of the prefrontal at the anterior margin of the orbit. At this

537 point, the bone is twice as broad transversely as the broadest part of the frontal.

538 On the right prefrontal, the prefrontal boss projects posterolaterally from the transversely

539 widest portion of the bone. The boss itself is laterally convex and forms a prominent anterodorsal

540 frame to the margin of the orbit. No boss is exposed on the left side, but it is likely that it remains

541 buried in the matrix. The prominent boss compares well with the prefrontal of the holotype of

542 Weigeltisaurus jaekeli (SSWG 113/7) and resembles the condition in iguanian squamates (e.g.,

543 Evans, 2008)

544 Posterior to the boss, the dorsal lamina of the prefrontal tapers posteromedially as a distinct

545 posterior process. Medially, the prefrontal contacts the frontal for much of its anteroposterior

546 length. The contact extends posteriorly for two-thirds the total length of the frontal, such that the

547 prefrontal makes up nearly the entire anterolateral border of the orbit. The prefrontal-frontal

548 suture is straight and roughly parasagittal in orientation. At its posterior tip, the prefrontal tapers

549 posterolaterally. 
550 The frontals are anteroposteriorly elongate and slender bones with a tapering anterior margin 551 and a transversely broadened posterior margin. Both frontals remain in articulation, and they are 552 exposed in ventral view. Although the outer margins of each frontal are discernible, the exposed 553 bone surfaces are heavily cracked, and much of the central portion of the right frontal has 554 weathered away completely. The bony contribution to the canal for the olfactory bulb and tract 555 cannot be discerned. We also cannot identify a ventral lamina of the medialmost portion of the 556 frontal in SMNK-PAL 2882. This feature was noted by Bulanov and Sennikov (2015a) as a 557 possible unique character of Coelurosauravus elivensis, contrasting with specimens of Rautiania 558 spp. and Weigeltisaurus jaekeli.

559 Anteriorly, the frontal extends just beyond the anterior margin of the orbit. The anterior 560 margin of the frontal is convex and makes contact with the posterior margin of the nasal. It is not 561 clear whether or not the tapered anterior margins of the two frontals met one another in the 562 midline.

563 Between the levels of the anterior and posterior margins of the orbit the frontal is roughly 564 rectangular, retaining the same transverse breadth. For much of its length, its lateral surface 565 contacts the medial surface of the prefrontal. At the posterolateral corner of the orbit, the 566 prefrontal-frontal contact terminates such that the latter element has a small, laterally concave 567 contribution to the orbit itself.

568 Posterior to its orbital contribution, the frontal expands transversely to twice its breadth 569 further anteriorly. This compares well with the transverse expansion of the frontals in many 570 squamates, such as Iguana iguana and Tupinambis teguixin (e.g., Evans, 2008; Gauthier et al., 571 2012). The anterolateral corner of this expanded region contacts the anteromedial edge of the 572 postfrontal bone at a laterally concave suture. Posterior to the postfrontal-frontal suture, the 
573 frontal bears a small posterolateral embayment for receipt of an anterolateral process of the 574 parietal.

575 Medially, the frontals remain in contact with one another along a sagittal suture from the

576 level of the anterior margin of the orbit to their contact with the parietals posteriorly. Medial to

577 the contact with the anterolateral process of the parietal noted above, the frontal contacts the

578 central portion of the parietal at a posterolaterally concave suture. This contact forms a broad,

579 'W'-shaped frontoparietal contact in ventral view, with a posteriorly convex central portion. By

580 contrast, many early diapsids have an anteriorly convex, 'U'-shaped frontoparietal contact as

581 seen in Clevosaurus hudsoni (Fraser, 1988) and Youngina capensis (Gow, 1975).

582 The parietal is a complex bone with three primary processes: a short anterolateral process, a

583 medial lamina in the skull roof, and a massive and elongate posterolateral process that frames the

584 dorsomedial margin of a large temporal fenestra. Both parietals are largely complete and exposed

585 in ventral view. The exposed ventral surface of both bones is cracked and weathered. Most of the

586 margins are well defined, although the medial edges of the left and right laminae in the skull roof

587 are heavily eroded.

588 The anterolateral process of the parietal is short and fits against the posterolateral corner of

589 the frontal. Posterior to its contact with the frontal, the right anterolateral process contacts the

590 right postfrontal throughout the rest of its anteroposterior length. The main portion of the roofing

591 lamina extends medially posterior to the frontal. The right lamina is heavily cracked medially,

592 such that its original outline is uncertain. The left lamina bears a deep medial concavity, which

593 we identify as a margin of the parietal foramen. The roofing lamina terminates immediately

594 posterior to the parietal foramen. Parietal foramina occur broadly in non-saurian amniotes such

595 as Aerosaurus wellesi (Langston and Reisz, 1981), Araeoscelis gracilis (MCZ 4173; Reisz et al., 
596 1984), and Youngina capensis (BP/1 70, 3859). They are absent in known drepanosauromorph

597 skulls (e.g., Megalancosaurus preonensis, MPUM 8437; Avicranium renestoi, AMNH FARB 598 30834).

599 The posterolateral processes of both parietals are well preserved. They are greatly 600 elongated - making up more than one-quarter of the total length of the skull—and convex

601 laterally. They are strongly posteriorly oriented, their long axes extending almost parasagittally.

602 This elongation and near posterior orientation occurs in Coelurosauravus elivensis

603 (MNHN.F.MAP327; Bulanov and Sennikov, 2015a), Rautiania spp. (Bulanov and Sennikov, 604 2006), and Glaurung schneideri (Bulanov and Sennikov, 2015c). The only other diapsids in 605 which the parietals achieve a similar proportional length and inclination are choristoderes, such 606 as Coeruleodraco jurassicus (Matsumoto et al., 2019) and Champsosaurus laramiensis (Brown, 607 1905).

608 Prominent horns are present along nearly the entire anteroposterior length of the lateral 609 surface of the parietal. Five lateral horns are evident on the left parietal and four are evident on 610 the right. Two small horns are present on the anteromedial margin as well. In their preliminary 611 description of SMNK-PAL 2882, Schaumberg et al. (2007) illustrated the parietals with 612 unornamented lateral margins. More recent preparation of the specimen by D. Scott revealed the 613 presence of these horns. Horns occur in the holotype of Weigeltisaurus jaekeli (SSWG 113/7;

614 Bulanov and Sennikov, 2015b) and Rautiania spp. (Bulanov and Sennikov, 2006). In

615 Coelurosauravus elivensis (MNHN.F.MAP327; Bulanov and Sennikov, 2015a) and Glaurung 616 schneideri (Bulanov and Sennikov, 2015c), the lateral margin of the parietal is marked by a 617 roughened, rugose margin but no distinct horns. 
In SMNK-PAL 2882, there are no clear embayments or crests for the attachment of adductor

619 muscles on the lateral surfaces of the parietals. The absence of such crests is commonplace in

620 other weigeltisaurids (e.g., SSWG 113/7, PIN 5130/1) and early diapsids such as Araeoscelis

621 gracilis (e.g., MCZ 4173; Vaughn, 1955), Avicranium renestoi (AMNH FARB 30834), and

622 Youngina capensis (BP/1 3859; Pritchard et al., 2018). Crests and embayments occur in most

623 early Sauria, such as Prolacerta broomi (BP/1 5375; Modesto and Sues, 2004), Protorosaurus

624 speneri (Gottmann-Quesada and Sander, 2009), Trilophosaurus buettneri (TMM 31025-140;

625 Gregory, 1945), and Clevosaurus hudsoni (NHMUK R 36832; O’Brien et al., 2018).

626 The left parietal in SMNK-PAL 2882 bears a series of four dorsolaterally projecting horns.

627 The horns appear blunt at their tips, similar to the second-from-the-dorsalmost horn on the left

628 squamosal. The dorsalmost horn on the left parietal is positioned just anterior to the parietal-

629 squamosal contact. Only three horns are present on the lateral surface of the posterolateral

630 process of the right parietal. These are positioned symmetrically relative to the first, third, and

631 fourth horns on the lateral edge of the left parietal. Each is blunt and similar in shape to the horns

632 on the right side. The number of horns evident on the parietals of SMNK-PAL 2882 is lower

633 than the number in SSWG 113/7 and those reconstructed for Rautiania spp. (Bulanov and

634 Sennikov, 2006). However, the total number in SMNK-PAL 2882 is likely higher and obscured

635 by the parietals being exposed in ventral view and the dorsal tips of both squamosals overlying

636 them.

637 Dorsal to the dorsalmost horn on the posterolateral process of the parietal, the bone is flat

638 where it contacted the posteromedial margin of the squamosal. Posteromedial to the contact, the

639 posterolateral process terminates in a flat and transversely oriented surface. The two bones are

640 slightly disarticulated on both sides. Medially, there are two small horns positioned one posterior 
641 to the other on each side. On the left posterolateral process, the anterior horn is narrow and

642 tapering whereas the posterior horn is very short and blunt. The tip of the anterior horn on the

643 right side is broken, such that its shape cannot be discerned. The posterior horn on the right side

644 is small and tapered, similar to the anterior horn on the left side. Posterior to the dorsalmost horn

645 on the medial margin, the posterolateral process of the parietal is linear and subtly concave. We

646 cannot identify a distinct supratemporal bone nor a sutural surface on the parietal for its

647 reception.

648 Both jugals are preserved disarticulated and exposed in medial view. Only the right jugal is

649 fully exposed. The element is triradiate, consisting of an anterior process, a dorsal process, and a

650 posterior process. The medial surface of the right jugal is cracked but not weathered. It appears

651 to be flat and unornamented, without a distinct sutural surface for the ectopterygoid.

652 The anterior process of the jugal is relatively shorter than the other two processes. It is

653 triangular and anteriorly tapered, comparing well with the holotype of Weigeltisaurus jaekeli

654 (SSWG 113/7). It differs markedly from the narrow, gradually tapering anterior processes in

655 Coelurosauravus elivensis (MNHN.F.MAP327) and in other early diapsids such as

656 Claudiosaurus germaini (Carroll, 1981), Acerosodontosaurus piveteaui (Bickelmann et al.,

657 2009), Youngina capensis (BP/1 3859; Gow, 1975), and Prolacerta broomi (UCMP 37151;

658 Modesto and Sues, 2004). In SMNK-PAL 2882, the dorsal margin of the anterior process slopes

659 anteroventrally, whereas the ventral margin is horizontal and continuous with the ventral margin

660 of the posterior process. Based on the articular surfaces on the posterior process of the maxilla

661 and the positions of the articulations in SSWG 113/7, the entire anterior process of the jugal

662 slotted over the posterodorsal margin of the posterior process of the maxilla. 
663 The dorsal process of the jugal forms the ventral half of the postorbital bar. It tapers along its

664 dorsoventral height, terminating in a dorsally positioned concavity. Based on comparisons with

665 SSWG 113/7, this concavity received the ventral tip of the ventral process of the postorbital. A

666 similarly broad tip of the dorsal process of the jugal occurs in Coelurosauravus elivensis (e.g.,

667 Bulanov and Sennikov, 2015a) and may represent a synapomorphy of Weigeltisauridae. In most

668 early diapsids, the dorsal process of the jugal tapers to a point dorsally and slots posterior to the

669 ventral process of the postorbital as seen in Petrolacosaurus kansensis (Reisz, 1981), Youngina

670 capensis (BP/1 3859; Gow, 1975), and Azendohsaurus madagaskarensis (Flynn et al., 2010).

671 The posterior process of the jugal is relatively longer than the other processes of this bone. It

672 is completely preserved on the right side, but its posterior tip is weathered on the left. The dorsal

673 and ventral margins of the process are subparallel throughout its anteroposterior length, such that

674 it does not taper posteriorly. The posterior tip of the posterior process is concave, a surface that

675 forms the suture for the quadratojugal in SSWG 113/7. All available evidence indicates that a

676 complete lower temporal bar was present in SMNK-PAL 2882 and other specimens of

677 Weigeltisauridae. A closed temporal bar formed by the jugal and quadratojugal also occurs in

678 Petrolacosaurus kansensis (Reisz, 1981), Youngina capensis (TM 3603; Gow, 1975),

679 hyperodapedontine rhynchosaurs (Benton, 1983), and basal archosauriforms (e.g., Nesbitt, 2011;

680 Ezcurra, 2016).

681 The postorbital and postfrontal are difficult to distinguish in SMNK-PAL 2882. We present

682 tentative sutural identifications in Figure 3B, and we described the bones by region below. The

683 articulated postorbital and postfrontal consist of a ventrolaterally projecting postorbital process

684 and an anteroposteriorly broad, subtriangular postfrontal process. 
685 The postorbital process is roughly rectangular, with subparallel anterior and posterior

686 margins. The ventral margin of the postorbital process is deeply concave, presumably at the facet

687 for the dorsal process of the jugal. At its dorsal tip, the process grade smoothly into the

688 ventrolateral edge of the triangular postfrontal process. The postfrontal process broadens

689 medially. The posterior margin of the postfrontal is straight and transversely oriented. A similar,

690 transversely oriented posterior margin of the postfrontal occurs in Petrolacosaurus kansensis

691 (Reisz, 1981), Protorosaurus speneri (Gottmann-Quesada and Sander, 2009), and Prolacerta

692 broomi (BP/1 5375; Modesto and Sues, 2004). However, this margin is in contact with a medial

693 process of a discrete postorbital in all of these species. The posterior margin of the postfrontal is

694 strongly posteromedially inclined in Avicranium renestoi (AMNH FARB 30834; Pritchard and

695 Nesbitt, 2017), Youngina capensis (BP/1 3859, SAM-PK 7578), Claudiosaurus germaini

696 (Carroll, 1981), Mesosuchus browni (SAM-PK 6536; Dilkes, 1998), and Trilophosaurus

697 buettneri (TMM 31025-140; Gregory, 1945).

698 In SMNK-PAL 2882, the medial articular surface of the postfrontal bears a posteromedial

699 concavity where it contacts the posterolateral edge of the frontal. It appears to have contacted the

700 lateral surface of the anterolateral process of the parietal for a short distance.

701 We cannot distinguish the quadratojugal and squamosal on either side of the skull in

702 SMNK-PAL 2882; based on comparisons with Rautiania spp. (e.g., PIN 5130/41), both

703 contribute to the posttemporal arch of the cranium. Together they frame the lateral and

704 posterodorsal margins of the quadrate. We will describe them here as a single unit.

705 The posttemporal arch forms a dorsoventrally tall, medially concave, and laterally convex

706 structure that forms the posterior margin of the large temporal fenestra. Laterally, the bones bear 
707 a single row of eight laterally oriented horns that vary in apicobasal length. Herein, we number 708 the horns $1-8$ from the dorsalmost to the ventralmost.

709 Horn 1 is the shortest and is laterally rounded. Horn 2 is substantially taller dorsoventrally 710 and wider transversely, but with a similarly rounded lateral margin to Horn 1 . Horns 3 and 4 are 711 similar in transverse breadth on the right and left sides, although they are substantially more 712 weathered on the right side. Each is longer than Horn 2. The complete left horns are strongly 713 tapered with sharp distal edges, although the weathered right horns appear more rounded. A tiny 714 additional hornlet sits just ventral to Horn 3 on the right side.

715 Horns 5-7 increase sequentially in both transverse breadth and dorsoventral height. Each is 716 similarly sharp and distally tapered. Horns 6 and 7 are the second-largest and largest horns, 717 respectively. The posterior surfaces of the seventh horns on the right and left sides are cracked, 718 exposing the internal surfaces of the horns. Each is clearly hollow, with the cortical bone being 719 less than a millimeter in thickness. The eighth horn sits directly dorsolateral to the lateral 720 quadrate condyle. It is the shortest transversely and is laterally rounded. Based on comparisons 721 with the sutures in the posttemporal arches of Rautiania spp. (e.g., PIN 5130/41), the 722 quadratojugal likely contributes only to this lowermost horn.

723 The nearly complete skull of the holotype of Weigeltisaurus jaekeli (SSWG 113/7) bears 724 eight horns, one of which was likely attached to the quadratojugal (Bulanov and Sennikov, 725 2015b). In Coelurosauravus elivensis, the squamosal bears only five horns (MNHN.F.MAP317, $726325,327)$. However, it may not be articulated with the quadratojugal such that the lowermost 727 horn is absent (Bulanov and Sennikov, 2015a). Seven spines, including a definitive lowermost 728 quadratojugal spine, occur in Rautiania sp. (PIN 5130/41). In both of these species, the spines 729 are slender and acuminate akin to those on the squamosal/quadratojugal of SMNK-PAL 2882. 
730 Ventrally, the squamosal overlaps the quadrate along a posterolaterally sloping suture. The

731 squamosal completely obscures the posterior surface of the dorsal tip of the quadrate in posterior

732 view. This contact is dorsoventrally short, reaching only to the dorsoventral level of the sixth

733 horn. The squamosal lamina lapping posterior to the quadrate compares favorably with Rautiania

734 sp. (PIN 5130/41; Bulanov and Sennikov, 2010). This tight contact in Weigeltisauridae

735 resembles the condition in early reptiles (e.g., Captorhinus aguti; Heaton, 1979; Paleothyris

736 acadiana; Carroll, 1969; Petrolacosaurus kansensis; Reisz, 1981) and drepanosauromorphs

737 (Avicranium renestoi; Pritchard and Nesbitt, 2017).

738 The posteroventral surface of the squamosal is heavily weathered on both sides. The left

739 element is eroded away medially between the fifth and seventh squamosal horns, whereas the

740 right is nearly completely weathered away between the first and third horns and laterally

741 weathered between the third and sixth horns. The best-preserved surface is the posterodorsal

742 surface of the left element, which is marked by subparallel dorsoventrally extending ridges.

743 The squamosal in SMNK-PAL 2882 bears only one clear articulation with other

744 dermatocranial elements, that of the dorsal portion of the bone with the posterolateral process of

745 the parietal. As in SSWG 113/7, there is no anterior process for articulation with the postorbital

746 to form a supratemporal arch. This absence is consistent with the squamosals known for

747 Coelurosauravus elivensis (MNHN.F.MAP327) and Rautiania spp. (e.g., PIN 5130/41),

748 supporting the reconstructions by Bulanov and Sennikov (2015a, 2015b) showing weigeltisaurid

749 skulls with continuous infratemporal and supratemporal fenestrae.

750 The configuration of the temporal region in Weigeltisauridae, with its single continuous

751 temporal opening spanning the lower temporal bar to the parietal, is remarkable for an amniote.

752 A continuity between the upper and lower temporal fenestrae occurs in numerous squamate 
753 species in which the postorbital and squamosal lack processes that contact one another, such as

754 Anniella pulchra and Eryx colubrinus. However, the absence of an upper temporal bar occurs in

755 concert with the absence of the lower temporal bar in these species, suggesting it may involve

756 the kinetic system in Squamata (Gauthier et al., 2012).

757 We identify two small, dorsoventrally flattened bones positioned posterior to the roofing

758 laminae of the parietals as the postparietals based on their topographic position, apparent

759 symmetry, and absence of complex articulations for the bones of the braincase. This differs from

760 the interpretation by Schaumberg et al. (2007), who identified the triangular bones as

761 exoccipitals. The bones do not resemble the exoccipitals of any other known diapsid. They are

762 triangular with a flattened anterior surface and a tapering posterior tip. We suggest that the

763 flattened anterior margin was appressed to the posterior margin of the dorsal roofing lamina. It is

764 not clear if the medial margins of the two postparietals contacted one another in life.

765 Postparietal ossifications are common among early eureptiles, such as Captorhinus aguti

766 (Heaton, 1979), Petrolacosaurus kansensis (Reisz, 1981), and Youngina capensis (BP/1 375;

767 Carroll, 1981). These vary widely in relative size and shape. The bones in captorhinids and

768 araeoscelids are transversely broad elements of the occiput, fitting against much of the posterior

769 margin of the parietals (Heaton, 1979; Reisz, 1981). In Y. capensis-the only early neodiapsid

770 for which it can be confidently identified - the postparietal is proportionally narrower than the

771 associated parietal. The narrow postparietal in SMNK-PAL 2882 compares most favorably with

772 the character state in $Y$. capensis.

773 The quadrate is preserved on the left and right sides, although both quadrates are overlain

774 posteriorly by the quadratojugal and squamosal. Only the lateral condyle of the articular end can

775 be seen. It appears strongly convex ventrally, suggesting the presence of a double convexity 
776 similar to those in Rautiania spp. (e.g., Bulanov and Sennikov, 2010) and Coelurosauravus

777 elivensis (e.g., MNHN.F.MAP327; Bulanov and Sennikov, 2015a). A small portion of the

778 medially oriented pterygoid lamina is preserved on both sides, preserving the dorsal margin of

779 the structure on the left side. The dorsal margin is positioned approximately at the level of the

780 second-from-ventralmost squamosal horn. Both pterygoid laminae are broken at a

781 posteromedially oriented crack, unsurprising considering the absence of any palatal bones. A

782 similar biconvex articulation for the articular bone occurs in Araeoscelis gracilis (Vaughn,

783 1955), Czatkowiella harae (Borsuk-Bialynicka and Evans, 2009), and Gephyrosaurus bridensis

784 (Evans, 1980). An undivided convexity is present in various, distantly related diapsids, including

785 Avicranium renestoi (Pritchard and Nesbitt, 2017) and Trilophosaurus buettneri (TMM $31025-$

786 140; Gregory, 1945).

787 Two small, rod-like bones are present on both sides of the skull posterior to the postorbitals

788 and medial to the quadrates. Each bears a slight expansion in the shaft at one end. They are quite

789 small, shorter in length than the longest of the squamosal horn. These could represent the stapes

790 or hyoid cornua.

791

792 Mandible

793 Both mandibular rami are partially preserved in SMNK-PAL 2882. The left ramus preserves

794 only its posteriormost tooth positions and the entire postdentary complex. The right ramus is

795 only partially exposed. The dentigerous portion of the dentary is fully exposed, and much of the

796 right postdentary complex remains buried in the matrix. Only a small portion of the surangular,

797 preserving a single lateral horn, is exposed anteroventral to the right quadrate. 
The dentaries are elongate, slender bones with tapered anterior tips. The dentigerous margin

799 of the jaw is straight. The right dentary is the more complete and exposed in medial (=lingual)

800 view. It is preserved in two pieces—one anterior and one posterior — but an impression in the

801 matrix shows its original extent. The anterior piece preserves the anterodorsal tip of the dentary

802 and six partial teeth. The medial surface of the posterior segment is covered almost entirely by

803 the splenial. It preserves 19 teeth in varying states of completeness.

804 The medial surface of the dentary on the right side is covered by a black sheet of bone, which

805 we identify as the splenial. It is fractured into many fragments along its dorsal margin, but it is

806 intact ventrally. The preserved bone is smoothly textured, and its ventral margin is straight.

807 The left postdentary complex is complete but badly fractured into small fragments. It is

808 exposed in dorsomedial view. The sutural boundaries between the angular, coronoid,

809 surangular, articular, and prearticular cannot be discerned. The postdentary complex

810 expanded slightly in dorsoventral height posterior to the tooth row, with a prominent, dorsally

811 convex coronoid eminence. In this way, it resembles the rounded coronoid eminence in

812 Petrolacosaurus kansensis (Reisz, 1981), Araeoscelis gracilis (MCZ 4173; Vaughn, 1955), and

813 Claudiosaurus germaini (SAM PK-8263). The dorsal margin of the bone slopes slightly

814 posteroventrally to its articulation with the quadrate. There is a small ventromedial bony

815 projection posterior to the articular, which may represent a short retroarticular process. A similar,

816 anteroposteriorly and dorsoventrally short retroarticular process occurs in the skull of the

817 holotype of Weigeltisaurus jaekeli (SSWG 113/7), Youngina capensis (BP/1 2871; Gow, 1975),

818 and Megalancosaurus preonensis (MFSN 1769; Renesto, 2000). By contrast, a retroarticular

819 process appears absent in Petrolacosaurus kansensis (Reisz, 1981) and Araeoscelis gracilis

820 (MCZ 4173; Vaughn, 1955). On the right side of the skull of SMNK-PAL 2882, a small laterally 
821 facing horn is exposed anteroventral to the right quadrate. Based on comparisons with the

822 postdentary complexes of Rautiania spp. and the skull of the holotype of Weigeltisaurus jaekeli,

823 this horn likely belongs to the right surangular (Bulanov and Sennikov, 2010, 2015b).

824

825 Dentition

826 The teeth are subtly heterodont in SMNK-PAL 2882, transitioning from small and relatively

827 simple pegs anteriorly to lanceolate, recurved teeth further posteriorly (Fig. 4). The anteriormost

828 teeth are preserved in the left premaxilla and the anterior end of the right dentary. They are small

829 and taper apically without being noticeably recurved. The dentary teeth are not as well preserved,

830 with the enamel being heavily worn. Similar conical teeth occur anteriorly in the skull of the

831 holotype of Weigeltisaurus jaekeli (SSWG 113/7). In Rautiania spp. the premaxillary teeth

832 possess a slight distal recurvature at the tips of the crowns but this may be a result of the

833 exceptional preservation of those specimens (Bulanov and Sennikov, 2010).

834 The left maxilla preserves spaces for 22 total teeth, whereas the right preserves space for 21.

835 This number is comparable with the 22-23 described in SSWG 113/7 (Bulanov and Sennikov,

836 2015b) and Rautiania minichi (Bulanov and Sennikov, 2006). 30 teeth are present in the maxillae

837 of Rautiania alexandri (Bulanov and Sennikov, 2006). Within the maxilla, the anteriormost three

838 or four teeth resemble larger versions of those in the premaxilla. However, they are relatively

839 longer apicobasally and exhibit a very slight degree of curvature. The mesial margins of these

840 teeth are apicodistally curved, and the distal margins are straight. The condition resembles

841 anterior maxillary teeth in the skull of the holotype of Weigeltisaurus jaekeli (SSWG 113/7). By

842 contrast, the anterior maxillary teeth of Rautiania alexandri are not recurved (PIN 5130/40;

843 Bulanov and Sennikov, 2006). 
844 In SMNK-PAL 2882, the next eight to 10 maxillary teeth further distally exhibit a modest

845 mesiodistal expansion at the crown-root junction, giving them a distinctly leaf-like shape (Fig.

846 4). The apex of the crown is slightly recurved. The lanceolate teeth occur distal to the anterior

847 process of the maxilla and mesial to the anteroposterior midpoint of the dorsal process of the

848 maxilla. The corresponding teeth in SSWG 113/7 are not particularly well preserved, but they do

849 seem to possess both a leaf-like shape and recurvature. The lanceolate teeth of the maxilla in

850 both species of Rautiania bear a subtler degree of mesiodistal expansion, but they are all

851 similarly recurved.

852 The maxillary teeth distal to the lanceolate teeth are rather poorly preserved in SMNK-PAL

853 2882, with weathered crowns and cracked enamel on both sides. They appear to lack any

854 mesiodistal expansion of the base of the crown, the mesial and distal margins of the teeth being

855 relatively straight. These teeth taper rapidly very close to the apex. They resemble the poorly

856 preserved posterior maxillary teeth of the holotype of Weigeltisaurus jaekeli (SSWG 113/7) and

857 those of Rautiania minichi (PIN 5130/3; Bulanov and Sennikov, 2006).

858 The teeth of the right dentary differ from those in the maxilla (Fig. 4). The anteriormost teeth

859 in the dentary are the smallest, increasing in size further posteriorly. As in the anterior part of the

860 maxilla, these anterior teeth are relatively simple and conical. The teeth around the

861 anteroposterior midpoint of the dentary are relatively larger, but appear simple and conical.

862 Lanceolate teeth occur in the posterior half of the dentary, well posterior to those in the right

863 maxilla. The right dentary contains the best-preserved of the lanceolate teeth. Each tooth bears

864 distinct apicobasal enamel striations on the apical half of the crown. In a partial dentary referred

865 to Rautiania sp. (PIN 5130/24), the anterior teeth are small and conical. The mid-posterior

866 dentary teeth are slightly larger, subtly expanded mesiodistally, and slightly recurved. 
In SMNK-PAL 2882, the posteriormost teeth in the right dentary are smaller than the mid-

868 dentary teeth, with simple, apically rounded crowns. Only the posteriormost part of the left

869 dentary is preserved, and all of the teeth it contains are similarly small, simple, and apically

870 rounded.

871 The implantation of the teeth varies along the jaws (Fig. 3, 4). The preserved teeth of the left

872 premaxilla show pleurodont implantation, similar to the 'iguanian mode' of pleurodonty

873 described by Jenkins et al. (2017). They sit within a groove, abutting against the medial surface

874 of the alveolar process of the premaxilla. There is no clear medial wall to support them and the

875 roots of individual teeth are anchored to the premaxilla by a ring of porous bone. However, the

876 tooth roots are proportionally much shorter than those in extant Iguana iguana or Gerrhosaurus

877 validus; in the relative shallowness of the roots, they most closely resemble the anterior

878 pleurodont teeth of the agamid Uromastyx acanthinura (Edmund, 1969). The teeth at the anterior

879 tip of the right dentary do not appear to have similarly sized roots; they are positioned on the 880 apex of the bone.

881 The teeth in the maxillae and dentaries — excluding the posteriormost three or four teeth—

882 also appear subtly pleurodont (Fig. 4). The short roots sit in a shallow groove, abutting against

883 the medial surface of the alveolar process of the bone. The roots of individual teeth are mostly

884 attached to the dentigerous elements by a ring of porous bone. There are no distinct interdental

885 ossifications forming alveolar walls as in many archosauromorphs (Edmund, 1969; Luan et al.,

886 2009; LeBlanc et al., 2018). Several teeth in both the maxillae and dentaries bear large medial

887 resorption pits that interrupt this ring of porous bone. Small replacement teeth can be seen within

888 some of the pits, similar to the condition in early synapsids such as Dimetrodon and Ophiacodon

889 (Edmund, 1960). However, the roots of some teeth are also cracked and broken such that the 
890 mesiodistal spacing between tooth replacement cycles in the jaws of SMNK-PAL 2882 (' $\mathrm{z}$ -

891 spacing' of DeMar and Bolt, 1981) cannot be assessed. In the posteriormost portion of the

892 maxilla and left dentary, the teeth do not appear to have deep roots. Instead the crowns attach at

893 or near the dentigerous margins of the jaw elements, similar to the condition at the anteriormost

894 tip of the right dentary.

895

\section{Vertebrae}

Multiple articulated segments of the vertebral column are preserved in SMNK 2882, 898 representing cervicals, dorsals, and caudals (Fig. 2, 5). The anteriormost cervicals spiral out from 899 a central point, and the long tail encircles the head and trunk region. The cervicals are not well 900 preserved, with only vestiges of the original bone present within the impressions of the complete 901 vertebrae. Large gaps are present in the trunk region although a series of six mid-to-posterior 902 dorsal vertebrae is preserved just anterior to the pelvis. No sacrals are exposed on the block, but 903 the apparent preservation of much of the pelvis suggests that they may still be buried in the 904 matrix. A segment of seven anterior caudal vertebrae is exposed posterior to the pelvis, although 905 the anteriormost caudals are covered by the longer patagial ossifications of the right 'wing.' The 906 adjoining portion of the tail is covered by the skull, beyond which a segment of 22 crushed, 907 poorly preserved mid-to-posterior caudals extends almost unobstructed.

908

909 Cervical Vertebrae

910 The presumably anteriormost cervical vertebrae in SMNK-PAL 2882 are partially

911 exposed in between the ninth and eleventh patagial spar ossifications (Fig. 5). Little can be said 912 of their morphology, as only a small portion is exposed. A sequence of five articulated cervical 
913 vertebrae is exposed between the anterior margin of the fourth patagial ossification and the

914 anterodorsal edge of the scapula. Preserved bone is present along the ventral surfaces of the

915 centra; everything else is preserved as a subtle impression.

916 The shapes of the neural spines are obscured by poor preservation. In the second vertebra

917 in the articulated series, there is a subtle vestige of a flat-topped spine that tapered ventrally to

918 join with the rest of the neural arch. The spine appears dorsoventrally short, shorter than the

919 corresponding centrum. The pedicles are also dorsoventrally short, accentuating the apparent

920 elongation of the neural arch of SMNK-PAL 2882. Short cervical neural spines with squared-off

921 tips and short pedicles occur in Coelurosauravus elivensis (MNHN.F.MAP 317, 327; Carroll,

922 1978) and Petrolacosaurus kansensis (Reisz, 1981), whereas proportionally taller spines and

923 pedicles are present in Hovasaurus boulei (Currie, 1981a) and Youngina capensis (BP/1 3859;

924 Gow, 1975).

925 Prezygapophyses are preserved as clear impressions on the second and third vertebrae in

926 the sequence. Each is anteriorly rounded and anterodorsally inclined (Fig. 5). The processes

927 extend well anteriorly of the anterior margin of the centrum. Postzygapophyses are not preserved 928 in either vertebra.

929 The second cervical vertebra in the sequence preserves a distinct diapophysis near the

930 dorsoventral level of the prezygapophyses (Fig. 5). This structure is positioned on the anterior

931 half of the vertebra. The third and fourth vertebrae do not preserve exposed facets. However,

932 probable dichocephalous cervical ribs are present in the same area of the lateral surface on the

933 third and fourth cervical vertebrae in the sequence (Fig. 5). The centra are anteroposteriorly

934 longer than dorsoventrally tall, although the ratio between these measures decreases from

935 anterior to posterior. The ratio of height to length in these centra $(=2.4$ in the third and most 
936 complete centrum in the series) compares well to the elongate cervical centra of

937 Coelurosauravus elivensis (MNHN.F.MAP317, 327; Carroll, 1978), Araeoscelis gracilis (MCZ

938 4173; Vaughn, 1955) and Zarcasaurus tanyderus (CM 41704; Brinkman et al., 1984) and

939 contrasts with the greater height/length ratio in Hovasaurus boulei (Currie, 1981a) and Youngina

940 capensis (BP/1 3859; Gow, 1975). Each centrum is cylindrical with a strong ventral concavity.

941 As preserved, the anterior and posterior articular surfaces are flat. They were either amphiplatyan

942 or amphicoelous, consistent with the morphology in most early eureptiles such as Captorhinus

943 aguti (Fox and Bowman, 1966), Araeoscelis gracilis (Vaughn, 1955), and Youngina capensis

944 (BP/1 3859; Gow, 1975).

945 In many ways, the proportionally elongate cervical centra with relatively short pedicles in

946 weigeltisaurids and araeoscelids (following Carroll, 1988) resemble those of many early

947 archosauromorphs, such as Protorosaurus speneri (Gottmann-Quesada and Sander, 2009),

948 Trilophosaurus buettneri (TMM 31025-140; Gregory, 1945), and Prolacerta broomi (BP/1

949 2675; Gow, 1975). Although these archosauromorph taxa with relatively long cervical vertebrae

950 were long considered members of a grouping variously dubbed Protorosauria or Prolacertiformes

951 (Wild, 1973; Benton, 1985; Evans, 1987, 1988), more recent analyses indicate that these reptiles

952 represent a paraphyletic grade relative to Archosauriformes (Dilkes, 1998; Pritchard et al., 2015;

953 Ezcurra, 2016; Pritchard and Nesbitt, 2017).

954 Both of these groups differ radically from the anatomy of the cervical vertebrae in non-

955 saurian neodiapsids (e.g., Youngina capensis, Thadeosaurus colcanapi) and most

956 lepidosauromorphs, in which the centra are much shorter anteroposteriorly and the pedicles and

957 neural spines are proportionally taller (Hoffstetter and Gasc, 1969; Gow, 1975; Carroll, 1981).

958 Among early lepidosauromorphs, such cervical vertebrae occur in Fraxinisaura rozynekae 
959 (Schoch and Sues, 2018), Planocephalosaurus robinsonae (Fraser and Walkden, 1984),

960 Clevosaurus hudsoni (Fraser, 1988), and vertebrae referred to Sophineta cracoviensis (Evans and

961 Borsuk-Bialynicka, 2009). Based on present phylogenetic hypotheses, it is plausible that diapsids

962 plesiomorphically had proportionally elongated cervical vertebrae before transitioning to the

963 relatively shorter, taller vertebrae seen in younginiforms and lepidosauromorphs. The condition

964 in early archosauromorphs would represent a reversal to the plesiomorphic diapsid state. The

965 transitions between these suites of vertebral features and their apparent fixation within certain

966 major clades of Diapsida warrant further study.

967

968 Trunk Vertebrae

969 As in the cervical region, trunk vertebrae are either disarticulated or preserved in short

970 segments (Fig. 5, 6). Two trunk vertebrae are preserved in articulation just posterior to the

971 exposed pectoral girdle. One and one-half articulated trunk vertebrae are positioned medial to the

972 ninth through twelfth patagial ossifications just dorsal to the gastral basket. A stretch of five mid-

973 to-posterior trunk vertebrae sits posterior to the level of the fifteenth patagial ossification,

974 curving along with the rest of the skeleton of the trunk.

975 The anterior trunk vertebrae preserved near the pectoral girdle only preserve small traces

976 of the centra (Fig. 6). These are proportionally shorter than those in the posterior cervical region,

977 a pattern evident in some diapsid reptiles such as Crocodylus acutus (Mook, 1921) and Varanus

978 spp. (Hoffstetter and Gasc, 1969). The relative length of the vertebral centra transition from

979 shorter to longer in many other lepidosaurian taxa, including Iguana, Ophisaurus, and

980 Tupinambis (Hoffstetter and Gasc, 1969). Each centrum is concave ventrally and the articular

981 surfaces - though poorly preserved — were flat or concave. 
982 A single complete trunk vertebra is preserved medial to the eighth and ninth patagial

983 ossifications (Fig. 6). It is heavily crushed and distorted. Its neural spine is not preserved. The

984 prezygapophyses are elongate, anterodorsally rounded, and extend far anteriorly of the centrum.

985 The centrum itself is proportionally longer than those in the anterior trunk region and bears a 986 prominent ventral concavity.

987 The vertebrae in the articulated series represent the mid-to-posterior trunk region (Fig. 6).

988 None of these preserves a clear neural spine. The preserved zygapophyses are smaller and

989 shorter than those in the cervical or anterior trunk region. They extend only slightly anteriorly

990 relative to the anterior margin of their respective centra. The postzygapophyses are similarly

991 small and barely extend beyond the posterior margins of their respective centra. There are

992 prominent anterior and posterior concavities ventral to the zygapophyses that clearly separate

993 them from the centra.

994 A small, subcircular facet is preserved on the third vertebra in this sequence.

995 It sits at the dorsal margin of the centrum at the anteroposterior midpoint of the vertebra. It is 996 plausible that ribs in this portion of the trunk were holocephalous, as is common in the mid-to997 posterior trunk vertebrae of diapsids (e.g., Hoffstetter and Gasc, 1969; Gow, 1975; Reisz, 1981;

998 Fraser and Walkden, 1984; Nesbitt et al., 2015). The centra are proportionally more elongate

999 than those in the anterior trunk region, similar to the increasing relative lengths in lepidosaurs

1000 such as Iguana, Tupinambis, and Chioninia (Hoffstetter and Gasc, 1969). The articular surfaces 1001 are not well exposed but were either flat or concave. Each centrum bears a prominent ventral 1002 concavity.

1003

1004 Sacral Vertebrae 

possible that some remain buried under the other pelvic elements.

1007

1008

\section{Caudal Vertebrae}

1009

The caudal vertebrae are the best represented region of the axial skeleton, being relatively

1010 well preserved and representing a wide variety of regions in the column (Fig. 5). A series of articulated anterior caudal vertebrae sit several probable vertebral positions posterior to the

1012 pelvic girdle. The dorsal margins of most of these caudal neural arches are well preserved, but 1013 none bears a distinct dorsal projection or spine. The preserved caudal vertebrae also lack distinct 1014 transverse processes, suggesting that they may have been absent from all but the anteriormost 1015 caudals, comparing favorably with the anteriormost caudal neural arches of Coelurosauravus 1016 elivensis (MNHN.F.MAP327; Carroll, 1978). This stands in stark contrast to the anterior caudal 1017 neural spines projecting well dorsally of the zygapophyses in early diapsids such as 1018 Petrolacosaurus kansensis (Reisz, 1981), Hovasaurus boulei (Currie, 1981a), Thadeosaurus 1019 colcanapi (MNHN.F.MAP360; Carroll, 1981), and Protorosaurus speneri (Gottmann-Quesada 1020 and Sander, 2009).

1022 (Fig. 5). They do not extend far beyond the anterior or posterior margins of the centra. They are 1023 separated from the centra by small anterior and posterior concavities, which are visible in lateral 1024 view. The centra themselves are cylindrical and substantially longer than they are dorsoventrally 1025 tall.

1026 The articulated portion of the vertebral column preserved further posteriorly extends from 1027 deep to the right mandibular ramus (Fig. 5). The first two vertebrae in this sequence are well 
1028 preserved, with much of the finished bone still intact. Further posteriorly, they are preserved as

1029 impressions with small vestiges of finished bone. None of these bears a distinct neural spine.

1030 Where visible, the zygapophyses are small and do not extend far beyond their respective centra.

1031 Each centrum is greatly elongated and slender, with a substantially greater length/height ratio

1032 than in the anterior caudal vertebrae. This pattern is similar to the condition in many extant

1033 squamates (Etheridge, 1967) and Trilophosaurus buettneri (TMM 31025-140; Nesbitt et al.,

1034 2015). Each vertebra decreases in absolute size further posteriorly.

1035 We consider it likely that the tail was even longer than is preserved in SMNK-PAL 2882.

1036 The posteriormost complete vertebrae still bear prominent pre- and postzygapophyses. A small

1037 portion of a caudal vertebra is preserved posterior to this, although this element is clearly

1038 incomplete.

1039

1040 Ribs

1041 Ribs are not well represented in SMNK-PAL 2882, but examples from the cervical and

1042 trunk regions are present (Fig. 5, 6). Two probable cervical ribs are present in the anterior-to-mid

1043 cervical region. Each has two distinct proximal heads that appear widely separated from one

1044 another. Dichocephalous ribs occur in Captorhinus aguti (Dilkes and Reisz, 1986) and

1045 Petrolacosaurus kansensis (Reisz, 1981), although the heads are connected via a web of bone in

1046 these taxa. Dichocephalous rib heads occur in the anterior cervical vertebrae of Hovasaurus

1047 boulei, transitioning to holocephalous ribs at the fifth cervical rib (Currie, 1981a). In SMNK-

1048 PAL 2882, each rib is positioned lateral to the anterior half of the vertebra. The ribs lack the

1049 distinct anterior process that characterizes cervical ribs in early archosauromorphs (e.g., Nesbitt 
1050 et al., 2015; Ezcurra, 2016). The rib shafts are not well preserved, but they do not appear to be

1051 longer anteroposteriorly than their respective vertebrae.

1052 A complete dorsal rib is exposed just posterior to the pectoral girdle (Fig. 5). It is

1053 dichocephalous, bearing two distinct articular eminences on its proximal end. The proximal

1054 expansion and double articular surfaces compare favorably to the anterior dorsal ribs of

1055 Coelurosauravus elivensis (MNHN.F.MAP327; Carroll, 1978), Petrolacosaurus kansensis

1056 (Reisz, 1981), and Araeoscelis gracilis (Vaughn, 1955). The shaft is relatively straight, tapering

1057 ventrally from this articulation. A dorsal rib of similar morphology is preserved alongside the

1058 gastral basket near the anteroposterior midpoint of the trunk. Splints of bone are preserved all

1059 around the trunk region that may represent partial ribs, but these cannot be differentiated from

1060 the many fragments of patagial ossifications scattered across SMNK-PAL 2882. No sacral or

1061 caudal ribs are exposed.

1062

1063 Chevrons

1064 Few definitive chevrons are exposed in SMNK-PAL 2882. A single, Y-shaped bone is

1065 preserved lateral to the gastral basket nearly two-thirds down the length of the trunk region (Fig.

1066 5). This bone likely represents a chevron from farther anteriorly within the caudal series. It is

1067 preserved in either anterior or posterior view, such that the shape in lateral view cannot be

1068 assessed. The dorsal tips of the 'Y' shape are connected by a crossbar, framing a dorsally flat and

1069 semicircular hemal canal. Similar Y-shaped chevrons with intercentrum-derived crossbars occur

1070 in Petrolacosaurus kansensis (Reisz, 1981) and Youngina capensis (AMNH FARB 5561; Currie,

1071 1981b). The chevron bears a distinct ventral process similar in extent to the height of the anterior 1072 caudal centra. 
1074 compare with the club-shaped anterior chevrons present in TWCMS B5937.1 and those noted by

1075 Evans and Haubold (1987) in the Gracilisaurus ottoi holotype. We identify a few chevrons still

1076 in articulation with the mid-to-posterior caudal vertebrae. Each is roughly triradiate (Fig. 5). A

1077 dorsoventrally short dorsal process articulates between two adjacent caudal centra. Further

1078 ventrally, the chevron bifurcates into distinct anterior and posterior processes that parallel the

1079 long axes of the caudal centra. The anterior and posterior processes are roughly equivalent in

1080 anteroposterior length, akin to the condition in Trilophosaurus buettneri (TMM 31025-140;

1081 Gregory, 1945). In the absence of prominent neural spines and elongated chevrons, the tail

1082 would have been extremely slender throughout much of its anteroposterior length. In extant

1083 lepidosaurs, these processes support the longitudinal muscles necessary for flexion of the tail

1084 (e.g., Ali, 1948). The lack of elongate processes throughout much of the caudal series in

1085 Weigeltisaurus jaekeli is strikingly similar to the condition in some species of Draco [e.g., D.

1086 dussumieri (FLMNH Herp 61535, ark:/87602/m4/M36111)]. This may indicate a limited degree

1087 of flexibility and powerful motions in the weigeltisaurid tail relative to those of most other

1088 Permo-Triassic diapsids.

1089

1090 APPENDICULAR SKELETON

1091

1092 Pectoral Girdle

1093 The pectoral girdle in SMNK-PAL 2882 is heavily crushed and fractured, such that

1094 determining the original sutural boundaries between elements - or even the relative extent of the

1095 right and left halves preserved - is difficult (Fig. 7). In our interpretation, the exposed portion of 
1096 the girdle includes the lateral surfaces of the left scapula, coracoid, clavicle, and cleithrum. The

1097 interclavicle, if it was present, cannot be distinguished from the crushed pieces of the

1098 scapulocoracoid.

1099 The scapula has a transversely thin blade that is dorsoventrally taller than it is

1100 anteroposteriorly long (Fig. 7). The posterior margin of the blade is angled posterodorsally, with

1101 a strong angulation near its dorsoventral midpoint. The dorsal margin of the blade is subtly

1102 convex and heavily weathered. The anterodorsal margin of the scapular blade is inclined

1103 anteroventrally, subparallel to the posterior margin of the bone. The preserved fragments of bone

1104 that make up the scapular blade are smoothly textured laterally. In its length/height ratio and

1105 orientation, the scapular blade in SMNK-PAL 2882 resembles the condition in Coelurosauravus

1106 elivensis (MNHN.F.MAP327; Carroll, 1978) and Youngina capensis (Gow, 1975).

1107 Further ventrally, the anterior surface of the scapular blade is convex and subtly rounded. In

1108 this region, the blade is more heavily fragmented with little of the original bone still exposed.

1109 Due to the fracturing of the bone, it is not at all clear where the scapula and coracoid contacted

1110 one another.

1111 At the posteroventral edge of the scapular blade, the smoothly textured bone abruptly

1112 transitions into pebbly, gray-colored bone (Fig. 7). This rougher-textured bone appears to be

1113 restricted to the posterolateral surface of the scapula ventral to the blade, which we consider to

1114 represent the position of the glenoid fossa. The fossa likely faced posterodorsally, as in Youngina

1115 capensis (BP/1 3859) and Prolacerta broomi (BP/1 2575, NMQR 3763).

1116 Ventral to the fossa, the scapulocoracoid is marked by finished bone surface. This surface

1117 continues posteroventral to the glenoid fossa as an anteroposteriorly elongate posterior process of

1118 the coracoid. Similar processes occur in Araeoscelis gracilis (MCZ 8828; Reisz et al., 1984), 
1119 Youngina capensis (AMNH FARB 5561), and Trilophosaurus buettneri (TMM 31025-140;

1120 Gregory, 1945). The bone anteroventral to the glenoid fossa is fractured into small fragments,

1121 such that the boundaries between the scapulocoracoid and elements further anteriorly (clavicle,

1122 cleithrum) cannot be discerned.

1123 Anterodorsal to the scapular blade, there is an anteroposteriorly slender and dorsoventrally

1124 tall blade of bone that we interpret as the left cleithrum based on morphology and position (Fig.

1125 7). The cleithrum is displaced strongly anterodorsally relative to the anterodorsal margin of the

1126 blade. The bone curves strongly anterodorsally, with a prominently concave anterior surface. The

1127 lateral surface of the cleithrum is made up of finished bone marked by slender, dorsoventrally

1128 extending ridges. Ventrally, the lateral surface of the cleithrum is poorly preserved, with little

1129 intact lateral surface. The bone tapers slightly at its ventral tip.

1130 The cleithrum is absent in nearly all known Permo-Triassic diapsid reptiles. It is present in

1131 Coelurosauravus elivensis (MNHN.F.MAP 327; Carroll, 1978), Araeoscelis gracilis (Vaughn,

1132 1955; Reisz et al., 1984), Petrolacosaurus kansensis (Reisz, 1981), and possibly Hovasaurus

1133 boulei (Currie, 1981a) and Acerosodontosaurus piveteaui (Bickelmann et al., 2009). A distinct

1134 cleithrum is absent in Drepanosaurus spp. (MCSNB 5728, GR 113; Renesto, 1994a; Harris and

1135 Downs, 2002) Youngina capensis (BP/1 3859; Gow, 1975), Protorosaurus speneri (Gottmann-

1136 Quesada and Sander, 2009), Clevosaurus hudsoni (NHMUK R36832; O’Brien et al., 2017), and

1137 Eusaurosphargis dalsassoi (Scheyer et al., 2017).

1138 A probable clavicle is preserved ventral to the cleithrum described above (Fig. 7). It sits

1139 anteriorly of the blade of the scapula, but it is partially articulated to the anterior margin of the

1140 coracoid further ventrally. The bone bears an anterodorsally curved shaft that is heavily

1141 weathered at its dorsal tip. Further ventrally, it passes deep to several unidentified fragments that 
1142 conceal its complete shape. The slenderness and shape of the bone resembles those of the

1143 clavicle of Coelurosauravus elivensis (MNHN.F.MAP 327; Carroll, 1978), Youngina capensis

1144 (Gow, 1975), and Prolacerta broomi (NMQR 3763; Gow, 1975).

1145

1146 Humerus

1147 Both humeri are preserved largely intact in SMNK-PAL 2882, with their proximal ends 1148 exposed in extensor view (Fig. 8, 9). The proximal ends and humeral shafts are preserved, but

1149 the distal articular surfaces and epicondyles are weathered away. Both humeri are fractured distal 1150 to the midshaft. They are hollow inside, and the cortical bone is extremely thin (thickness $<1$ $1151 \mathrm{~mm})$.

1152 As preserved, the proximal end of the humerus is expanded to approximately three times the 1153 breadth at midshaft. The proximal thirds of the left and right humeri are exposed in extensor 1154 view and heavily crushed. The humeral head is convex proximally. There is no clear internal 1155 tuberosity raised beyond the humeral head, similar to the condition in Araeoscelis gracilis 1156 (Vaughn, 1955), Claudiosaurus germaini (SAM-PK 8580), and Youngina capensis (BP/1 3859;

1157 Gow, 1975). The preserved bone surface on the extensor surface of the proximal humerus is 1158 smooth.

1159 The humerus tapers distally, achieving a breadth one third that of the proximal end at 1160 approximately one-third the length of the humerus. It maintains this breadth for the central one1161 third of the length of the humerus, broadening again at the distal one-third the length of the bone.

1162 The elongate slender shaft and limited expansion of the proximal and distal ends compare 1163 favorably to Coelurosauravus elivensis (MNHN.F.MAP327; Carroll, 1978), Rautiania sp. (PIN 1164 5130/54; Bulanov and Sennikov, 2010), and Araeoscelis gracilis (Vaughn, 1955). The humerus 
1165 is relatively more robust, with more expanded ends and a proportionally shorter shaft, in

1166 Thadeosaurus colcanapi (MNHN.F.MAP360; Carroll, 1981), Youngina capensis (BP/1 3859;

1167 Gow, 1975), and Protorosaurus speneri (Gottmann-Quesada and Sander, 2009).

1168 In SMNK-PAL 2882, the left humerus preserves its central one-third largely uncrushed (Fig.

1169 9). This uncrushed portion does not bear any prominent crests or ridges. The central one-third of

1170 the right humerus is cracked open, exposing the medullary cavity and the submillimeter-thick

1171 cortical bone (Fig. 8). The exposed cavity indicates that the humeri were subcircular in cross-

1172 section at midshaft. The distal one-third of the humerus expands relative to midshaft. Very little

1173 morphology can be seen due to weathering. It is not clear if the humeri in SMNK-PAL 2882 bore

1174 the distally expanded entepicondyle characteristic of Coelurosauravus elivensis

1175 (MNHN.F.MAP317; Carroll, 1978) and Rautiania sp. (PIN 5130/54).

1176

\section{Radius}

1178 The radius is a simple bone, consisting of an elongate shaft with an ovoid cross-section and

1179 small proximal and distal expansions. The right radius preserves only a faint outline of its

1180 proximal third (Fig. 10). The central third of the bone is uncrushed, but the distal end is heavily

1181 crushed and weathered. The left radius is more complete, preserving nearly the full length of the

1182 bone, but it is heavily cracked and crushed throughout its length (Fig. 11). The midshaft region

1183 and the distal end are heavily weathered, obscuring their original morphology.

1184 The shaft of the radius is straight, lacking the sinusoidal curvature present in some early

1185 diapsids (e.g., Thadeosaurus colcanapi, MNHN.F.MAP360, 19a; Trilophosaurus buettneri,

1186 TMM 31025-140). The straight shaft more closely resembles the radii of the holotype of

1187 Weigeltisaurus jaekeli (SSWG 113/7), Coelurosauravus elivensis (MNHN.F.MAP327; Carroll, 
1188 1978), and Megalancosaurus preonensis (MFSN 1769; Renesto, 1994b). The proximal end of

1189 the radius is subtly expanded relative to the midshaft, being 1.5 times wider. The radial shaft is

1190 smoothly textured without any prominent crests or tubers. At its distal end, the bone expands

1191 subtly relative to midshaft. The distal articular surface appears to be slightly convex without a

1192 complex, screw-shaped articulation. Such a complex, screw-shaped articulation occurs in

1193 Drepanosaurus sp. (GR 737; Pritchard et al., 2016), and squamates such as Iguana iguana

1194 (Gauthier et al., 1988; Russell and Bauer, 2008). In SMNK-PAL 2882, it is not clear which

1195 carpals the radius met at its distal end, as the carpi are not preserved.

1196

1197 Ulna

1198 Both ulnae are complete (Fig. 10, 11). However, the proximal and distal articular surfaces 1199 and the olecranon processes are heavily weathered. The shafts of both ulnae are crushed. They 1200 remain in articulation with both the radii and humeri, likely in their original articulations.

1201 The olecranon process of the ulna is elongate and straight, extending well beyond the ulnar 1202 articulation with the humerus (Fig. 11). The apex of this process is not upturned. Similarly 1203 elongate olecranon processes extending beyond the margins of the humeral articulation occur in 1204 Coelurosauravus elivensis (MNHN.F.MAP317; Carroll, 1978), Captorhinus aguti (Fox and 1205 Bowman, 1966), Petrolacosaurus kansensis (Reisz, 1981), and Megalancosaurus preonensis 1206 (MPUM 6008; Renesto et al., 2010). In Thadeosaurus colcanapi (MNHN.F.MAP360; Carroll, 1207 1981), Trilophosaurus buettneri (TMM 31025-140; Gregory, 1945), Azendohsaurus

1208 madagaskarensis (Nesbitt et al., 2015), and many early lepidosaurs (Cocude-Michel, 1963;

1209 Simões et al., 2016) the olecranon does not extend beyond the defined margins of the humeral

1210 articulation. The olecranon process is poorly developed in Youngina capensis (BP/1 3859; Gow, 
1211 1975), Claudiosaurus germaini (Carroll, 1981), and Macrocnemus bassanii (PIMUZ T/4355;

1212 Peyer, 1937).

1213 The shaft of the ulna is expanded to its greatest diameter just distal to the articulation with

1214 the humerus. Just distal to the humeral articulation, the flexor surface of the right ulna contacts

1215 the proximal end of the radius for a short length. Distal to the radioulnar articulation, the ulna

1216 tapers slightly.

1217 The ulnar shaft is straight, retaining roughly the same diameter throughout its length. In its

1218 distal fourth, the shaft expands slightly. The distal end of the ulna is heavily eroded on the left

1219 side, but the right retains some of its original shape (Fig. 11). The distal articular surface was

1220 slightly convex. On the right side, the radius and ulna are in contact at their distal tips (Fig. 10).

1221 However, this may be a preservational artifact. In the absence of carpals, we cannot determine

1222 which carpals contacted the ulna.

1223

1224 Carpus

1225 Both carpi are poorly preserved. None of the left carpus is visible, whereas four poorly

1226 preserved clumps of bone are present on the right (Fig. 12). These lack defined boundaries, such

1227 that their morphology cannot be discerned. The largest clump is positioned several millimeters

1228 distal to the radius and just proximal to the first, second, and third metacarpals. It may represent

1229 portions of distal carpals 1, 2, and 3. The holotype of Weigeltisaurus jaekeli (SSWG 113/7) has

1230 two or three proximal carpals and five distal carpals (Evans and Haubold, 1987).

1231

1232 Manus 
1233 The left and right manus are well preserved (Fig. 12, 13). The left preserves all metacarpals

1234 and phalanges (Fig. 12), whereas the right preserves everything but the phalanges of the first

1235 digit (Fig. 13). Both hands are exposed in roughly dorsal view, although certain digits are twisted

1236 into lateral and medial views. Although many metacarpals and phalanges are weathered, the

1237 hands provide excellent detail concerning the structure and proportions in the manual digits.

1238 The manual phalangeal formula of Weigeltisaurus jaekeli is 2-3-4-5-4 based on SMNK-PAL

12392882 and SSWG 113/7. The same formula occurs in a probable manus of Rautiania sp. (PIN

1240 5130/10; Bulanov and Sennikov, 2010). This is one more phalanx in the fifth digit than in the

1241 manus of most early eureptiles and diapsids; a formula of 2-3-4-5-3 occurs in Labidosaurus

1242 hamatus (Sumida, 1989), Hovasaurus boulei (Currie, 1981a), Vallesaurus cenensis (MCSNB

1243 4751; Renesto and Binelli, 2006), Protorosaurus speneri (Gottmann-Quesada and Sander, 2009),

1244 and Macrocnemus fuyuanensis (GMPKU-P-3001; Jiang et al., 2011). It may represent a

1245 synapomorphy of Weigeltisauridae.

1246 The metacarpals are best preserved in the left hand of SMNK-PAL 2882, where they radiate

1247 outwards from the distal end of the carpus (Fig. 12). The proximal articular surfaces of the

1248 metacarpals do not appear to overlap one another, although this may be due to post-mortem

1249 disarticulation. The proximal articular surfaces of the metacarpals do overlap in the holotype of

1250 of Weigeltisaurus jaekeli (SSWG 113/7; Evans and Haubold, 1987), Petrolacosaurus kansensis

1251 (Reisz, 1981), Protorosaurus speneri (Gottmann-Quesada and Sander, 2009), Mesosuchus

1252 browni (SAM-PK 6046; Dilkes, 1998), and Iguana iguana (Russell and Bauer, 2008).

1253 In SMNK-PAL 2882, each metacarpal is broad proximally, tapering to a slender shaft. The

1254 shafts expand slightly at their distal ends, terminating in a distally convex articulation for the

1255 proximal phalanges. The proximodistal lengths of metacarpals I through III increase 
1256 sequentially, with the fourth metacarpal being roughly the same length as the third. The same

1257 relative lengths occur in the holotype of Weigeltisaurus jaekeli (SSWG 113/7) and the manus

1258 referred to Rautiania sp. (PIN 5130/10; Bulanov and Sennikov, 2010). Although its exact length

1259 cannot be determined, the fifth metacarpal is relatively shorter than the fourth. Similar relative

1260 metacarpal proportions also occur in Thadeosaurus colcanapi (MNHN.F.MAP360; Carroll,

1261 1981), Hovasaurus boulei (Currie, 1981a), and Protorosaurus speneri (Gottmann-Quesada and

1262 Sander, 2009).

1263 The non-ungual phalanges are relatively uniform in shape (Fig. 12, 13). Each has slightly

1264 expanded proximal and distal ends and an elongate, tapered shaft. The fifth digit of the left hand

1265 and the first through fourth digits of the right are exposed in lateral view, such that a slight

1266 bowing of the palmar surfaces of each phalanx may be seen. The relative lengths of the non-

1267 terminal phalanges closely resemble the condition in Rautiania sp. (PIN 5130/10; Bulanov and

1268 Sennikov, 2010). In each digit, the penultimate phalanx is the longest proximodistally. Similar

1269 relative elongation of the penultimate phalanges occurs in Megalancosaurus preonensis (MFSN

1270 1769; Renesto, 1994b), Trilophosaurus buettneri (TMM 31025-140; Gregory, 1945), and the

1271 first manual digit (the only one completely preserved) of Icarosaurus siefkeri (AMNH FARB

1272 2101; Colbert 1970). Similar proportions occur in some extant arboreal squamates, such as

1273 Draco dussumieri (FLMNH Herp 19920, ark:/87602/m4/M36111) and Plica plica (CAS HERP

1274 231777, ark:/87602/m4/M74709).

1275 The unguals are relatively proximodistally shorter than any non-ungual phalanges and

1276 metacarpals (Fig. 12, 13). The manual unguals all are similar in proximodistal length. The shape

1277 is best preserved in the second and third digits of the left manus and the second digit of the right 
1278 hand. Each ungual bears a strong curvature towards the palmar surface of the hand and a large 1279 ventral flexor tubercle.

1280 The articular facet for the penultimate phalanx is positioned at the proximodorsal margin of

1281 the ungual. Its dorsal margin is framed by a proximodistally short, proximally projecting process.

1282 There is a dorsoventrally short, flattened surface ventral to the phalangeal articular surface.

1283 Proximoventrally, each well-preserved ungual bears a prominent, ventrally convex flexor

1284 tubercle. The flexor tubercle is similarly rounded, pendent, and proximally positioned in

1285 Protorosaurus speneri (Gottmann-Quesada and Sander, 2009), Trilophosaurus buettneri (TMM

1286 31025; Gregory, 1945), and Azendohsaurus madagaskarensis (Nesbitt et al., 2015).

1287 The well-preserved examples taper prominently throughout their proximodistal lengths, with

1288 the distal tip positioned ventrally relative to the flexor tubercle. A distinct lateral groove is

1289 present on the lateral surfaces of the best preserved unguals. It extends distoventrally along the

1290 ventrolateral margin of the bone, from the level of the flexor tubercle to the distal tip. The arcing

1291 of the distal tips of the unguals compares favorably with Trilophosaurus buettneri (TMM 31025-

1292 140; Gregory, 1945) and Azendohsaurus madagaskarensis (Nesbitt et al., 2015). It contrasts with

1293 the relatively straight unguals in Thadeosaurus colcanapi (MNHN.F.MAP360; Carroll, 1981),

1294 Boreopricea funerea (PIN 3708/1), and “Chasmatosaurus” yuani (IVPP 4067).

1295

1296 Pelvis

1297 As is the case with the pectoral girdle, the pelvis is heavily crushed and difficult to interpret

1298 (Fig. 14). Unfortunately, there are few other weigeltisaurid specimens that preserve pelves in

1299 articulation to use for comparisons. Our interpretation of this region is tentative, largely based on

1300 the position of the femora relative to the crushed pelvic bones. 
1301 The proximal articular surfaces of both femora sit lateral to trapezoidal bones with dorsally 1302 expanded margins that we interpret as ilia (Fig. 14). Both are broken ventrally and exposed in 1303 medial view. The medial surfaces are all heavily weathered, such that no articular surfaces for 1304 the sacral ribs nor other pelvic elements can be discerned. Both bones bear a distinct, dorsolateral 1305 concavity positioned dorsal to the femoral articulation. The anterior tips of the iliac blades and 1306 likely most of the pubes are covered by clusters of the left patagial ossifications.

1307 Under our interpretation, both ischia are exposed in dorsal view (Fig. 14). The ischial 1308 symphysis is preserved as a somewhat sigmoid line, the anterior tip of which may be seen 1309 posterior to the left ilium. The symphysis curves slightly towards the right ilium along its length. 1310 The left ischium is displaced further posteriorly than the right.

1311 A small, posterolateral process with a posteriorly convex margin is present posterior to the 1312 acetabulum on both sides. We interpret these as posterolateral processes comparable to similar 1313 processes in sphenodontians (e.g., Carroll, 1985; Fraser, 1988) and drepanosauromorphs (e.g., 1314 Renesto, 1994a; Colbert and Olsen, 2001). Posteromedially, the ischia are drawn out into 1315 elongate posteromedial processes that form much of the anteroposterior lengths of the bones.

1316 This conformation of processes in SMNK-PAL 2882 is quite similar to the ischium of the stem1317 turtles Pappochelys rosinae (e.g., Schoch and Sues, 2018b) and Eorhynchochelys sinensis (e.g., 1318 Li et al., 2018).

1319 Only one weigeltisaurid specimen preserves the pelvis in mostly lateral view: a skeleton of 1320 Coelurosauravus elivensis (MNHN.F.MAP327; Carroll, 1978; Evans and Haubold, 1987). In 1321 that specimen, only the right ilium and right pubis are clearly exposed. The right ischium is 1322 overlain by the proximal portion of the right femur, which remains in articulation with the 1323 acetabulum. The ilium is trapezoidal, broadening from the level of the acetabulum to a mostly 
1324 flat dorsal margin. As a result, there are prominent anterior and posterior processes of the ilium

1325 that taper anterodorsally, a shape similar to the crushed ilium of a specimen of Weigeltisaurus

1326 jaekeli described by Evans (1982). These processes compare favorably with the dorsally

1327 expanding blade of what we consider the ilium in SMNK-PAL 2882. The inverted trapezoid

1328 shape of the iliac blade resembles the condition in Hyperodapedon gordoni (Benton, 1983) and

1329 Teraterpeton hyrnewichorum (NSM 018GF010.002; Pritchard and Sues, 2019). It contrasts

1330 sharply with the posterodorsally tapered, anteriorly flattened shape of the iliac blades of

1331 Araeoscelis gracilis (Vaughn, 1955), Thadeosaurus colcanapi (MNHN.F.MAP360; Carroll,

1332 1981), and Youngina capensis (BP/1 3859; Gow, 1975). The ilium of MNHN.F.MAP327 bears

1333 an apparent embayment along its dorsolateral surface that also compares favorably with the

1334 morphology of the proposed ilia from SMNK-PAL 2882.

1335

1336 Femur

1337 The left femur is nearly complete (Fig. 15). A portion of the cortical bone of the left shaft is

1338 missing, as is a section of the femoral head. The proximal and distal ends are somewhat crushed.

1339 The proximal end of the right femur is preserved in articulation with the pelvis (Fig. 2). It lies

1340 dorsal to the posteriormost seven patagial ossifications. The shaft and distal end of the right

1341 femur are completely missing.

1342 The proximal end of the left femur is positioned in articulation with the crushed left pelvic

1343 girdle (Fig. 15). Its head is convex, and the posterior margin is heavily weathered. A proximally

1344 convex femoral head occurs in the holotype of Weigeltisaurus jaekeli, Coelurosauravus elivensis

1345 (MNHN.F.MAP327; Carroll, 1978), Araeoscelis gracilis (MCZ 4360; Vaughn, 1955),

1346 Hypuronector limnaios (AMNH FARB 7759), Vallesaurus cenensis (MCNSB 4751), and 
1347 Clevosaurus hudsoni (NHMUK PLR 600a). Proximally flattened or slightly concave proximal

1348 articular surfaces occur in Thadeosaurus colcanapi (MNHN.F.MAP360, Carroll, 1981),

1349 Youngina capensis (BP/1 3859), Prolacerta broomi (BP/1 2676; Gow, 1975), and Pamelaria

1350 dolichotrachela (Sen, 2003).

1351 On the left femoral head of SMNK-PAL 2882, weathering has formed a prominent

1352 depression in its posterior edge, framed by a ring of cortical bone. The internal trochanter forms

1353 a prominent crest that extends ventrally from the femoral head on the left side. At its proximal

1354 end of the femur in SMNK-PAL 2882, the crest is equivalent in dorsoventral depth to the

1355 femoral head. It decreases in height further distally, becoming indistinguishable from the femoral

1356 shaft one quarter the length down the shaft. A similarly short internal trochanter occurs in

1357 Coelurosauravus elivensis (MNHN.F.MAP 17). The internal trochanter remains distinct for a

1358 greater portion of the shaft in Araeoscelis gracilis (Vaughn, 1955), Thadeosaurus colcanapi

1359 (MNHN.F.MAP360), and Prolacerta broomi (BP/1 2676; Gow, 1975).

1360 The femoral shaft is elongate and slender, consistently maintaining a narrow diameter for

1361 approximately one-half its total length (Fig. 15). The posterodorsal surface of the femoral shaft is

1362 largely weathered away, exposing the medullary cavity. Similar to the humeral shaft, the cortical

1363 bone of the femur is extremely thin $(<1 \mathrm{~mm})$ throughout the exposed length of the shaft. Due to

1364 this weathering, any crests or muscle attachments on the femoral shaft are not preserved.

1365 Similarly thin cortical bone occurs in the forelimb bones of Drepanosaurus sp. (Pritchard et al.,

1366 2016), extant flighted birds (Sullivan et al., 2017), and pterosaurs (de Ricqlès and Padian, 2000).

1367 The shaft of the femur expands in diameter three quarters the length down the shaft,

1368 expanding into the distal articular surface (Fig. 15). The distal end is exposed in posterodorsal

1369 view. Although the dorsal surface of the distal femur is heavily weathered, it seems to lack a 
1370 proximodistally extending depression separating the lateral and medial condyles. A similar

1371 condition is present in Thadeosaurus colcanapi (MNHN.F.MAP360; Carroll, 1981), Prolacerta

1372 broomi (BP/1 2676; Gow, 1975), and Clevosaurus hudsoni (NHMUK PLR 600a). A prominent

1373 depression occurs between the condyles of Captorhinus aguti (Fox and Bowman, 1955),

1374 Araeoscelis gracilis (Vaughn, 1955), and Petrolacosaurus kansensis (Reisz, 1981).

1375 The distal end of the left femur in SMNK-PAL 2882 may be divided into three distinct

1376 condyles: the medial tibial, lateral tibial, and fibular condyles. The fibular and lateral tibial

1377 condyles are closely associated, comprising much of the posterior portion of the distal end of the

1378 femur. These two condyles notably extend distally relative to the medial tibial condyle. Similar

1379 prominence of the lateral two condyles occurs in Coelurosauravus elivensis

1380 (MNHN.F.MAP325), Petrolacosaurus kansensis (Reisz, 1981), Zarcasaurus tanyderus (CM

1381 41704; Brinkman et al., 1984), and Vallesaurus cenensis (MCSNB 4751). In contrast, the

1382 femoral condyles are similarly distally expressed in Claudiosaurus germaini (SAM-PK 8266),

1383 Prolacerta broomi (BP/1 2676; Gow, 1975), and Clevosaurus hudsoni (NHMUK PLR 600a;

1384 Fraser, 1988).

1385 The posterior condylar surface is marked by a prominent, distally rounded crest that we

1386 identify as the fibular condyle. The central portion of the fibular condyle is marked by a

1387 prominent depression. An additional condyle - the lateral tibial condyle - sits ventral to the

1388 fibular condyle. It appears to be similar in dorsoventral height to the fibular condyle, but little

1389 can be said of its morphology due to surficial weathering. The medial tibial condyle is also

1390 heavily weathered. Its distal margin is subtly convex.

1391

1392 Tibia 
1393 The full proximodistal length of the left tibia is preserved, although the bone is heavily

1394 crushed and much of the cortical bone of the tibial shaft has weathered away (Fig. 16). The distal

1395 end of the right tibia is exposed and well preserved; the proximal end of the bone is buried

1396 beneath the bundle of patagial ossifications from the right side of the body.

1397 The tibia is overall straight and slender, with expansions proximally and distally (Fig. 16).

1398 The proximal end of the bone is only visible on the left tibia, and it is both crushed and

1399 weathered. The exposed portion of the bone is not as transversely broad as the distal end of the

1400 femur, which could be a product of distortion or of some portion of the tibia remaining concealed

1401 in the rock. On the left hindlimb, the exposed proximal tibial articular surface is flat and

1402 positioned close to the medial tibial condyle of femur. There is a small cnemial eminence on the

1403 anterior surface of the proximal tibia, similar to the condition in Thadeosaurus colcanapi

1404 (MNHN.F.MAP360; Carroll, 1981), Prolacerta broomi (BP/1 2676; Gow, 1975), and

1405 Clevosaurus hudsoni (NHMUK PLR 600a; Fraser, 1988). This cnemial crest does not extend

1406 proximally as a prominent tuberosity, as occurs in Captorhinus aguti (Fox and Bowman, 1966)

1407 and Zarcasaurus tanyderus (CM 41704; Brinkman et al., 1984). In SMNK-PAL 2882, the left

1408 tibia remains in articulation with the proximal end of the left fibula. The exposed bone of the

1409 extensor surface of the tibia is smooth, without any obvious crests or muscle scars.

1410 Distal to the proximal articular surface, the tibia continuously decreases in diameter. One-

1411 third the length down the shaft, the diameter of the bone is roughly one third that of its proximal

1412 articular surface. For most of the length of the tibia distal to this point, the cortical bone of the

1413 extensor surface is weathered away. The cortical bone of the tibial shaft is $<1$ millimeter in

1414 thickness, similar to that of the femur and the humerus. 
1415 The distal one fifth of the left tibia preserves the outer surface of the bone, although the 1416 anterior half of this surface is broken into small bone fragments (Fig. 16). The distal fifth of the

1417 bone is roughly two times the diameter of the thinnest portion of the tibial shaft. The preserved

1418 bone on the posterior surface of the tibia is smoothly textured. The distal articular surface of the 1419 right tibia for the tarsals is too weathered to describe adequately.

1420 The right tibia is compressed but relatively well preserved, with much of the cortical bone 1421 intact (Fig. 2). As in the left tibia, the distal fifth expands to be approximately twice the diameter 1422 of the shaft. The distal articular surface preserves a distinct step, but it is not clear whether the 1423 distally projecting portion of the surface was positioned anteriorly or posteriorly. A similarly 1424 stepped distal articular surface occurs in Araeoscelis gracilis (MCZ 4173; Vaughn, 1955), 1425 Zarcasaurus tanyderus (CM 47104; Brinkman et al., 1984), and some archosauriforms (Nesbitt, 1426 2011). In SMNK-PAL 2882, the tarsus is not preserved, so the relationships of the tibia to more 1427 distal elements cannot be discerned. Evans and Haubold (1987) described the pes of the holotype 1428 of Coelurosauravus elivensis (MNHN.F.MAP325) as consisting of a distinct astragalus, 1429 calcaneum, lateral centrale, and five distal tarsals.

1430

1431 Fibula

1432 Only the left fibula is exposed in SMNK-PAL 2882 (Fig. 16). The right element is concealed 1433 under the patagial ossifications from the right side of the body. The left is largely complete, with 1434 only the distal tip of the bone being weathered away. It is heavily crushed and exposed mostly in 1435 anterior view.

1436 The left fibula appears to retain its articular contacts with both the left femur and tibia. It 1437 extends further proximally than the tibia, fitting against the lateral surface of the lateral tibial 
1438 condyle. The proximal end of the bone is largely flat with a small proximally projecting process

1439 on its extensor margin. Distal to the proximal articular surface, the shaft of the fibula does not

1440 constrict in diameter. The preserved surface of the bone is smoothly textured.

1441 Near three quarters the length down the shaft, the fibula becomes heavily weathered with 1442 only a few splinters of bone remaining to reflect its original shape. The shaft appears to have

1443 expanded slightly in diameter at this point. The preserved portion of the fibula terminates at a

1444 jagged break well proximal to the distal end of the left tibia. It is not clear whether the fibula was

1445 sigmoidally curved or straight-shafted, but the fibulae in Coelurosauravus elivensis

1446 (MNHN.F.MAP325; Carroll, 1978) and the Eppleton weigeltisaurid specimen (TWCMS

1447 B5937.1) are straight along their proximodistal lengths.

1448

1449 Pes

1450 The pedes are preserved in a condition similar to the manus (Fig. 17, 18). As is the case for

1451 the carpi, the tarsi are not preserved in SMNK-PAL 2882. The space between the distal ends of

1452 the tibiae and fibulae and the proximal ends of the metacarpals is devoid of bone. There is a

1453 prominent, brown discoloration of the matrix at the proximal end of the left foot, which may

1454 relate to the original position of the tarsal bones. The tarsus of the holotype of Weigeltisaurus

1455 jaekeli has a large astragalus, a small calcaneum, a broad centrale, and five distal tarsals (Evans

1456 and Haubold, 1987). By contrast, the metatarsals and phalanges are well preserved such that a

1457 full account of the feet can be given.

1458 The pedal digital formula indicated by SMNK-PAL 2882 is 2-3-4-5-?. An ungual and

1459 penultimate phalanx of the fourth digit is preserved in the right foot, and the space between these

1460 bones and the metatarsals indicates the presence of either three or four phalanges in this digit 
1461 (Fig. 17). These observations are consistent with the pedal phalangeal formula of 2-3-4-5-4

1462 observed in the Eppleton skeleton (TWCMS B5937.1; Evans, 1982).

1463 The proximal ends of the metatarsals on the left pes are heavily weathered (Fig. 18), and only

1464 the third metatarsal is completely preserved on the right foot (Fig. 17). The metatarsals are more

1465 robust than the metacarpals, with proportionally larger expansions to the transverse breadth of

1466 the bone both proximally and distally. The shaft of the metatarsal makes up approximately two-

1467 thirds to the length of the bone and is half the transverse breadth of the proximal and distal

1468 expansions.

1469 The proximal margin of the articular surface of a typical metatarsal is mostly flat and

1470 transversely oriented (Fig. 17). It is not clear if the proximal ends of the metatarsals overlapped

1471 one another, but the bones were close to articulation at their proximal ends in both feet. Distally,

1472 the metatarsals expand. The distal articular surfaces for the proximal pedal phalanges are flat.

1473 The fifth metatarsal also bears a straight shaft and lacks an "outer process" (sensu Robinson,

1474 1975) extending from its proximolateral margin. Hooked metatarsals with outer processes occur

1475 broadly in saurian reptiles such as Prolacerta broomi (Gow, 1975), Clevosaurus hudsoni (Fraser,

1476 1988), and Trilophosaurus buettneri (TMM 31025-140; Gregory, 1945).

1477 The pedal phalanges are relatively uniform in shape (Fig. 17). Each is more robust than the

1478 manual phalanges, with a slightly more pronounced expansion of the proximal and distal ends.

1479 This may be seen best in the proximal phalanges of the third and fourth digits of the left pes and

1480 the second, third, and fourth digits of the right foot, all of which are exposed in dorsal view. The

1481 expansions of the distal ends of the phalanges become narrower further distally. As in the

1482 metacarpals, those metatarsals exposed in either lateral or medial views exhibit a prominent 
1483 bowing of the ventral surface. This shape is particularly evident in the penultimate phalanges of

1484 the first and fifth digits of the right foot.

1485 The pedal ungual phalanges are dorsoventrally deep and taper strongly at their distal tips.

1486 Based on the well-preserved unguals of the third pedal digits, most of the proximal surface of the

1487 bone formed a slightly concave articular surface for the penultimate phalanx. In all unguals that

1488 preserve a complete ventral surface, a prominent, ventrally convex flexor tubercle extends well

1489 ventral to the proximal articular surface. Based on the more complete unguals of the right foot,

1490 the second through fifth unguals were elongate, each longer than half the proximodistal length of

1491 the associated penultimate phalanx. The tapered tip of these unguals extends well ventral to the

1492 level of the flexor tubercle. Similar proximal articular surfaces, pendulous flexor tubercles, and

1493 ventrally tapering distal tips occur in the pedal unguals of the Eppleton weigeltisaurid specimen

1494 (TWCMS B5937.1).

1495 The ungual of the first pedal digit is only preserved on the right foot, and its shape appears to

1496 differ from those on the other digits of the same foot. It is much shorter proximodistally, much

1497 less than half the length of its respective penultimate phalanx. Its tapering distal tip curves

1498 ventrally more abruptly than in the other unguals. A clear lateral groove is not preserved on any

1499 of the pedal unguals.

1500

1501 Gastralia

1502 The venter region of SMNK-PAL 2882 preserves a large number of disarticulated gastralia

1503 extending along the ventral margin of the trunk, indicating an extensive gastral basket along

1504 nearly the full length of the trunk posterior to the preserved pectoral girdle (Fig. 5). Each

1505 gastralium is rod-like and unbranched. Each is at least slightly curved, with some near the mid- 
1506 length of the trunk being more strongly curved. None of the gastralia bears a midline apex that 1507 would suggest an anteriorly pointed median element.

1508 Similarly shaped, disarticulated gastralia occur in specimens of Coelurosauravus elivensis 1509 (MNHN.F.MAP327) and the Eppleton skeleton (TWCMS B5937.1; Evans, 1982). Only the 1510 privately owned Wolfsberg specimen of Weigeltisaurus jaekeli (described by Schaumberg, 1976)

1511 preserves the gastral basket in its apparent original position. It suggests a very slender trunk 1512 region with a strongly convex venter. We consider it likely that the medial elements of the 1513 baskets were unbranched, overlapping rods as in Proterosuchus alexanderi (NMQR 1484;

1514 Cruickshank, 1972), Postosuchus alisonae (e.g., Weinbaum, 2013), and some dinosaurs (e.g., 1515 Sternberg, 1933; Fechner and Gößling, 2014). As preserved in SMNK-PAL 2882, the gastralia 1516 were internal to the ventral bases of the patagial ossifications. In Coelurosauravus elivensis 1517 (MNHN.F.MAP327) and the Wolfsberg specimen of Weigeltisaurus jaekeli, the patagial rods 1518 appear to overlap the lateral third of the gastral basket.

1519

1520 Patagial Ossifications

1521 The longest and most prominent bones in the entire skeleton of SMNK-PAL 2882 are the 1522 rod-like supporting bones interpreted as supporting a gliding membrane or patagium (Fig. 19).

1523 Henceforth, we will refer to these ossifications as "patagials." The patagials on the right side of 1524 the body are mostly complete, extending from near the posterolateral margin of the pectoral 1525 girdle to nearly the anterior margin of the pelvis. The shafts and distal tips of the left patagials 1526 from the anteroposterior midsection of the trunk are preserved. No ventral bases from the left 1527 side are preserved. Most of the patagials are crushed transversely and some are weathered to the 1528 point where their internal cavities are exposed. 
1529 Based on SMNK-PAL 2882, there is no 'standard' patagial in Weigeltisaurus jaekeli. There is

1530 substantial variation in the patagials throughout the anteroposterior length of the trunk, with

1531 typically proximodistally longer, anteroposteriorly thicker rods in the anterior one-third of the

1532 trunk region. Further posteriorly, the rods decrease in both proximodistal length and

1533 anteroposterior thickness. We estimate a minimum of 24 patagials based on the count in SMNK-

1534 PAL 2882, slightly higher than the count of 22 for the same skeleton given by Frey et al. (1997).

1535 We estimate a count of 29 patagials in Coelurosauravus elivensis (based on MNHN.F.MAP327).

1536 Approximately 23 patagials are preserved in the Eppleton specimen, although the anteriormost

1537 preserved element is one of the absolute longest; as the longest include the sixth through tenth

1538 patagials in SMNK-PAL 2882, the Eppleton specimen would also have at least 28 patagials.

1539 Thus, a total patagial count of between 25 and 30 elements appears to be consistent across

1540 known Weigeltisauridae.

1541 We will first describe the general morphology of the individual patagials based on the

1542 preserved structures on the right and left sides of the body. We will then describe the condition

1543 of the individual patagials on SMNK-PAL 2882.

1544 The first patagial arises posterior to the coracoid, its base laying across the lateral surface of

1545 the anteriormost part of the gastral basket. It maintains a consistent anteroposterior width

1546 throughout the proximal four fifths of its proximodistal length, which is straight. Further distally,

1547 the bone curves slightly posteriorly and tapers to a rounded terminus. The first patagial in

1548 Weigeltisaurus jaekeli compares favorably with that in Coelurosauravus elivensis

1549 (MNHN.F.MAP327), although the distal tip of the first patagial in that specimen curves slightly

1550 anteriorly before curving posteriorly and tapering to its distal tip. 
1551 The second patagial is larger, with its proximal base and proximodistal lengths being roughly

1552 twice those of the first patagial. The bone tapers subtly from its proximal base to approximately

1553 one half the length up the shaft. Further distally, the bone tapers more abruptly to a sharper point

1554 than the first patagial. The anterior surface of the distal half of the second patagial is subtly

1555 anterodorsally convex, whereas the posterior surface of the distal half is flat.

1556 The third patagial is roughly one quarter longer than the second, although the bone is

1557 incompletely preserved on both sides of SMNK-PAL 2882. It bears an anteroposteriorly broad

1558 base that tapers abruptly to the width it maintains throughout most of its proximodistal length.

1559 The bone tapers subtly from the level of the distal tip of the second patagial to the distal

1560 terminus.

1561 The fourth patagial is roughly twice the proximodistal length of the third. The bone maintains

1562 its anteroposterior width for most of its proximodistal length to the level of the distal tip of the

1563 third patagial. Further distally, the fourth patagial begins to taper subtly. The morphology of the

1564 distal terminus is unclear. The shaft of the bone bears a distinct, longitudinal depression

1565 throughout much of its proximodistal length. A similar longitudinal depression also occurs in the

1566 fifth through 16th patagials.

1567 The fifth patagial is roughly $40 \%$ proximodistally longer than the fourth. It maintains its

1568 anteroposterior breadth throughout the first half of its proximodistal length, after which it begins

1569 to taper gradually. The sixth patagial is roughly $25 \%$ proximodistally longer than the fifth. It

1570 begins to gradually taper some three fifths up the proximodistal length of the shaft. In the distal

1571 fifth of its proximodistal length, the sixth patagial maintains a consistent, anteroposteriorly

1572 narrow width $(<1$ millimeter) to its distal tip. This thin distal portion of the patagial arcs

1573 smoothly throughout its length. 
1574 The seventh patagial is only slightly longer proximodistally than the sixth. It begins to taper

1575 near its proximodistal midpoint. In contrast to the elongate, thin distal segment in the sixth

1576 patagial, the seventh patagial only has a thin, curved segment for a very short length. The thin

1577 segment begins at the level of the distal tip of the sixth patagial.

1578 In SMNK-PAL 2882, the eighth patagial appears to be the absolutely longest of all. It is

1579 roughly $15 \%$ longer than the seventh patagial. It is not clear at what point down the shaft the

1580 eight patagial begins to taper. Much as in the sixth patagial, the distal fifth of the eighth is

1581 consistently extremely thin throughout its length. This thin segment arcs anteriorly near its distal

1582 tip.

1583 The ninth through 14th patagials are all similar in robusticity and anteroposterior breadth to

1584 the eighth. The relative lengths of the ninth and 10th patagials are not clear, as they are both

1585 buried deep to the left hindlimb. The tenth through fourteenth patagials begin to taper

1586 anteroposteriorly at roughly two thirds the length of the eighth patagial (the longest one that can

1587 be evaluated). The full lengths of the 10th through 14th patagials cannot be fully evaluated, as

1588 they are embedded below the left pes. However, one of these bones is broken near its midpoint,

1589 and the distal tip angles anteriorly. It is tapered to a thin splint that appears to terminate at

1590 roughly four fifths down the shaft of the eighth patagial.

1591 The 15th through 18th patagials are anteroposteriorly narrower at their bases than the ninth

1592 through 14th, being roughly two-thirds as broad as those further anterior patagials. These two

1593 begin to taper rapidly near their anteroposterior midpoints, terminating as thin threads. These

1594 bones are roughly three fifths the length of the eighth and longest patagial.

1595 Further posteriorly, the remaining patagials are tightly bundled together on the right side of

1596 the body, which is the only one that preserves them. We estimate that there are at least six 
1597 patagials posterior to the 18 th for a minimum total of 24 . Each of these patagials is

1598 anteroposteriorly narrower than the one anterior to it. Their full proximodistal lengths are

1599 obscured by other bones on both sides, but they are all certainly shorter than those between the

1600 eighth and 18th positions. The bases of these posteriormost patagials are obscured by the

1601 proximal end of the right femur and the pelvis, both of which overlie the right wing. However, it

1602 is evident that the patagials nearly extended to the posterior edge of the trunk region just anterior

1603 to the pelvic girdle. A reconstruction of the skeleton with patagials extended is presented in

1604 Figure 20.

1605

1606 Phylogenetic Analysis

1607 The analysis produced 10 most-parsimonious trees of 1,228 steps recovered in 7,440 out of 160810,000 replicates $(C I=0.306, R I=0.644)$. All most-parsimonious trees recover Weigeltisauridae 1609 as the sister taxon of Drepanosauromorpha in a monophyletic Avicephala (sensu Senter, 2004). 1610 Avicephala forms a clade with all 'younginiform'-grade diapsids and Sauria (simplified topology 1611 presented in Fig. 21). This Avicephala + Sauria clade forms a polytomy with Orovenator 1612 mayorum and Claudiosaurus germaini. See 'Discussion' section for character supports for the 1613 major clades in question for this study and comparisons with previous analyses of diapsid 1614 phylogeny. Characters with a consistency index greater than 0.5 are marked with an asterisk (*).

1615

1616

1617 Discussion

1618

1619 HOMOLOGY AND FUNCTION OF THE PATAGIAL OSSIFICATIONS 


\section{Historical Context}

1622 SMNK-PAL 2882 preserves a nearly complete patagial apparatus. Our reconstruction of the 1623 skeleton and complete patagium in SMNK-PAL 2882 is presented in Figure 20. A similarly 1624 complete structure is otherwise only known from a skeleton of Coelurosauravus elivensis 1625 (MNHN.F.MAP327; Carroll, 1978), the holotype of “Daedalosaurus madagascariensis”. Since 1626 the initial reports of weigeltisaurid skeletons early in the twentieth century, the homology and 1627 function of these structures have been a source of continued controversy. In his description of 1628 SSWG 113/7— the holotype of Weigeltisaurus jaekeli-Weigelt (1930a: 626) noted that he had 1629 first heard about the specimen as a rumored record of "Der Flugsaurier im Perm" — the pterosaur 1630 in the Permian-from the Kupferschiefer.

1631 Weigelt (1930a) dismissed the idea that SSWG 113/7 represented a flying reptile of any kind, 1632 despite the wing-like appearance of the patagials framing the partially preserved skeleton.

1633 Weigelt argued strongly that these elements were in fact the fin rays of a coelacanth, specifically 1634 Coelacanthus haasiae (now considered a subjective junior system of C. granulatus; 1635 Schaumberg, 1978), illustrating his taphonomic hypothesis with a photograph of a skeleton of a 1636 present-day pelican with a fish skeleton draped over it. Subsequent discussions of the holotype of 1637 Weigeltisaurus jaekeli in later decades would ignore the patagial ossifications based on this 1638 hypothesis (e.g., Huene 1930, 1956). Around the same time as Weigelt's work, Piveteau (1926) 1639 reported the first weigeltisaurid specimens from the Permian of Madagascar. The two skeletons 1640 he identified as Coelurosauravus elivensis clearly show the ribs of the trunk region, but neither 1641 preserved the patagial ossifications. 
1642 Schaumberg (1976) reported on two additional skeletons of Weigeltisaurus jaekeli. The so-

1643 called Wolfsberg specimen was part of the private collection of Wolfgang Munk (presently being

1644 transferred to the collections of the Naturkundemuseum im Ottoneum in Kassel) and consists of

1645 a partial skull and portions of the cervical, trunk, and caudal regions. The specimen preserves

1646 curved trunk ribs, part of the gastral basket ventrally, and two partial patagial-supported wings.

1647 The second specimen — dubbed the Bauhaus specimen—was discovered by the private collector

1648 W. Simon. It preserves only a partial caudal series, partial fore- and hindlimbs, and a series of

1649 patagials.

1650 Schaumberg (1976) recognized the bony rods as belonging to the skeleton of Weigeltisaurus

1651 rather than fin rays from a coelacanth, noting both the improbability of the association in three

1652 skeletons and the dissimilarity of the patagials from coelacanth fin rays. Although he offered no

1653 definitive hypothesis of their homology, Schaumberg speculated that the bones were related to

1654 the integument of the animal, rather than being part of the axial skeleton.

1655 Carroll (1978) re-examined the skeletons of Coelurosauravus elivensis and described a third

1656 skeleton (MNHN.F.MAP327) that he designated as the holotype of a new, closely related taxon,

1657 Daedalosaurus madagascariensis. This specimen consists of a fragmentary skull and nearly

1658 complete, articulated postcranial skeleton complete with the right patagial ossifications. Carroll

1659 (1978:144) noted a few characters differentiating the species, one of which was the presence of

1660 "greatly elongate ribs, resembling those of the Upper Triassic gliding lizards Kuehneosaurus

1661 (Robinson, 1962) and Icarosaurus (Colbert, 1970)." Carroll noted both typical diapsid dorsal

1662 ribs and greatly elongated bony rods in the skeleton, but he considered these to represent the

1663 anteriormost and posterior dorsal ribs respectively. This was reflected in his reconstruction of the

1664 skeleton of Daedalosaurus madagascariensis (Carroll, 1978: fig. 9). Evans (1982) later argued 
1665 that no major differences existed between Coelurosauravus elivensis and Daedalosaurus

1666 madagascariensis, and she synonymized the two under the former name.

1667 Pettigrew (1979) reported on a beautifully articulated partial postcranial skeleton referred to

1668 Weigeltisaurus from the upper Permian Marl Slate of England (TWCMS B5937.1). The skeleton

1669 bears many complete, dichocephalous dorsal ribs of plesiomorphic diapsid morphology

1670 articulated throughout the preserved posterior dorsal vertebral column. The distal tips of these

1671 are closely associated with the ventral tips of a series of patagial ossifications. Pettigrew (1979)

1672 assumed a one-to-one correspondence between the ribs and the patagials, indicating that the

1673 latter were a distal segment of the ribs themselves that connected with the proximal rib at a

1674 mobile joint. Evans (1982) re-studied the Eppleton skeleton and agreed with Pettigrew's

1675 assessment of bipartite ribs.

1676 Schaumberg (1986) returned to the anatomy of Weigeltisaurus jaekeli with studies of

1677 additional new specimens from the Kupferschiefer of Germany. He questioned the

1678 interpretations of Pettigrew (1979) and Evans (1982) regarding the homology of the patagials,

1679 noting that a one-to-one correspondence of patagial ossifications and dorsal ribs would require

1680 over 30 dorsal vertebrae in the Eppleton skeleton. He argued that the new skeletons he reported

1681 and the Wolfsberg specimen indicated a much lower dorsal vertebral count relative to the

1682 number of patagials. Homology of the patagial ossifications with any other part of the axial

1683 skeleton was considered unlikely; Schaumberg suggested both osteoderms or ossified tendons as

1684 potential homologs.

1685 Frey et al. (1997) briefly reported on SMNK-PAL 2882, the most complete weigeltisaurid

1686 skeleton to date. They also noted the discrepancy between the number of dorsal vertebrae and

1687 patagial bones, arguing that the bones were "neomorphic dermal ossifications that formed the 
1688 internal support of a lateral gliding membrane" (Frey et al., 1997: 1451). In this contribution, we

1689 strongly support the hypothesis of Frey et al. (1997) and provide additional observations on

1690 relevant structures in extant reptiles.

1691

1692 Trunk anatomy and the homology of patagial ossifications

1693 In considering the possible associations between the patagial ossifications and both hard- and 1694 soft-tissue structures in present-day reptiles, it is important to accurately assess how the bases of

1695 the patagial ossifications relate to the other bony elements of the trunk region. Among

1696 weigeltisaurid skeletons, the association between the patagials and the rest of the thoracolumbar

1697 region is best seen in medial view in SMNK-PAL 2882 and in lateral view in MNHN.F.MAP327

1698 (Coelurosauravus elivensis). In both skeletons, the ventral tips of the patagials extend ventrally

1699 beyond the ventral tips of the preserved dorsal ribs, extending laterally over the gastral basket.

1700 The gastral baskets in SMNK-PAL 2882 and MNHN.F.MAP327 are preserved but

1701 extensively disarticulated in both specimens. No gastralium clearly maintains its original

1702 articulation with another although the individual gastralia remain at or near the venter of the

1703 trunk of the animal, still arranged in a roughly anteroposterior row. In both cases, the patagials

1704 extend just ventral to the lateral edge of the lateralmost gastralia.

1705 The position of the patagial ossifications external to both the body cavity as framed by the

1706 ribs and the gastralia is important for understanding their homology. The gastral basket is not

1707 part of the axial skeleton of the thoracolumbar region, but instead a structure of dermal origin. In

1708 the few extant diapsids that possess a gastral basket (e.g., Sphenodon punctatus and Crocodylia),

1709 the bones develop in the dermis of the venter of the thoracolumbar region (Claessens, 2004;

1710 Fechner and Schwarz-Wings, 2012). They extend from the posterior end of the pectoral girdle to 
1711 the anterior edge of the pubis, embedded in the superficial layers of the M. rectus abdominis

1712 (Reese, 1915; Byerly, 1926; Vickaryous and Hall, 2008). They develop in loose mesenchyme

1713 externally superficially to the hypaxial musculature (Vickaryous and Hall, 2008) and become

1714 secondarily integrated into the muscles during development in Crocodylus (Claessens, 2004).

1715 Thus, the patagial ossifications would be positioned entirely external to the M. rectus abdominis.

1716 The ventral edges of the patagials are adjacent to the lateral edge of the gastral basket, which

1717 may indicate a relationship between those soft tissue structures attached to the lateral edges of

1718 the gastralia. In Sphenodon punctatus, the M. obliquus abdominis externus originate on the

1719 dorsal ribs, extending ventrolaterally to the lateral edges of the gastralia (Byerly, 1926). In

1720 Alligator mississippiensis, the M. obliquus abdominis externus inserts superficially on the ventral

1721 fascia surrounding the $M$. rectus abdominis and the gastral basket, but deep to the specialized

1722 trunco-caudalis portion of the posterior part of the latter muscle (Romer, 1923; Chiasson, 1962;

1723 Frey, 1988; Fechner and Schwarz-Wings, 2012). Considering this positioning across extant

1724 diapsids, it is likely that at least the ventral edge of the patagials were dermal ossifications

1725 directly associated with the musculature attached to the lateral edge of the gastral basket, namely

1726 the M. obliquus abdominis externus.

1727 Clarifying the patagials as dermal ossifications suggests various possible origins for the

1728 bones. One unlikely possibility is that a patagial represents an intermembranous ossification that

1729 formed within the myosepta of external trunk musculature. Such intermembranous bones are

1730 present in a wide variety of teleostean fishes, forming in the myosepta of the epaxial and

1731 hypaxial musculature of the body (Patterson and Johnson, 1995; Gemballa and Britz, 1998).

1732 However, such myosepta are eliminated early in the development of the trunk region of present-

1733 day amniotes such that the muscles form continuous sheets. Among tetrapods, the only reported 
1734 example of intermembranous bones are ossifications in the caudal region of pachycephalosaurian

1735 dinosaurs (Brown and Russell, 2012).

1736 An additional possibility is that the patagials represent lateral gastralia. In the few

1737 weigeltisaurid specimens to preserve extensive gastralia, the elements are often disarticulated

1738 such that it is not clear how many bones made up an individual segment within the basket. Those

1739 specimens preserve uniform, curved gastralia, which may represent the medial elements within

1740 each segment. The elongate, straight patagials would thus represent lateral gastralia. This

1741 hypothesis of homology would explain the higher number of patagials than dorsal vertebrae, as

1742 most Permo-Triassic diapsids (and Sphenodon punctatus) possess a higher number of gastral

1743 segments than trunk vertebrae (Romer, 1956; Carroll, 1981; Benton, 1983; Muscio, 1996).

1744 Alternatively, the patagial ossifications may represent true neomorphs without homology with

1745 any pre-existing soft or hard tissues. It is to be hoped that future discoveries and studies of

1746 articulated weigeltisaurid skeletons will clarify the relationships of the patagials to other skeletal

1747 elements.

1748

1749 Comparative and functional morphology of the gliding membrane in

1750 Weigeltisauridae

1751 Patagia that support a gliding membrane independently evolved several times in diapsid

1752 reptiles, with weigeltisaurids representing only the oldest known example of such a system

1753 (Table 1). However, in all other cases the homologies of the bones supporting the patagium are

1754 well understood. The most common patagium supports represented in extinct reptiles are

1755 elongated dorsal ribs (e.g., Kuehneosauridae, Mecistotrachelos apreoros, Xianglong zhaoi) that

1756 extend laterally or posterolaterally from their articulations with trunk vertebrae. A rib-supported 
1757 patagium is also present in the extant gliding iguanians of the genus Draco of southeast Asia

1758 (e.g., Colbert, 1967; John, 1970; Russell and Dijkstra, 2001). The patagial supports would have

1759 prevented curling-up of the lateral edges of the patagial membrane during gliding, which would

1760 have decreased the surface area of the patagium and reduce its aerodynamical performance (Frey

1761 et al., 1997). Dehling (2017) showed that Draco attaches the forelimbs to the leading edge of the

1762 patagium while airborne. This attachment of the forelimbs to the patagium suggests that the

1763 airfoil is controlled through movements of the forelimbs. Dehling furthermore suggested that this

1764 was also probably the case in weigeltisaurids. As in Draco, the long tail may have aided in

1765 steering (Frey et al., 1997).

1766 Weigeltisaurids likely had different gliding mechanisms from other patagium-borne gliders.

1767 In all other known gliders where the patagium is supported by a series of transversely elongate

1768 bony rods, the support structures are modified dorsal ribs (Table 1). These patagial ribs project

1769 laterally or ventrolaterally from the costal facets of the dorsal vertebrae, such that the patagium

1770 arises from the dorsolateral margin of the trunk. By contrast, the cross-section of the trunk in

1771 weigeltisaurids would be very different, with the patagials arising from the ventrolateral surface

1772 of the trunk and projecting laterally or dorsolaterally. This low-wing configuration is unique

1773 among known vertebrate gliders and emphasizes the distinctiveness of the gliding mechanism of

1774 weigeltisaurids. Frey et al. (2003) presented evidence of a low-wing configuration in tapejarid

1775 pterosaurs. Drawing an analogy with aircraft wings, they suggested that low-wing configurations

1776 allowed greater maneuverability at the expense of lower stability than high-wing configurations.

1777 Stability in a low-wing configuration could be increased by angling the wings slightly dorsally

1778 (=dihedrally angled wings). Such dihedral angling of the wings would be present in 
1779 weigeltisaurid patagia, considering the position of their bases within the ventrolateral margin of 1780 the trunk.

1781 The gliding snake Chrysopelea paradisi presents a body cross-section most similar to that

1782 reconstructed for weigeltisaurids. In contrast to the gliding lizard Draco, the ribs in Chrysopelea

1783 paradisi do not support a thin patagial membrane. To form its gliding surface, the snake abducts

1784 its ribs laterally such that the ventral surface of the trunk region is flat and the cross-section of

1785 the body resembles that of a cambered wing. However, this cross-section is not held more or less

1786 orthogonally to the direction of the glide as would be expected in a weigeltisaurid. Instead, the

1787 snake actively undulates its body so that parts of the cambered trunk cross-section are held in

1788 line with the direction of the glide (Socha, 2011; Holden et al., 2014).

1789 The patagial ribs in extant Draco are highly flexible, capable of a great deal of bending.

1790 Colbert (1967) noted that the bending allows sufficient curvature to shift the shape of the wing

1791 from a flattened plane to a dorsally convex surface. Russell and Dijkstra (2001) noted strong

1792 posterior bending at the distal tips of the ribs when the patagium was fully extended. The tips of

1793 the patagials in some weigeltisaurid specimens show distinct posteromedial bending (e.g.,

1794 TWCMS B5937.1, MNHN.F.MAP317) in otherwise undistorted skeletons, indicating flexibility

1795 comparable to that of the patagial ribs of Draco. Although the thickness of the anterior patagials

1796 in weigeltisaurids may have made them rigid, the flexible tips indicate the possibility of three-

1797 dimensional changes to the shape of the wing.

1798 The patagium of weigeltisaurids was likely under muscular control in much the same way

1799 that rod-supported patagia are in extant reptiles. The wings of Draco have received the most

1800 attention, with published dissections by Colbert (1967), John (1970), and Russell and Dijkstra

1801 (2001). All these authors noted prominent ligamentous connections between adjacent dorsal ribs 
1802 and prominent intercostal musculature at the anterior and posterior margins of the intercostal

1803 spaces. They also reported the presence of a series of posterolaterally expanding muscles at the

1804 anterior margin of the patagium, although there exists disagreement concerning the homology of

1805 the muscles.

1806 Colbert (1967) argued that this muscle was a component of the M. iliocostalis, whereas John

1807 (1970) considered it a component of the M. obliquus abdominis externus. Colbert (1967) did not

1808 note any muscular tissue framing the outer perimeter of the patagium, and Russell and Dijkstra

1809 (2001) described a collagen-rich band extending between the tips of the patagial ribs. However,

1810 John (1970) described a muscular expansion of the protracting muscles at the anterior margin of

1811 the patagium that extends along the perimeter of the wing. It is not clear if these discrepancies

1812 are a result of the contrasting interpretations of the authors or genuine differences between

1813 species of Draco. Colbert (1967) dissected D. maculatus whiteheadi, whereas John (1970)

1814 dissected D. dussumieri.

1815 As the patagials of weigeltisaurids are definitely not derived from costal elements, it is highly

1816 unlikely that the patagium in weigeltisaurids was controlled by intercostal musculature.

1817 However, their close association with the gastral basket suggests that the M. rectus abdominis

1818 and M. obliquus abdominis externus may have been involved in the positioning of the patagials,

1819 at least at their proximal ends. In the lateral wall of the trunk in extant diapsid reptiles, the fibers

1820 of the M. obliquus abdominis externus pass ventrolaterally from their origins on the trunk ribs to

1821 insert on the fascia of the M. rectus abdominis and in close association with the gastralia where

1822 present. Such an orientation provides a mechanism by which the patagials could be protracted,

1823 abducted, and elevated from the lateral surface of the trunk. The scale of the patagials also

1824 suggests that the muscles of the trunk wall were modified to accommodate the wings of 
1825 weigeltisaurids. Examining the distribution of Sharpey's fibers within well-preserved individual

1826 patagials may provide further insight into the muscular mechanisms of patagial control in

1827 Weigeltisauridae.

1828 McGuire and Dudley (2011) studied gliding performance in a range of species referable to

1829 Draco and compared their results with those for the Late Triassic gliding reptile Kuehneosaurus

1830 sp. and the weigeltisaurid Coelurosauravus elivensis. They argued that, due to their larger body

1831 size, both extinct taxa performed relatively poorly compared to both Draco and their estimates

1832 for the Late Triassic gliding reptile Icarosaurus siefkeri. McGuire and Dudley (2011) inferred

1833 that Coelurosauravus would have employed shallow-trajectory gliding requiring an extended

1834 ballistic dive and a substantial drop in height over the glide distance during each glide event. The

1835 Zechstein flora included a diversity of conifers and ginkgophytes but it is not known what

1836 heights the arborescent plants attained (Bernardi et al., 2017).

1837

1838 Character support and discussion of relevant clades

1839

1840 Unnamed Clade Avicephala + (“younginiforms" + Sauria)

$1841 \quad($ Bremer $=1, \mathrm{GC}[$ frequency difference $]=26)$

1842

1843 Unambiguous synapomorphies - one row of teeth on transverse process of pterygoid (87.1),

$1844 *$ dentition absent on cultriform process of parabasisphenoid (104.1), * retroarticular process

1845 present (137.1), vertebrae holocephalous in posterior dorsal region (192.1).

1846 Discussion - We include five operational taxonomic units of early African diapsids that have

1847 been recovered within a monophyletic Younginiformes by some earlier analyses (e.g., Benton, 
1848 1985; Gauthier et al., 1988) and as a paraphyletic or polyphyletic grouping of early diapsid taxa

1849 (e.g., Bickelmann et al., 2009; Pritchard and Nesbitt, 2017; Simões et al., 2018). This excludes

1850 the Malagasy taxon Claudiosaurus germaini, which is recovered outside of the clade

1851 hypothesized here. Our analysis incorporates the Tropidostoma Zone younginiform identified as

1852 Youngina capensis by Smith and Evans (1996) as a separate operational taxonomic unit (OTU)

1853 because there are substantial differences in the skull and limb skeletons from the material of

1854 Youngina capensis from the Dicynodon Assemblage Zone (pers. obs. based on SAM-PK 7719,

18558565 vs. BP/1 3859).

1856 The early diapsid Claudiosaurus germaini is recovered in a polytomy with Orovenator

1857 mayorum and this clade. Most previous analyses find the former species more proximate to

1858 'younginiform’ diapsids (e.g., Müller, 2004; Pritchard et al., 2017; Simões et al., 2018; Ford and

1859 Benson, 2019b). The constraint analysis of Pritchard and Nesbitt (2017) holding

1860 Weigeltisauridae and Drepanosauromorpha as sister taxa — as occurred in our study—did recover

1861 Claudiosaurus in a similarly basal position.

1862

1863 Avicephala

$1864($ Bremer $=2, \mathrm{GC}=29)$

1865

1866 Unambiguous synapomorphies - absence of intercentra in cervical region (184.1); absence of

1867 intercentra in dorsal region (208.1); scapulocoracoid, ratio of anteroposterior length at base of

1868 scapular blade to dorsoventral height of scapular blade between 0.4 and 0.25 (233.1); outer

1869 process of fifth metatarsal absent (318.0). 
1870 Discussion - This analysis recovers a sister-group relationship between Drepanosauromorpha

1871 and Weigeltisauridae, the first iteration of the analysis by Pritchard and Nesbitt (2017) to do so.

1872 Pritchard and Nesbitt (2017), Pritchard et al. (2018), and Pritchard and Sues (2019) all found

1873 Drepanosauromorpha as the sister taxon to a clade including Weigeltisauridae and all other

1874 neodiapsids except Orovenator mayorum. Unambiguous synapomorphies supporting the clade

1875 have uniformly low consistency indices and include reductions in ossification of the postcranial

1876 skeleton (e.g., absence of intercentra throughout the vertebral column).

1877 A monophyletic clade uniting weigeltisaurids and drepanosauromorphs was first

1878 proposed by Merck (2003) in an abstract for a presentation at the Annual Meeting of the Society

1879 of Vertebrate Paleontology in St. Paul, Minnesota. In his analysis, successive sister taxa to

1880 drepanosauromorphs included Longisquama, Coelurosauravus, and Wapitisaurus. Senter (2004)

1881 subsequently hypothesized a similar arrangement of early diapsids, recovering a clade

1882 Coelurosauravus + Longisquama as the sister taxon of drepanosauromorphs. He defined this as a

1883 stem-based taxon including "all taxa most closely related to Coelurosauravus and

1884 Megalancosaurus than to Neodiapsida" (Senter, 2004:261). However, Renesto and Binelli

1885 (2006) presented modified versions of the Senter (2004) matrix, incorporating the pterosaur

1886 Eudimorphodon and numerous additional codings of drepanosauromorph taxa. The analysis

1887 based on the recoded matrix placed Drepanosauromorpha + Eudimorphodon as the sister taxon

1888 of Archosauriformes, whereas Coelurosauravus + Longisquama remained outside of the diapsid

1889 crown-group.

1890 Other previous analyses of early diapsid interrelationships have recovered

1891 Weigeltisauridae and Drepanosauromorpha in a wide variety of different positions. Müller

1892 (2004) recovered Coelurosauravus as the sister taxon of a clade including the poorly known 
1893 South African diapsids Palaeagama and Saurosternon. By contrast, Drepanosauridae was

1894 recovered as sister to Kuehneosauridae in a clade one step closer to the reptilian crown group.

1895 Simões et al. (2018) incorporated two weigeltisaurid species (Coelurosauravus elivensis

1896 and "C." jaekeli) and only one drepanosauromorph, Megalancosaurus preonensis, into their

1897 character-taxon matrix. The two weigeltisaurid species were recovered in a monophyletic

1898 grouping outside of the reptilian crown group. Megalancosaurus preonensis was found as the

1899 sister taxon of the tanystropheid Langobardisaurus pandolfii, deeply nested in a clade outside of

1900 Sauria that also includes a polyphyletic grouping of tanystropheids and kuehneosaurids. This

1901 result differs radically from all other cladistic studies of early Diapsida and Archosauromorpha,

1902 in which tanystropheids, rhynchosaurs, azendohsaurids, and trilophosaurs are recovered as

1903 monophyletic groups nested closer to Archosauria than to Lepidosauria (e.g., Gauthier, 1984;

1904 Benton, 1985; Rieppel, 1994; Dilkes, 1998; Müller, 2004; Gottmann-Quesada and Sander, 2009;

1905 Ezcurra, 2016; Pritchard and Nesbitt, 2017; Ezcurra and Butler, 2018).

1906

1907

1908 Weigeltisauridae

$1909($ Bremer $=5, \mathrm{GC}=99)-$

1910

1911 Unambiguous synapomorphies - lacrimal contribution to lateral surface of rostrum restricted to

1912 orbital margin (25.2); jugal posterior process present and contacting quadratojugal posteriorly to

1913 form complete lower temporal bar (58.2); *horn-like projections on lateral surface of squamosal

1914 (59.1); neural spines dorsoventrally lower than anteroposteriorly long (201.1); *patagial 
1915 ossifications present in trunk region (204.1); chevrons T-shaped with prominent anterior process

1916 (219.1); *entepicondyle of humerus projecting distal to articular condyles (252.1).

1917 Discussion - Our OTUs follow the taxonomic framework offered by Bulanov and Sennikov

1918 (2006, 2015a, 2015b, 2015c), maintaining Weigeltisaurus jaekeli and Coelurosauravus elivensis

1919 in distinct genera. The monophyly of Weigeltisauridae has been accepted by previous authors

1920 studying this clade (e.g., Evans, 1982; Bulanov and Sennikov, 2006, 2015b). Pritchard and

1921 Nesbitt (2017) provided the first computational phylogenetic analysis to support the monophyly

1922 of this group with the same weigeltisaurid OTUs presented here. In their phylogenetic analysis,

1923 Simões et al. (2018) also recovered a monophyletic Weigeltisauridae.

1924 Evans (1982) offered a general diagnosis for the clade, which included both apomorphies

1925 and plesiomorphies of the group. She recognized a small lacrimal, 'denticulated' squamosal, and

1926 low dorsal neural spines as diagnostic characters (Evans, 1982:297), all of which are also

1927 recovered here. In contrast to this study, Evans (1982) and Evans and Haubold (1987)

1928 reconstructed the temporal region of Coelurosauravus with an incomplete lower temporal bar

1929 and bipartite ribs rather than dermal patagial bones. Here we add T-shaped chevrons with a

1930 prominent anterior processes and a distally expanded entepicondyle of the humerus to the

1931 diagnostic characters of the clade.

1932

1933

1934 Weigeltisaurus jaekeli + Rautiania spp.

$1935 \quad($ Bremer $=1, \mathrm{GC}=69)$

1936 
1937 Unambiguous synapomorphies - *horn-like projections on dorsolateral surface of parietal 1938 (43.1).

1939 Discussion - Limited support for a clade including the European Weigeltisaurus jaekeli and

1940 Rautiania spp. is offered by this analysis. These taxa share the presence of horn-like projections

1941 on the parietal bones, in contrast to the Malagasy Coelurosauravus elivensis. The latter bears

1942 small ridges on the dorsolateral surfaces of the parietals, although these are not nearly as strongly

1943 developed as in the other weigeltisaurids. Although it is not coded into this analysis because the

1944 holotype is not curated in a public accessible museum collection, the German weigeltisaurid

1945 Glaurung schneideri also has a rugose dorsolateral margin of the parietal rather than horn-like

1946 projections. It is possible that G. schneideri is also basal to the $W$. jaekeli+Rautiania spp. clade

1947 or that it represents the sister taxon to C. elivensis.

1948 Bony horn development and ontogeny can be closely associated in diapsid reptiles. The

1949 horns and epiossifications often grow at differential rates on a single animal's skull, as in 1950 marginocephalian dinosaurs (e.g., Sampson et al. 1997; Horner and Goodwin, 2006; Goodwin et 1951 al., 2006) and phrynosomatid lizards (e.g., Powell et al., 2002; Bergmann and Berk, 2012). It is 1952 plausible that weigeltisaurid horns also developed at different rates such that the lateral arcade of 1953 horns developed prior to the parietal horns, such that the condition in Coelurosauravus elivensis 1954 represents an earlier ontogenetic state than is represented by known specimens of Rautiania spp. 1955 and Weigeltisaurus jaekeli. Testing that hypothesis will require discovery of ontogenetic 1956 sequences of skulls from at least one weigeltisaurid species.

1957

1958 
1959 (Youngina capensis + Tropidostoma Zone 'younginiform') $+($ Acerosodontosaurus piveteaui +

1960 Hovasaurus boulei + Thadeosaurus colcanapi) + Sauria

$1961 \quad($ Bremer $=1, \mathrm{GC}=25)$

1962

1963 Unambiguous synapomorphies - *squamosal posterior lamina absent, fully exposing quadrate

1964 in posterior view (61.1); * basal tubera of basioccipital project strongly ventral to occipital 1965 condyle (101.1).

1966 Discussion - "Younginiformes" has been used to describe a monophyletic grouping of largely

1967 Permian diapsids including the eponymous Youngina capensis and several species from Permian 1968 deposits of Madagascar, such as Acerosodontosaurus piveteaui, Hovasaurus boulei, and 1969 Thadeosaurus colcanapi (Currie, 1980, 1981a). 'Younginiforms' were long considered the 1970 earliest diverging clade of lepidosauromorphs, and numerous early cladistic studies explored this 1971 hypothesis (e.g. Gauthier, 1984; Gauthier et al., 1988; Evans, 1988). However, more 1972 comprehensive analyses of early diapsid and saurian clades began to recover the traditional 1973 'younginiform' taxa outside of Sauria (e.g., Laurin, 1991; Merck, 1997; Dilkes, 1998; Müller, 1974 2004; Senter, 2004; Ezcurra et al., 2014; Pritchard and Nesbitt, 2017). Bickelmann et al. (2009) 1975 noted many anatomical differences among 'younginiform' species and raised the possibility that 1976 "Younginiformes" as traditionally conceived (e.g., Currie, 1982; Benton, 1985) represent a 1977 paraphyletic grade of non-saurian diapsids.

1978 Although this node is not strongly supported in this phylogenetic analysis, the clade 1979 incorporating traditional 'younginiform' taxa and Sauria to the exclusion of all other early 1980 Diapsida has been recovered in prior iterations of the phylogenetic analysis of Pritchard and 1981 Nesbitt (2017). A similar topology was recovered by Laurin (1991) and Ezcurra et al. (2014), in 
1982 which a clade of Youngina capensis + Acerosodontosaurus piveteaui was recovered as the sister

1983 taxon of Sauria. Our analysis does not recover a monophyletic younginiform clade in the strict

1984 consensus. However, the Malagasy diapsids Acerosodontosaurus piveteaui, Thadeosaurus

1985 colcanapi, and Hovasaurus boulei are recovered as one clade. Youngina capensis and the

1986 Tropidostoma Zone younginiform are recovered as another. Both are part of a polytomy with

1987 Sauria.

1988 By contrast, Merck (1997) recovered a clade Acerosodontosaurus + (Youngina

1989 capensis + Hovasaurus boulei) as the sister taxon of a clade Claudiosaurus+Sauria. Müller (2004)

1990 found his Younginiformes OTU well removed from Sauria, with Claudiosaurus,

1991 Coelurosauravus, Kuehneosauridae, and Drepanosauridae all positioned more proximate to the

1992 latter. Simões et al. (2018) similarly recovered a variety of diapsid clades as closer to Sauria than

1993 Younginiformes, including Coelurosauravus, a comprehensive marine reptile clade (unnamed),

1994 Choristodera, and a monophyletic Protorosauria. The exclusion of 'protorosaurs' from the stem

1995 leading to Archosauria is a highly divergent result, in contrast to all other published studies of

1996 early diapsid interrelationships.

1997 The position of the traditional 'younginiform' reptiles as intermediate between archaic

1998 diapsid lineages and Sauria in this analysis is supported by changes in the posterior portion of the

1999 skull, including the reduction in the breadth of the ventral process of the squamosal and

2000 consequent lateral exposure of the quadrate. Youngina capensis and the Tropidostoma Zone

2001 younginiform also share with early saurians the absence of a posterior lamina of the squamosal

2002 and the presence of a dorsal articular condyle on the quadrate for the squamosal. These all appear

2003 to be an incipient version of the prominent cephalic condyle of the quadrate in early Sauria and

2004 the narrow, laterally positioned ventral process of the squamosal. In many early saurians, these 
2005 traits are accompanied by a posterior concavity of the quadrate and the presence of a lateral crest

2006 that likely supported a tympanic membrane (e.g., Robinson, 1973; Müller et al., 2018). In others,

2007 the ventral lamina of the squamosal is completely absent such that the quadrate may have been

2008 mobile, allowing the streptostyly of Squamata (e.g., Robinson, 1973; Rieppel and Gronowski,

2009 1981). As such, the Youngina-type condition of the temporal region may be functionally

2010 intermediate in two ways: first, as the initial stage of reduction in the lateral and posterior

2011 bracing of quadrate by squamosal that would possibly permit cranial kinesis in some early

2012 saurian lineages (e.g., Robinson, 1973; Rieppel and Gronowski, 1981); and second, the lateral

2013 exposure of the portion of the quadrate that, in derived diapsids, closely correlates with the

2014 support of the tympanum in early Sauria (e.g., Robinson, 1973; Montefeltro et al., 2016; Sobral

2015 and Müller, 2019).

2016

2017 CONCLUSIONS

2018

2019

SMNK-PAL 2882 substantially advances our understanding of skeletal structure in the

2020 Weigeltisauridae, the oldest-known example of a lineage of gliding tetrapods in the fossil record.

2021 The skeleton not only provides detailed information for the anatomy and proportions of the

2022 skeleton in Weigeltisaurus jaekeli, but also provides key insights into the topology of the patagial

2023 ossifications to the remainder of the skeleton. Our study supports the hypothesis that the

2024 patagials represent dermal ossifications embedded in the ventrolateral surface of the trunk,

2025 possibly associated with the M. obliquus abdominis externus. Our phylogenetic analysis

2026 corroborates the hypothesis that the Weigeltisauridae represent an early-diverging diapsid clade.

2027 In our analysis, we resolve the neodiapsids Youngina capensis, Thadeosaurus colcanapi, and 
2028 other traditional 'younginiforms' as closer relatives of Sauria. Future studies of this skeleton and

2029 other weigeltisaurid specimens using advanced imaging techniques may increase our three-

2030 dimensional understanding of the skeletal structure in these reptiles.

2031

\section{ACKNOWLEDGMENTS}

2033

2034 We thank Eberhard Frey and Dieter Schreiber for facilitating access to the collections of the

2035 Staatliches Museum für Naturkunde Karlsruhe and the extended loan of SMNK-PAL 2882. We

2036 also thank J. Sébastien Steyer and Valentin Buffa for valuable discussions about the specimen

2037 and Weigeltisauridae. A. Pritchard would like to thank V. Bulanov and A. Sennikov (PIN), R.

2038 Allain (MNHN), R. Schoch and E. Maxwell (SMNS), S. Chapman and L. Steel (NHMUK), R.

2039 and Z. Erasmus (SAM), B. Zipfel (BP/1), J. Botha-Brink (NMQR), A. Downs (GR), M. Norell

2040 and C. Mehling (AMNH), A. Dooley and R. Vodden (VMNH), J. Liu (IVPP), A. Paganoni

2041 (MCSNB), A. Tintori (MPUM), G. Muscio (MFSN), J. Cundiff (MCZ), T. Rowe and M. Brown

2042 (TMM), and H. Furrer (PIMUZ) for access to specimens that proved invaluable for our

2043 comparative description. We thank D. Blackburn for access to digital datasets of extant reptiles

2044 on the Morphosource digital data repository (www.morphosource.org). For Plica plica, the

2045 California Academy of Sciences provided access to these data, the collection of which was

2046 funded by oVert TCN; NSF DBI-1701714; NSF DBI-1701713; NSF DBI-1701870. For Draco

2047 dussumieri, the Florida Museum of Natural History provided access to these data the collection

2048 of which was funded by oVert Thematic Collections Network (TCN), NSF DBI-1701714. The

2049 TNT software is freely available courtesy of the Willi Hennig Society. We thank J. Dzik, S.

2050 Renesto, and V. Buffa for their detailed reviews, which improved the quality of this manuscript. 
2051 We also thank the editorial staff of PeerJ, especially R. Langshaw and F. Knoll, for their

2052 technical assistance with this submission.

2053

2054 FUNDING

2055 - A. Pritchard's work on SMNK-PAL 2882 and the phylogeny of early Diapsida was supported 2056 by a Peter Buck Postdoctoral Fellowship and the Smithsonian Institution. Funding for H.-D.

2057 Sues was provided by the Smithsonian Institution. R. R. Reisz and D. Scott were funded by an

2058 NSERC Discovery Grant (to R. R. Reisz). The funding organizations had no role in the design 2059 of the study.

2060

2061 COMPETING INTERESTS

2062 - The authors declare no competing interests.

2063

2064 AUTHOR CONTRIBUTIONS

2065 - Adam Pritchard performed the experiments, analyzed the data, prepared figures and/or tables, 2066 authored and reviewed drafts of the manuscript, and approved the final draft.

2067 - Hans-Dieter Sues conceived and designed the experiments, performed the experiments, 2068 prepared figures and/or tables, authored and reviewed drafts of the manuscript, and approved 2069 the final draft.

2070 - Robert R. Reisz conceived and designed the experiments, performed the experiments, 2071 reviewed drafts of the manuscript, and approved the final draft.

2072 - Diane Scott performed the experiments, reviewed drafts of the manuscript, and approved the 2073 final draft. 


\section{DATA AVAILABILITY}

2076 - The following information was supplied regarding data availability:

2077 - The phylogenetic data matrix is presented in supplemental files S1 and S2 in TNT and

$2078 \quad$ NEXUS formats, respectively.

2079 - The data matrix is also available as Morphosource Project 3656 at morphobank.org.

2080 - Changes to the codings in the matrix from its prior iteration in Pritchard and Sues (2019) are

2081 presented in Supplemental File S3.

2082 - The specimen primarily described in this contribution is SMNK-PAL 2882.

2083 - Housed in the paleontological collections of the Staatliches Museum für Naturkunde

2084 Karlsruhe, Erbprinzenstrasse 13, D-76133 Karlsruhe, Germany.

2085

2086

2087

2088

2089

2090

2091

2092

2093

2094

2095

2096

2097

2098

2099

2100

2101

2102

2103

2104

2105

2106

2107

Ali SM. 1948. Studies on the anatomy of the tail in Sauria and Rhynchocephalia. Proceedings of the Indian Academy of Sciences-Section B 28:151-165.

Benton MJ. 1983. The Triassic reptile Hyperodapedon from Elgin: functional morphology and relationships. Philosophical Transactions of the Royal Society B: Biological Sciences 302:605718.

Benton MJ. 1985. Classification and phylogeny of the diapsid reptiles. Zoological Journal of the Linnean Society 84:97-164.

Bergmann PJ, Berk CP. 2012. The evolution of positive allometry of weaponry in horned lizards (Phrynosoma). Evolutionary Biology 39:311-323.

Bernardi M, Petti FM, Kustatscher E, Franz M, Hartkopf-Fröder C, Labandeira CC, Wappler T, van Konijnenburg-van Cittert JHA, Peecook BR, Angielczyk KD. 2017. Late Permian terrestrial ecosystems: a global comparison with new data from the low-latitude Bletterbach Biota. EarthScience Reviews 175:18-43. 
Bickelmann C, Müller J, Reisz RR. 2009. The enigmatic diapsid Acerosodontosaurus piveteaui

2111

2112

2113

2114

2115

2116

2117

(Reptilia: Neodiapsida) from the Upper Permian of Madagascar and the paraphyly of

"younginiform" reptiles. Canadian Journal of Earth Sciences 46:651-661.

2118

2119

2120

2121

2122

2123

2124

2125

2126

2127

2128

2129

Bonde N, Leal MEC. 2015. The detailed anatomy of Rhamphorhynchus II: braincase, pneumatics, jaws. Historical Biology 27:755-770.

Borsuk-Białynicka M, Evans SE. 2009. A long-necked archosauromorph from the Early Triassic of Poland. Palaeontologia Polonica 65:203-234.

Brandt S. 1997. Die Fossilien des Mansfelder und Sangerhäuser Kupferschiefers. Schriftenreihe des Mansfeld-Museums (Neue Folge) 2:1-68.

Brinkman DB, Berman DS, Eberth DA. 1984. A new araeoscelid reptile, Zarcasaurus tanyderus, from the Cutler Formation (Lower Permian) of north-central New Mexico. New Mexico Geology 6:34-39.

Brown B. 1905. The osteology of Champsosaurus Cope. Memoirs of the American Museum of Natural History 9:1-26.

2130

2131

2132

2133

Brown CM, Russell AP. 2012. Homology and architecture of the caudal basket of

Pachycephalosauria (Dinosauria: Ornithischia): the first occurrence of myorhabdoi in Tetrapoda.

PLoS One 7:e30212.

2134

2135

2136

2137

Buffrénil V de, Mazin J-M. 1989. Bone histology of Claudiosaurus germaini (Reptilia, Claudiosauridae) and the problem of pachyostosis in aquatic tetrapods. Historical Biology 2:311-322.

2138

2139

2140

2141

2142

2143

2144

2145

Bulanov VV, Sennikov AG. 2006. The first gliding reptiles from the Upper Permian of Russia.

Paleontological Journal 40:S567-S570.

Bulanov VV, Sennikov AG. 2010. New data on the morphology of Permian gliding weigeltisaurid reptiles of Eastern Europe. Paleontological Journal 44:682-694

Bulanov VV, Sennikov AG. 2015a. New data on the morphology of the Late Permian gliding reptile Coelurosauravus elivensis Piveteau. Paleontological Journal 49:413-423.

2150

2151

Bulanov VV, Sennikov AG. 2015b. Substantiation of validity of the Late Permian genus

Weigeltisaurus Kuhn, 1939 (Reptilia, Weigeltisauridae). Paleontological Journal 49:1101-1111.

2152

Bulanov VV, Sennikov AG. 2015c. Glaurung schneideri gen. et sp. nov., a new weigeltisaurid (Reptilia) from the Kupfershiefer [sic] (Upper Permian) of Germany. Paleontological Journal 49:1353-1364. 
2153 Byerly T. 1926. The myology of Sphenodon punctatum. University of Iowa Studies in Natural 2154 History 11:3-51.

2155

2156

2157

2158

2159

2160

2161

2162

2163

2164

2165

2166

2167

2168

2169

2170

2171

2172

2173

2174

Carroll RL. 1969. A Middle Pennsylvanian captorhinomorph, and the interrelationships of primitive reptiles. Journal of Paleontology 43:151-170.

Carroll RL. 1978. Permo-Triassic "lizards" from the Karoo system. Part II. A gliding reptile from the Upper Permian of Madagascar. Palaeontologia africana 21:143-159.

Carroll RL. 1981. Plesiosaur ancestors from the Upper Permian of Madagascar. Philosophical Transactions of the Royal Society of London B: Biological Sciences 293:315-383.

Carroll RL. 1985. A pleurosaur from the Lower Jurassic and the taxonomic position of the Sphenodontida. Palaeontographica Abteilung A 189:1-28.

Carroll RL. 1988. Vertebrate paleontology and evolution. New York: W. H. Freeman.

Carroll RL, Thompson P. 1982. A bipedal lizardlike reptile from the Karroo. Journal of Paleontology 56:1-10.

2175

2176

2177

2178

2179

2180

2181

2182

2183

2184

2185

Chiasson RB. 1962. Laboratory anatomy of the alligator. Dubuque: Wm. C. Brown Company Publishers.

Claessens LP. 2004. Dinosaur gastralia; origin, morphology, and function. Journal of Vertebrate Paleontology 24:89-106.

Cocude-Michele M. 1963. Les Rhynchocéphales et les Sauriens des calcaires lithographiques (Jurassique supérieur) d'Europe Occidentale. Nouvelles Archives du Muséum d'Histoire Naturelle de Lyon 7:1-187.

2186

2187

2188

2189

2190

2191

2192

2193

2194

2195

2196

2197 Cruickshank ARI. 1972. The proterosuchian thecodonts. In: Joysey KA, Kemp TS eds. Studies

2198 in vertebrate evolution. Edinburgh: Oliver \& Boyd, 89-119. 
2200 Currie PJ. 1981a. Hovasaurus boulei, an aquatic eosuchian from the Upper Permian of

2201 Madagascar. Palaeontologia africana 24:99-168.

2202

2203

2204

2205

2206

2207

2208

2209

2210

2211

2212

2213

2214

2215

2216

2217

2218

2219

2220

2221

2222

2223

2224

2225

2226

2227

2228

2229

2230

2231

2232

2233

2234

2235

2236

2237

2238

2239

2240

2241

2242

Currie PJ. 1981b. The vertebrae of Youngina (Reptilia: Eosuchia). Canadian Journal of Earth Sciences 18:815-818.

Currie PJ. 1982. The osteology and relationships of Tangasaurus mennelli Haughton (Reptilia, Eosuchia). Annals of the South African Museum 86:247-265.

Dehling JM. 2017. How lizards fly: a novel type of wing in animals. PLoS One 12(12):e189573.

DeMar R, Bolt JR. 1981. Dentitional organization and function in a Triassic reptile. Journal of Paleontology 55:967-984.

Denison RE, Peryt TM. 2009. Strontium isotopes in the Zechstein (Upper Permian) anhydrites of Poland: evidence of varied meteoric contributions to marine brines. Geological Quarterly $53: 159-166$.

De Stefano G. 1903. I Sauri del Quercy appartenenti alla collezione Rossignol. Atti della Società Italiana di Scienze naturali e del Museo Civico di Storia naturale in Milano 42:382-418.

Dilkes DW. 1998. The Early Triassic rhynchosaur Mesosuchus browni and the interrelationships of basal archosauromorph reptiles. Philosophical Transactions of the Royal Society B: Biological Sciences 353:501-541.

Dilkes DW, Reisz RR. 1986. The axial skeleton of the Early Permian reptile Eocaptorhinus laticeps (Williston). Canadian Journal of Earth Sciences 23:1288-1296.

Dzik J, Sulej T. 2016. An early Late Triassic long-necked reptile with a bony pectoral shield and gracile appendages. Acta Palaeontologica Polonica 61:805-823.

Edmund AG. 1969. Dentition. In: Gans C, Parsons TS eds. Biology of the Reptilia. Volume 1:

Morphology A. London and New York: Academic Press, 117-200.

Etheridge R. 1967. Lizard caudal vertebrae. Copeia 1967:699-721.

Evans SE. 1980. The skull of a new eosuchian reptile from the Lower Jurassic of South Wales. Zoological Journal of the Linnean Society 70:203-264.

Evans SE. 1982. The gliding reptiles of the Upper Permian. Zoological Journal of the Linnean Society 76:97-123.

2243

Evans SE. 1987. The phylogeny of Prolacertiformes. In: Currie PJ, Koster EH eds. Fourth Symposium on Mesozoic Terrestrial Ecosystems, Short Papers. 76-81. 
Evans SE. 1988. The early history and relationships of the Diapsida. In: Benton MJ ed. The phylogeny and classification of the Tetrapoda, Volume 1. Oxford: Clarendon Press, 221-260.

Evans SE. 2008. The skull of lizards and tuatara. In: Gans C, Gaunt AS, Adler K eds. Biology of the Reptilia. Volume 20: Morphology H. Society for the Study of Amphibians and Reptiles, 1347.

Evans SE. 2009. An early kuehneosaurid reptile from the Early Triassic of Poland. Palaeontologia Polonica 65:145-178.

Evans SE, Borsuk-Białynicka M. 2009. A small lepidosauromorph reptile from the Early Triassic of Poland. Palaeontologica Polonica 65:179-202.

Evans SE, Haubold H. 1987. A review of the Upper Permian genera Coelurosauravus, Weigeltisaurus and Gracilisaurus (Reptilia: Diapsida). Zoological Journal of the Linnean Society 90:275-303.

Ezcurra MD. 2016. The phylogenetic relationships of basal archosauromorphs, with an emphasis on the systematics of proterosuchian archosauriforms. PeerJ 4:e1778.

Ezcurra MD, Butler RJ. 2018. The rise of the ruling reptiles and ecosystem recovery from the Permo-Triassic mass extinction. Proceedings of the Royal Society B 285:20180361.

Ezcurra MD, Scheyer TM, Butler RJ. 2014. The origin and early evolution of Sauria: reassessing the Permian saurian fossil record and the timing of the crocodile-lizard divergence. PloS One 9:e89165.

Fechner R, Gößling R. 2014. The gastralial apparatus of Plateosaurus engelhardti: morphological description and soft-tissue reconstruction. Palaeontologia Electronica 17.1.13A:1-11.

Fechner R, Schwarz-Wings D. 2013. The muscles of the infrapubic abdominal wall of a 6month-old Crocodylus niloticus (Reptilia: Crocodylia). Anatomia, Histologia, Embryologia $42: 175-182$.

Flynn JJ, Nesbitt SJ, Parrish JM, Ranivoharimanana L, Wyss AR. 2010. A new species of Azendohsaurus (Diapsida: Archosauromorpha) from the Triassic Isalo Group of southwestern Madagascar: cranium and mandible. Palaeontology 53:669-688.

Ford DP, Benson RB. 2019a. A redescription of Orovenator mayorum (Sauropsida, Diapsida) using high-resolution $\mu \mathrm{CT}$, and the consequences for early amniote phylogeny. Papers in Palaeontology 5:197-239.

Fox RC, Bowman MC. 1966. Osteology and relationships of Captorhinus aguti (Cope)(Reptilia: Captorhinomorpha). University of Kansas Paleontological Contributions 11:1-79. 
Fraser NC. 1988. The osteology and relationships of Clevosaurus (Reptilia: Sphenodontida). Philosophical Transactions of the Royal Society of London B: Biological Sciences 321:125-178.

Fraser NC, Olsen PE, Dooley AC Jr, Ryan TR. 2007. A new gliding tetrapod (Diapsida: ?Archosauromorpha) from the Upper Triassic (Carnian) of Virginia. Journal of Vertebrate Paleontology 27:261-265.

Fraser NC, Walkden GM. 1984. The postcranial skeleton of the Upper Triassic sphenodontid Planocephalosaurus robinsonae. Palaeontology 27:575-595.

Frey E. 1988. Anatomie des Körperstammes von Alligator mississippiensis Daudin. Stuttgarter Beiträge zur Naturkunde, Serie A 424:1-106.

Frey E, Sues H-D, Munk W. 1997. Gliding mechanism in the Late Permian reptile Coelurosauravus. Science 275:1450-1452.

Frey E, Buchy MC, Martill DM. 2003. Middle- and bottom-decker pterosaurs: unique designs among active flying vertebrates. In: Buffetaut E, Mazin J-M eds. Evolution and Palaeobiology of Pterosaurs. Geological Society of London Special Publications 217:267-274.

Gans C, Darevski I, Tatarinov LP. 1987. Sharovipteryx, a reptilian glider? Paleobiology 13:415426.

Gauthier JA. 1984. A cladistic analysis of the higher systematic categories of the Diapsida. Ph.D. dissertation. University of California, Berkeley.

Gauthier JA, Estes R, de Queiroz K. 1988. A phylogenetic analysis of Lepidosauromorpha. In Estes R, Pregill G eds. Phylogenetic relationships of the lizard families. Stanford: Stanford University Press, 15-98.

Gauthier JA, Kearney M, Maisano JA, Rieppel O, Behlke AD. 2012. Assembling the squamate tree of life: perspectives from the phenotype and the fossil record. Bulletin of the Peabody Museum of Natural History, Yale University 53:3-308.

Gemballa S, Britz R. 1998. Homology of intermuscular bones in acanthomorph fishes. American Museum Novitates 3241:1-25.

Goloboff PA, Catalano SA. 2016. TNT version 1.5, including a full implementation of phylogenetic morphometrics. Cladistics 32:221-238.

Goodwin MB, Clemens WA, Horner JR, Padian K. 2006. The smallest known Triceratops skull: new observations on ceratopsid cranial anatomy and ontogeny. Journal of Vertebrate Paleontology 26:103-112. 
2335 Gottmann-Quesada A, Sander PM. 2009. A redescription of the early archosauromorph

2336 Protorosaurus speneri MEYER, 1832, and its phylogenetic relationships. Palaeontographica

2337 Abteilung A 287:123-220.

2338

2339

2340

2341

2342 Gregory JT. 1945. Osteology and relationships of Trilophosaurus. University of Texas

2343

2344

2345

2346

2347

2348

2349

2350

2351

2352

2353

2354

2355

2356

2357

2358

2359

2360

2361

2362

2363

2364

2365

2366

2367

2368

2369

2370

2371

2372

2373

2374

2375

2376

2377 Huene F von. 1930. Palaeochamaeleo und Coelurosauravus. Centralblatt für Mineralogie,

2378 Geologie und Paläontologie, Abteilung B 1930:440-441.

2379

Gow CE. 1975. The morphology and relationships of Youngina capensis Broom and Prolacerta broomi Parrington. Palaeontologia africana 18:89-131.

Publication 4401:273-359.

Harris JD, Downs A. 2002. A drepanosaurid pectoral girdle from the Ghost Ranch (Whitaker) Coelophysis Quarry (Chinle Group, Rock Point Formation, Rhaetian), New Mexico. Journal of Vertebrate Paleontology 22:70-75.

Haubold H, Schaumberg G. 1985. Die Fossilien des Kupferschiefers. Wittenberg-Lutherstadt: A. Ziemsen Verlag.

Heaton MJ. 1979. Cranial anatomy of primitive captorhinid reptiles from the late Pennsylvanian and Early Permian Oklahoma and Texas. Oklahoma Geological Survey Bulletin 127:1-84.

Heinicke MP, Greenbaum E, Jackman TR, Bauer AM. 2012. Evolution of gliding in Southeast Asian geckos and other vertebrates is temporally congruent with dipterocarp forest development. Biology Letters 8:994-997.

Heyer WR, Pongsapipatana S. 1970. Gliding speeds of Ptychozoon lionatum (Reptilia:

Gekkonidae) and Chrysopelea ornata (Reptilia: Colubridae). Herpetologica 26:317-319.

Hoffstetter R, Gasc J-P. 1969. Vertebrae and ribs of modern reptiles. In: Gans C, Parsons TS eds. Biology of the Reptilia. Volume 1: Morphology A. London and New York: Academic Press, 201-310.

Holden D, Socha JJ, Cardwell ND, Vlachos PP. 2014. Aerodynamics of the flying snake Chrysopelea paradisi: how a bluff body cross-sectional shape contributes to gliding performance. Journal of Experimental Biology 217:382-394.

Horner JR, Goodwin MB. 2006. Major cranial changes during Triceratops ontogeny. Proceedings of the Royal Society B: Biological Sciences 273:2757-2761.

Hounslow MW, Balabanov YP. 2018. A geomagnetic polarity timescale for the Permian, calibrated to stage boundaries. In: Lucas SG, Shen SZ eds. The Permian timescale. Geological Society, London, Special Publications 450. 61-103.

Peer) reviewing PDF | (2020:09:52512:4:0:NEW 8 Apr 2021) 
2380 Huene F von. 1956. Paläontologie und Phylogenie der niederen Tetrapoden. Jena: Gustav

2381 Fischer Verlag.

2382

2383

2384

2385

2386

2387

2388

2389

2390

2391

2392

2393

2394

2395

2396

2397

2398

2399

2400

2401

2402

2403

2404

2405

2406

2407

2408

2409

2410

2411

2412

2413

2414

2415

2416

2417

2418

2419

2420

2421

2422

2423

2424

2425

Jenkins KM, Jones ME, Zikmund T, Boyde A, Daza JD. 2017. A review of tooth implantation among rhynchocephalians (Lepidosauria). Journal of Herpetology 51:300-306.

Jiang D-Y, Rieppel O, Fraser NC, Motani R, Hao W-C, Tintori A, Sun Y-L, Sun Z-Y. 2011. New information on the protorosaurian reptile Macrocnemus fuyuanensis Li et al., 2007, from the Middle/Upper Triassic of Yunnan, China. Journal of Vertebrate Paleontology 31:1230-1237.

John KO. 1970. The "patagial musculature" of the south Indian flying lizard Draco dussumieri. British Journal of Herpetology 4:161-168.

Kuhn O. 1939. Schädelbau und systematische Stellung von Weigeltisaurus. Palaeontologische Zeitschrift 21:163-167.

Langston W, Reisz RR. 1981. Aerosaurus wellesi, new species, a varanopseid mammal-like reptile (Synapsida: Pelycosauria) from the Lower Permian of New Mexico. Journal of Vertebrate Paleontology 1:73-96.

Laurin M. 1991. The osteology of a Lower Permian eosuchian from Texas and a review of diapsid phylogeny. Zoological Journal of the Linnean Society 101:59-95.

Laurin M, Piñeiro GH. 2017. A reassessment of the taxonomic position of mesosaurs, and a surprising phylogeny of early amniotes. Frontiers in Earth Science 5:88.

Laurin M, Piñeiro GH. 2018. Response: Commentary: A reassessment of the taxonomic position of mesosaurs, and a surprising phylogeny of early amniotes. Frontiers in Earth Science 6:220.

Laurin M, Reisz RR. 1995. A reevaluation of early amniote phylogeny. Zoological Journal of the Linnean Society 113:165-223.

LeBlanc AR, Brink KS, Whitney MR, Abdala F, Reisz RR. 2018. Dental ontogeny in extinct synapsids reveals a complex evolutionary history of the mammalian tooth attachment system. Proceedings of the Royal Society B 285:20181792.

Li C, Fraser NC, Rieppel O, Wu X-C. 2018. A Triassic stem turtle with an edentulous beak. Nature 560:476-479.

Li P-P, Gao K-Q, Hou L-H, Xu X. 2007. A gliding lizard from the Early Cretaceous of China. Proceedings of the National Academy of Sciences of the United States of America 104:55075509.

Luan X, Walker C, Dangaria S, Ito Y, Druzinsky R, Jarosius K, Lesot H, Rieppel O. 2009. The mosasaur tooth attachment apparatus as paradigm for the evolution of the gnathostome periodontium. Evolution \& Development 11:247-259. 
MacDougall MJ, Modesto SP, Brocklehurst N, Verrière A, Reisz RR, and Frobisch J. 2018. Response: A reassessment of the taxonomic position of mesosaurs, and a surprising phylogeny of early amniotes. Frontiers in Earth Science 6:99.

Matsumoto R, Dong L, Wang Y, Evans SE. 2019. The first record of a nearly complete choristodere (Reptilia: Diapsida) from the Upper Jurassic of Hebei Province, People's Republic of China. Journal of Systematic Palaeontology 17:1031-1048.

McGuire JA, Heang KB. 2001. Phylogenetic systematics of Southeast Asian flying lizards (Iguania: Agamidae: Draco) as inferred from mitochondrial DNA sequence data. Biological Journal of the Linnean Society 72:203-229.

Merck JW. 1997. A phylogenetic analysis of the euryapsid reptiles. Ph.D. dissertation. University of Texas, Austin.

Merck JW. 2003. An arboreal radiation of non-saurian diapsids. Journal of Vertebrate Paleontology 13:78A. [Abstract]

Modesto SP, Sues H-D. 2004. The skull of the Early Triassic archosauromorph reptile Prolacerta broomi and its phylogenetic significance. Zoological Journal of the Linnean Society 140:335-351.

Montefeltro FC, Andrade DV, Larsson HCE. 2016. The evolution of the meatal chamber in crocodyliforms. Journal of Anatomy 228:838-863.

Mook CC. 1921. Notes on the postcranial skeleton in the Crocodilia. Bulletin of the American Museum of Natural History 44:67-100.

Müller J. 2004. The relationships among diapsid reptiles and the influence of taxon selection. In: Arratia G, Wilson MVH, Cloutier R eds. Recent advances in the origin and early radiation of vertebrates. Munich: Verlag Dr. Friedrich Pfeil, 379-408.

Müller J, Bickelmann C, Sobral G. 2018. The evolution and fossil history of sensory perception in amniote vertebrates. Annual Review of Earth and Planetary Sciences 46:495-519.

Muscio G. 1996. Preliminary note on a new specimen of Prolacertiformes (Reptilia) from the Norian (Late Triassic) of Perone (Udine, north-eastern Italy). Gortania 18:33-40.

Nesbitt SJ. 2011. The early evolution of archosaurs: relationships and the origin of major clades. Bulletin of the American Museum of Natural History 352:1-292.

Nesbitt SJ, Flynn JJ, Pritchard AC, Parrish JM, Ranivoharimanana L, Wyss AR. 2015. Postcranial osteology of Azendohsaurus madagaskarensis (?Middle to Upper Triassic, Isalo Group of Madagascar) and its systematic position among stem archosaurs. Bulletin of the American Museum of Natural History 398:1-126. 
2473 O'Brien A, Whiteside DI, Marshall JE. 2018. Anatomical study of two previously undescribed 2474 specimens of Clevosaurus hudsoni (Lepidosauria: Rhynchocephalia) from Cromhall Quarry, 2475 UK, aided by computed tomography, yields additional information on the skeleton and hitherto 2476 2477 undescribed bones. Zoological Journal of the Linnean Society 183:163-195.

Patterson C, Johnson GD. 1984. The intermuscular bones and ligaments of teleostean fishes. Smithsonian Contributions to Zoology 559:1-83.

Paul J. 2006. Der Kupferschiefer: Lithologie, Stratigraphie, Fazies und Metallogenese eines Schwarzschiefers. Zeitschrift der deutschen Gesellschaft für Geowissenschaften 157:57-76.

Pettigrew TH. 1979. A gliding reptile from the Upper Permian of North East England. Nature 281:297-298.

Peyer B. 1937. Die Triasfauna der Tessiner Kalkalpen. XII. Macrocnemus bassanii Nopesa. Abhandlungen der Schweizerischen Palaeontologischen Gesellschaft 59:1-140.

Piveteau, J. 1926. Paléontologie de Madasgascar. XIII—Amphibiens et Reptiles Permiens. Annales de Paléontologie 15:55-178.

2494

2495

2496

2497

2498

2499

2500

2501

2502

2503

2504

2505

2506

2507

2508

2509

2510

2511

2512

2513

Powell GL, Russell AP, Ryan MJ. 2002. Ontogenetic scaling of the cranial horn array in

Phrynosoma orbiculare (Squamata: Phrynosomatidae). Journal of Herpetology 36:578-589.

Pritchard AC, Gauthier JA, Hanson M, Bever GS, Bhullar B-AS. 2018. A tiny Triassic saurian from Connecticut and the early evolution of the diapsid feeding apparatus. Nature

Communications 9:1213.

Pritchard AC, Nesbitt SJ. 2017. A bird-like skull in a Triassic diapsid reptile increases

heterogeneity of the morphological and phylogenetic radiation of Diapsida. Royal Society Open Science 4:170499. DOI: 10.1098/rsos.170499.

Pritchard AC, Sues H-D. 2019. Postcranial remains of Teraterpeton hrynewichorum (Reptilia: Archosauromorpha) and the mosaic evolution of the saurian postcranial skeleton. Journal of Systematic Palaeontology 17:1745-1765.

Pritchard AC, Turner AH, Irmis RB, Nesbitt SJ, Smith ND. 2016. Extreme modification of the tetrapod forelimb in a Triassic diapsid reptile. Current Biology 26:2779-2786.

Pritchard AC, Turner AH, Nesbitt SJ, Irmis RB, Smith ND. 2015. Late Triassic tanystropheids (Reptilia, Archosauromorpha) from northern New Mexico (Petrified Forest Member, Chinle Formation) and the biogeography, functional morphology, and evolution of Tanystropheidae.

2514 Journal of Vertebrate Paleontology 35:e911186.

Reese AM. 1915. The alligator and its allies. New York and London: G.P. Putnam's Sons. 
2518 Reisz RR. 1981. A diapsid reptile from the Pennsylvanian of Kansas. Special Publications of the

2519

2520

2521

2522

2523

2524

2525

2526

2527

2528

2529

2530

2531

2532

2533

2534

2535

2536

2537

2538

2539

2540

2541

2542

2543

2544

2545

2546

2547

2548

2549

2550

2551

2552

2553

2554

2555

2556

2557

2558

2559

2560

2561

2562

2563

Museum of Natural History, University of Kansas 7:1-74.

Reisz RR, Berman DS, Scott D. 1984. The anatomy and relationships of the Lower Permian reptile Araeoscelis. Journal of Vertebrate Paleontology 4:57-67.

Renesto S. 1994a. The shoulder girdle and anterior limb of Drepanosaurus unguicaudatus (Reptilia, Neodiapsida) from the upper Triassic (Norian) of Northern Italy. Zoological Journal of the Linnean Society 111:247-264.

Renesto S. 1994b. Megalancosaurus, a possibly arboreal archosauromorph (Reptilia) from the Upper Triassic of Northern Italy. Journal of Vertebrate Paleontology 14:38-52.

Renesto S. 2000. Bird-like head on a chameleon body: new specimens of the enigmatic diapsid reptile Megalancosaurus from the Late Triassic of Northern Italy. Rivista Italiana di Paleontologia e Stratigrafia 106:157-180.

Renesto S, Binelli G. 2006. Vallesaurus cenensis Wild, 1991, a drepanosaurid (Reptilia, Diapsida) from the Late Triassic of northern Italy. Rivista Italiana di Paleontologia e Stratigrafia 112:77-94.

Renesto S, Dalla Vecchia FM. 2005. The skull and lower jaw of the holotype of Megalancosaurus preonensis (Diapsida, Drepanosauridae) from the Upper Triassic of northern Italy. Rivista Italiana di Paleontologia e Stratigrafia 111:247-257.

Renesto S, Spielmann JA, Lucas SG, Spagnoli GT. 2010. The taxonomy and paleobiology of the Late Triassic (Carnian-Norian: Adamanian-Apachean) drepanosaurs (Diapsida:

Archosauromorpha: Drepanosauromorpha): Bulletin 46. Bulletin of the New Mexico Museum of Natural History and Science 46:1-81.

Ricqlès AJ de, Padian K, Horner JR, Francillon-Viellot H. 2000. Palaeohistology of the bones of pterosaurs (Reptilia: Archosauria): anatomy, ontogeny, and biomechanical implications.

Zoological Journal of the Linnean Society 129:349-385.

Rieppel O. 1994. Osteology of Simosaurus gaillardoti and the relationships of stem-group Sauropterygia. Fieldiana Geology, new series 28:1-81.

Rieppel O, Gronowski RW. 1981. The loss of the lower temporal arcade in diapsid reptiles. Zoological Journal of the Linnean Society 72:203-217.

Robinson PL. 1962. Gliding lizards from the Upper Keuper of Great Britain. Proceedings of the Geological Society of London 1601:137-146.

Robinson PL. 1973. A problematic reptile from the British upper Trias. Journal of the Geological Society of London 129:457-479.

Peer) reviewing PDF | (2020:09:52512:4:0:NEW 8 Apr 2021) 
2564 Robinson PL. 1975. The functions of the hooked fifth metatarsal in lepidosaurian reptiles. In:

2565 Lehman J-P ed. Problèmes Actuels de Paléontologie-Évolution des Vertébrés. Colloques

2566 International du C.N.R.S. 218:461-483.

2567

2568

2569

2570

2571

2572

2573

2574

2575

2576

2577

2578

2579

2580

2581

2582

2583

2584

2585

2586

2587

2588

2589

2590

2591

2592

2593

2594 Schaumberg G, Unwin DM, Brandt S. 2007. New information on the anatomy of the Late

2595

2596

2597

2598

2599

2600

2601

2602

2603

2604

2605 Schoch RR, Sues H-D. 2018a. A new lepidosauromorph reptile from the Middle Triassic 2606 (Ladinian) of Germany and its phylogenetic relationships. Journal of Vertebrate Paleontology 2607 38:e1444619.

2608

Romer AS. 1923. Crocodilian pelvic muscles and their avian and reptilian homologues. Bulletin of the American Museum of Natural History 48:533-552.

Romer AS. 1956. Osteology of the reptiles. Chicago: University of Chicago Press.

Russell AP, Bauer AM. 2008. The appendicular locomotor apparatus of Sphenodon and normallimbed squamates. In: Gans C, Gaunt AS, Adler K eds. Biology of the Reptilia. Volume 21: Morphology I. Society for the Study of Amphibians and Reptiles, 1-465.

Russell AP, Dijkstra LD. 2001. Patagial morphology of Draco volans (Reptilia: Agamidae) and the origin of glissant locomotion in flying dragons. Journal of Zoology 253:457-471.

Sampson SD, Ryan MJ, Tanke DH. 1997. Craniofacial ontogeny in centrosaurine dinosaurs (Ornithischia: Ceratopsidae): taxonomic and behavioral implications. Zoological Journal of the Linnean Society 121:293-337.

Schaumberg G. 1976. Zwei Reptilneufunde (Weigeltisaurus Kuhn?, Lepidosauria?, Reptilia) aus dem Kupferschiefer von Richelsdorf (Perm, Hessen). Philippia 3:3-8.

Schaumberg G. 1978. Neubeschreibung von Coelacanthus granulatus Agassiz (Actinistia, Pisces) aus dem Kupferschiefer von Richelsdorf (Perm, W.-Deutschland). Paläontologische Zeitschrift 52:169-197.

Schaumberg G. 1986. Bemerkungen zu einem Neufund von Weigeltisaurus jaekeli (Weigelt) im nordhessischen Kupferschiefer. Paläontologische Zeitschrift 60:319-327.

Permian gliding reptile Coelurosauravus. Paläontologische Zeitschrift 81:160-173.

Scheyer TM, Neenan JM, Bodogan T, Furrer H, Obrist C, Plamondon M. 2017. A new, exceptionally preserved juvenile specimen of Eusaurosphargis dalsassoi (Diapsida) and implications for Mesozoic marine diapsid phylogeny. Scientific Reports 7:1-22.

Scheyer TM, Spiekman SNF, Sues H-D, Ezcurra MD, Butler RJ, and Jones MEH. 2020. Colobops: a juvenile rhynchocephalian (Lepidosauromorpha), not a diminuitive archosauromorph with an unusually strong bite. Royal Society Open Science 7:192179. 
2609 Schoch RR, Sues H-D. 2018b. Osteology of the Middle Triassic stem-turtle Pappochelys rosinae

2610

2611

2612

2613

2614

2615

2616

2617

2618

2619

2620

2621

2622

2623

2624

2625

2626

2627

2628

2629

2630

2631

2632

2633

2634

2635

2636

2637

2638

2639

2640

2641

2642

2643

2644

2645

2646

2647

2648

2649

2650

2651

2652

2653

2654

and the early evolution of the turtle skeleton. Journal of Systematic Palaeontology 16:927-965.

Sen K. 2003. Pamelaria dolichotrachela, a new prolacertid reptile from the Middle Triassic of India. Journal of Asian Earth Sciences 21:663-681.

Sennikov AG. 1988. The role of the oldest thecodonts in the vertebrate assemblages of Eastern Europe. Paleontological Journal 23:78-87.

Senter P. 2004. Phylogeny of Drepanosauridae (Reptilia: Diapsida). Journal of Systematic Palaeontology 2:257-268.

Simões TR, Caldwell MW, Talanda M, Bernardi M, Palci A, Vernygora O, Bernardini F, Mancini L, Nydam RL. 2018. The origin of squamates revealed by a Middle Triassic lizard from the Italian Alps. Nature 557:706-709.

Smith RMH, Evans SE. 1996. An aggregation of juvenile Youngina from the Beaufort Group, Karoo Basin, South Africa. Palaeontology 39:289-303.

Sobral G, Müller J. 2019. The braincase of Mesosuchus browni (Reptilia, Archosauromorpha) with information on the inner ear and description of a pneumatic sinus. PeerJ 7:e6798.

Socha JJ. 2002. Gliding flight in the paradise tree snake. Nature 418:603-604.

Socha JJ. 2006. Becoming airborne without legs: the kinematics of take-off in a flying snake, Chrysopelea paradisi. Journal of Experimental Biology 209:3358-3369.

Socha JJ. 2011. Gliding flight in Chrysopelea: turning a snake into a wing. Integrative and Comparative Biology 51:969-982.

Sternberg CM. 1933. A new Ornithomimus with complete abdominal cuirass. 47:79-83.

Sues H-D. 2020a. The rise of reptiles: 320 million years of evolution. Baltimore: Johns Hopkins University Press.

Sues H-D. 2020b. Wirbeltiere des Zechsteins. In: Paul J, Heggemann H eds. Stratigraphie von Deutschland. XII. Zechstein. Schriftenreihe der Deutschen Gesellschaft für Geowissenschaften 89:59-67.

Sullivan TN, Wang B, Espinosa HD, Meyers MA. 2017. Extreme lightweight structures: avian feathers and bones. Materials Today 20:377-391.

Sumida SS. 1989. The appendicular skeleton of the Early Permian genus Labidosaurus (Reptilia, Captorhinomorpha, Captorhinidae) and the hind limb musculature of captorhinid reptiles.

Journal of Vertebrate Paleontology 9:295-313.

Peer) reviewing PDF | (2020:09:52512:4:0:NEW 8 Apr 2021) 
2655 Szurlies M. 2013. Late Permian (Zechstein) magnetostratigraphy in western and central Europe.

2656 In: Gasiewicz A, Słowakiewicz M eds. Palaeozoic climate cycles: their evolutionary and

2657 sedimentological impact. Geological Society, London, Special Publications 376: 73-85.

2658

2659

2660

2661

2662

2663

2664

2665

2666

2667

2668

2669

2670

2671

2672

2673

2674

2675

2676

2677

2678

2679

2680

2681

2682

2683

2684

2685

2686

2687

2688

2689

2690

2691

2692

2693

2694

2695

2696

2697

2698

Unwin DM. 2005. The pterosaurs: from Deep Time. New York: Pi Press.

Unwin DM, Alifanov VR, Benton MJ. 2000. Enigmatic small reptiles from the Middle-Late

Triassic of Kirgizstan. In: Benton MJ, Shishkin MA, Unwin DM, Kurochkin EN eds. The Age of Dinosaurs in Russia and Mongolia. Cambridge: Cambridge University Press 177-186.

Vaughn PP. 1955. The Permian reptile Araeoscelis restudied. Bulletin of the Museum of Comparative Zoology, Harvard College 113:305-467.

Vickaryous MK, Hall BK. 2008. Development of the dermal skeleton in Alligator

mississippiensis (Archosauria, Crocodylia) with comments on the homology of osteoderms.

Journal of Morphology 269:398-422.

Wang M, O'Connor JK, Xu X, Zhou Z. 2019. A new Jurassic scansoriopterygid and the loss of membranous wings in theropod dinosaurs. Nature 569:256-259.

Wedepohl K. 1994. Composition and origin of the Kupferschiefer bed. Geological Quarterly $38: 623-638$.

Weigelt J. 1930a. Palaeochameleo jaekeli nov. gen., nov. sp., ein neuer Rhynchocephale aus dem Mansfelder Kupferschiefer. Leopoldina 6:625-642.

Weigelt J. 1930b. Über die vermutliche Nahrung von Protorosaurus und über einen vollkörperlich erhaltenen Fruchtstand von Archaeopodocarpus germanicus aut. Leopoldina 6:269-280.

Weinbaum JC. 2013. Postcranial skeleton of Postosuchus kirkpatricki (Archosauria:

Paracrocodylomorpha), from the upper Triassic of the United States. Geological Society, London, Special Publications 379:525-553.

Wellnhofer P. 1991. The illustrated encyclopedia of pterosaurs. New York: Crescent Books.

Wild R. 1973. Die Triasfauna der Tessiner Kalkalpen. XXIII. Tanystropheus longobardicus (Bassani) (neue Ergebnisse). Schweizerische Paläontologische Abhandlungen 95:1-162.

Wild R. 1978. Die Flugsaurier (Reptilia, Pterosauria) aus der Oberen Trias von Cene bei Bergamo, Italien. Bollettino della Società Paleontologica Italiana 17:176-256.

Witton MT. 2013. Pterosaurs: natural history, evolution, anatomy. Princeton: Princeton University Press.

2699 
2700 Xu X, Zheng X, Sullivan C, Wang X, Xing L, Wang Y, Zhang X, O'Connor JK, Zhang F, Pan 2701 Y. 2015. A bizarre Jurassic maniraptoran theropod with preserved evidence of membranous 2702 wings. Nature 521:70-73.

2703 


\section{Figure 1}

Holotype skeleton of Weigeltisaurus jaekeli (SSWG 113/7) from the Kupferschiefer of Germany.

A. Photograph of complete specimen as preserved in 2010. B. Close-up photograph of articulated skull in right lateral view. Photographs taken in 2010, following removal of most patagial elements by 0 . Jaekel. Scale bar equals five millimeters. 





Figure 2

The skeleton of SMNK-PAL 2882 (Weigeltisaurus jaekeli).

Scale bar equals 5 centimeters. 


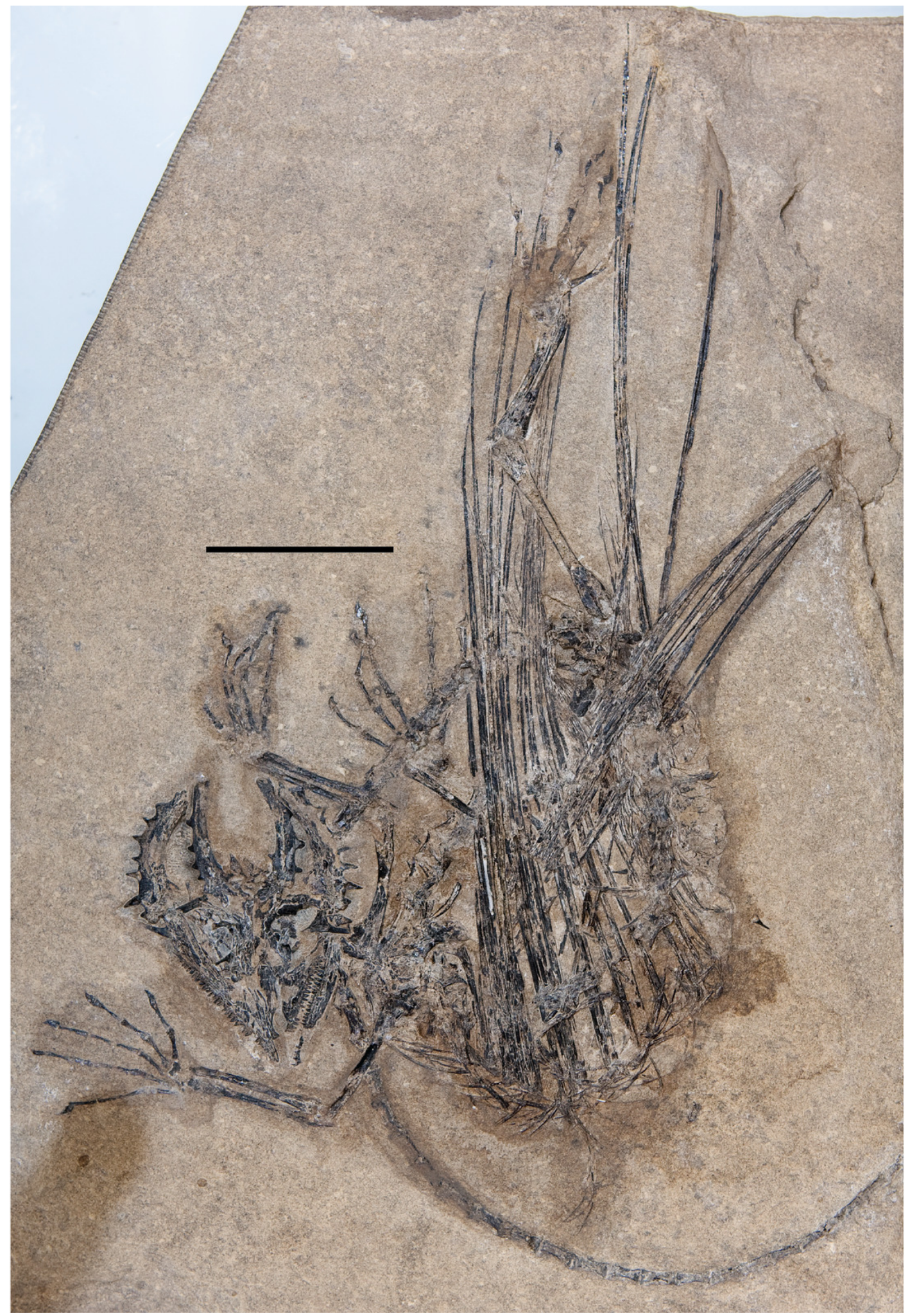




\section{Figure 3}

The skull of SMNK-PAL 2882 (Weigeltisaurus jaekeli).

A. Photograph of specimen. B. Tracing of skull elements with identification callouts.

Abbreviations: de, dentary; fr, frontal; $\mathbf{m x}$, maxilla; pd, postdentary bones (unable to delineate sutures); pf, postfrontal; pm, premaxilla; po, postorbital; pp, postparietal; pr, prefrontal; qu, quadrate; sa, surangular (right horn); sp, splenial; sq, squamosal and quadratojugal (unable to delineate sutures between bones). Scale bar equals 1 centimeter.
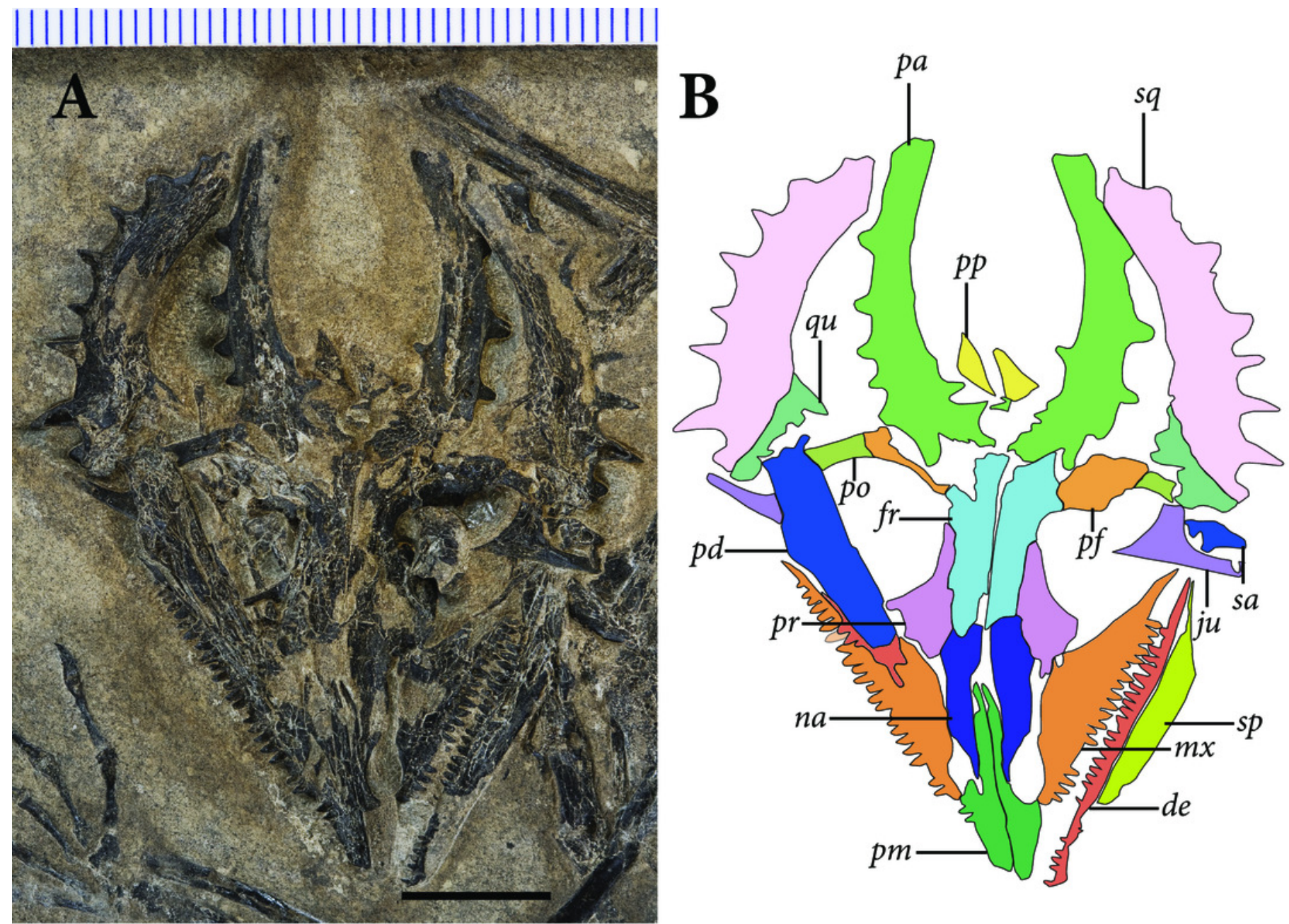


\section{Figure 4}

The right upper and lower marginal dentition of SMNK-PAL 2882 (Weigeltisaurus jaekeli) in lingual view.

Abbreviations: 8, eighth maxillary tooth position; 18, eighteenth dentary tooth position; $\mathbf{2 1}$, twenty-first maxillary tooth position; 32, thirty-second dentary tooth position; ma, mandibular ramus; $\mathbf{m x}$, maxilla. Arrow indicates anteroposterior axis of the skull. Scale bar equals 2 millimeters.

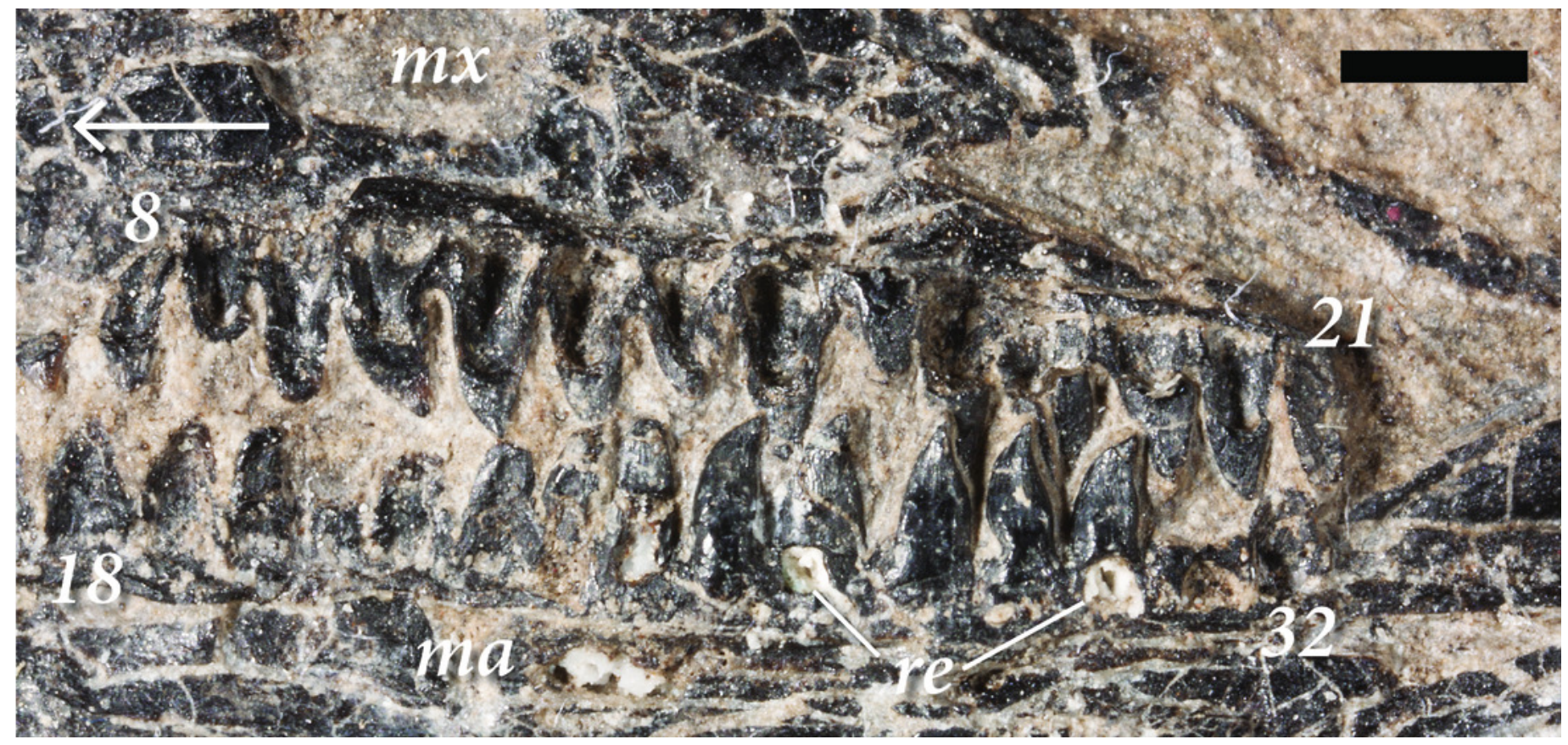




\section{Figure 5}

Reduced opacity image of the trunk, pelvis, and tail of SMNK-PAL 2882 (Weigeltisaurus jaekeli), highlighted preserved segments of the vertebral column, with identification callouts.

Abbreviations: ca, anterior caudal vertebrae; ch, chevron; $\mathbf{c p}$, posterior caudal vertebrae; $\mathbf{c r}$, cervical rib; cv, cervical vertebrae; da, anterior dorsal vertebrae; di, cervical diapophysis; $\mathbf{d m}$, mid-dorsal vertebrae; $\mathbf{d p}$, posterior dorsal vertebrae; $\mathbf{d r}$, dorsal rib; ga, gastralia. Hashmarks indicate millimeter scale. Readers may refer to Figure 2 for an unmodified photograph of the SMNK-PAL 2882 slab. Scale bar equals 1 centimeter. 


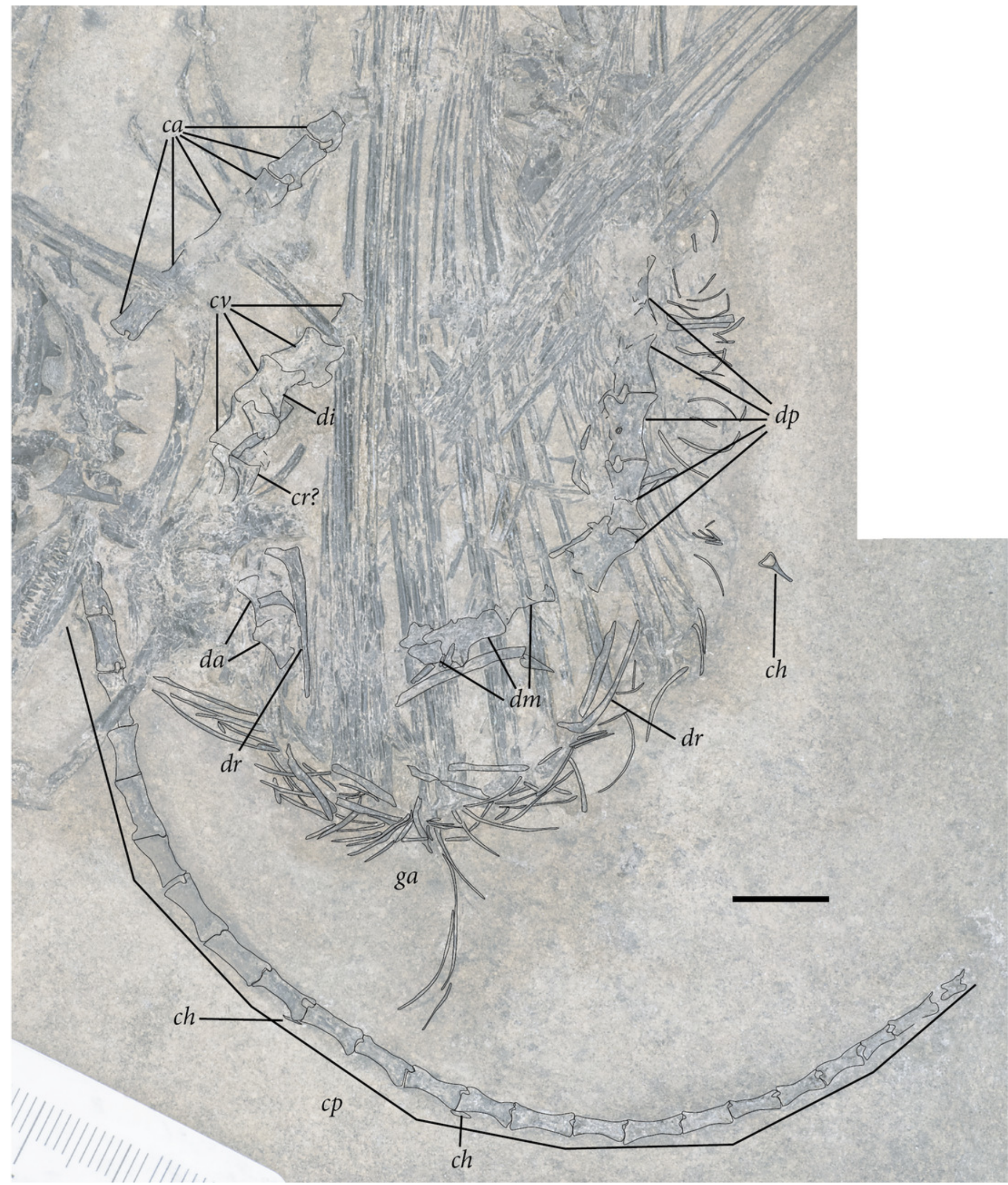


Figure 6

The preserved mid- and posterior dorsal vertebrae and associated ribs of SMNK-PAL 2882 (Weigeltisaurus jaekeli).

A. Photograph and B. Interpretative drawing demarcating the margins of elements with interpretive callouts. Abbreviations: dr, dorsal ribs; tp, transverse process. Scale bar equals 1 centimeter. 


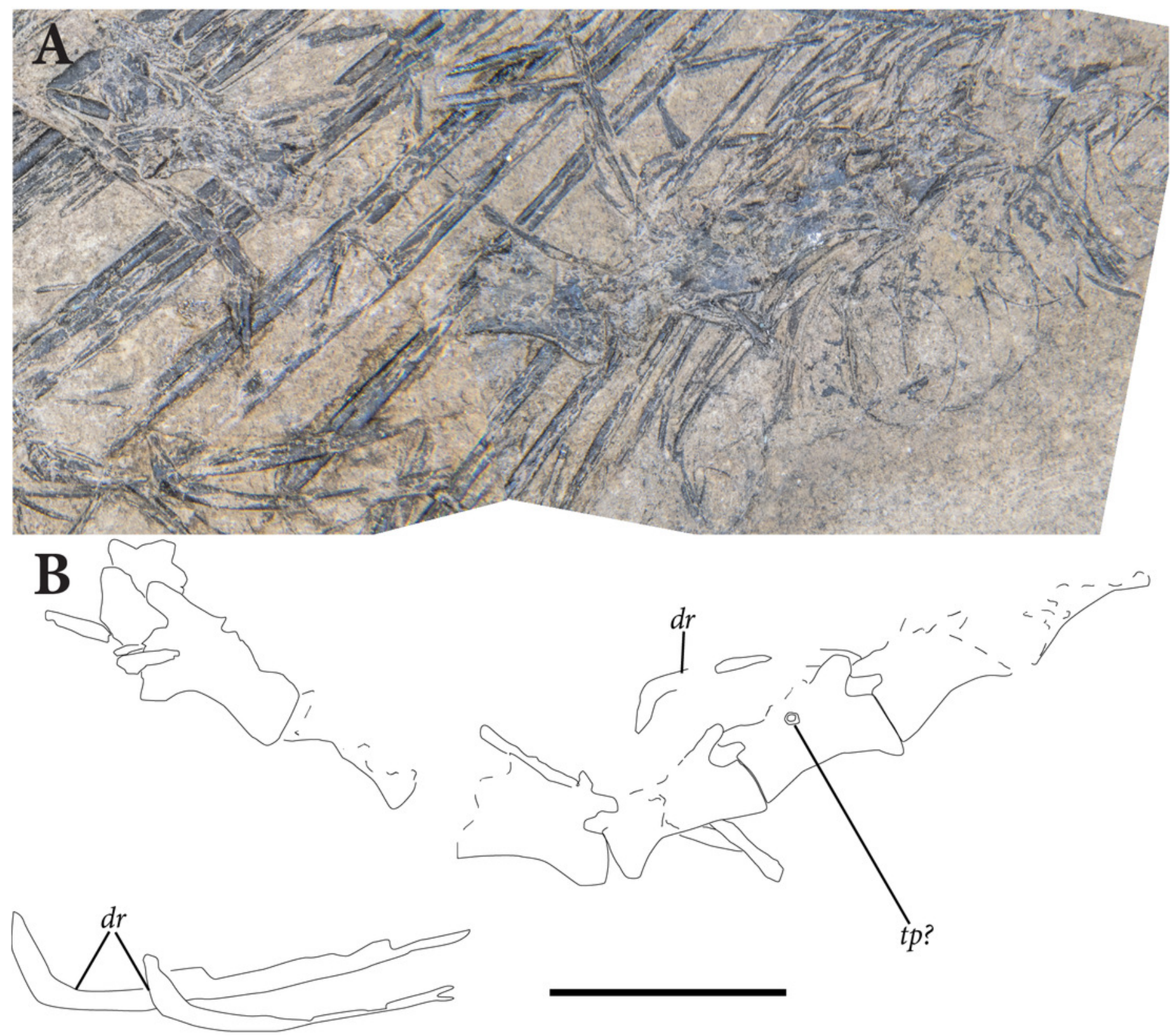




\section{Figure 7}

The pectoral girdle and anterior trunk region of SMNK-PAL 2882 (Weigeltisaurus jaekeli) in left lateral view.

A. photograph of specimen. B. Interpretative drawing demarcating the margins of elements and the cracks and gaps within individual bones and identification callouts. Abbreviations: co, coracoid; cr, cervical rib; ct, cleithrum; dr, dorsal rib; gl, glenoid fossa of scapulocoracoid; sc, scapula. Scale bar equals 1 centimeter.
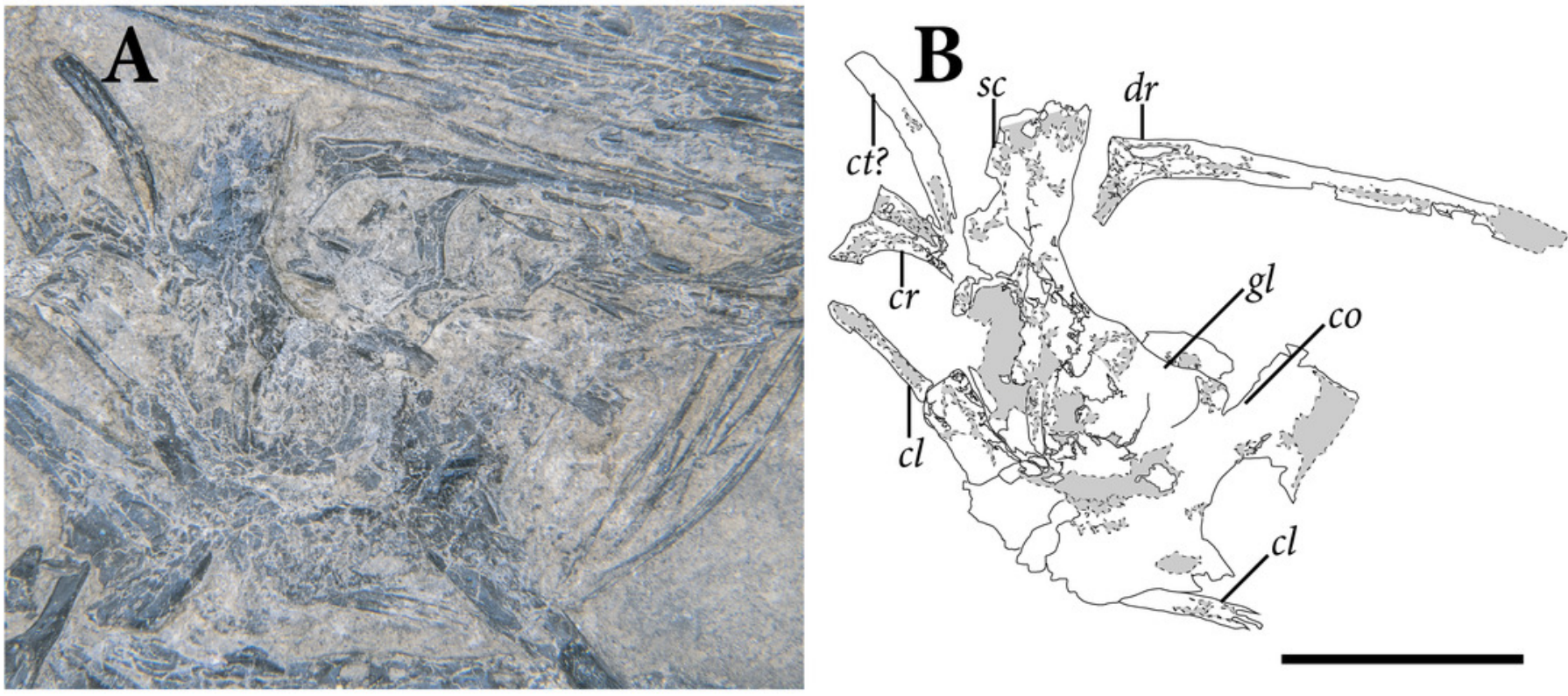


\section{Figure 8}

The right humerus of SMNK-PAL 2882 (Weigeltisaurus jaekeli) in dorsal/extensor view.

A. photograph of specimen. B. Interpretative drawing demarcating the margins of elements and the cracks and gaps within individual bones and identification callouts. Scale bar equals 1 centimeter.
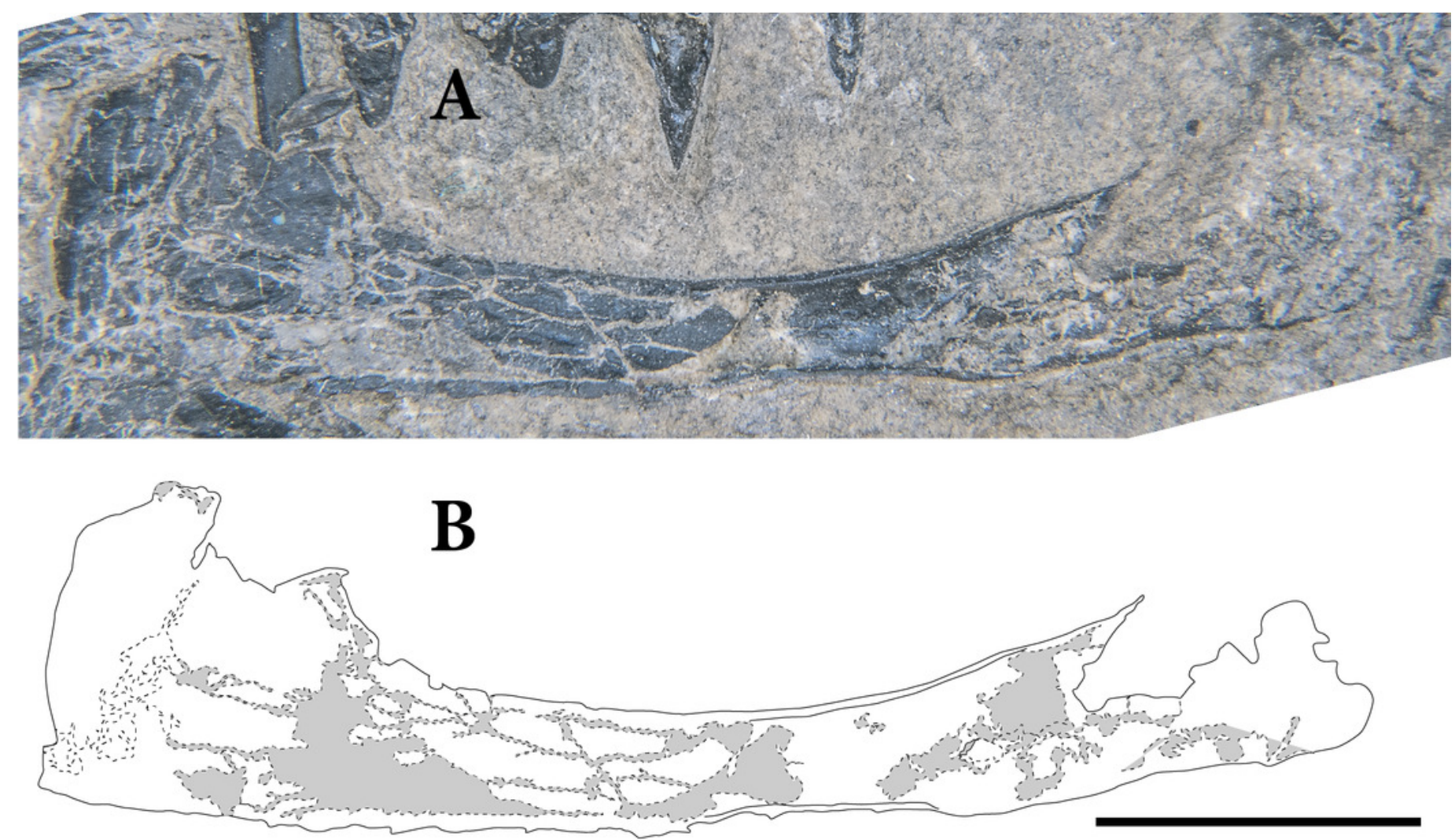


\section{Figure 9}

The left humerus of SMNK-PAL 2882 (Weigeltisaurus jaekeli) in lateral view.

A. photograph of specimen. B. Interpretative drawing demarcating the margins of elements and the cracks and gaps within individual bones and identification callouts. Scale bar equals 1 centimeter
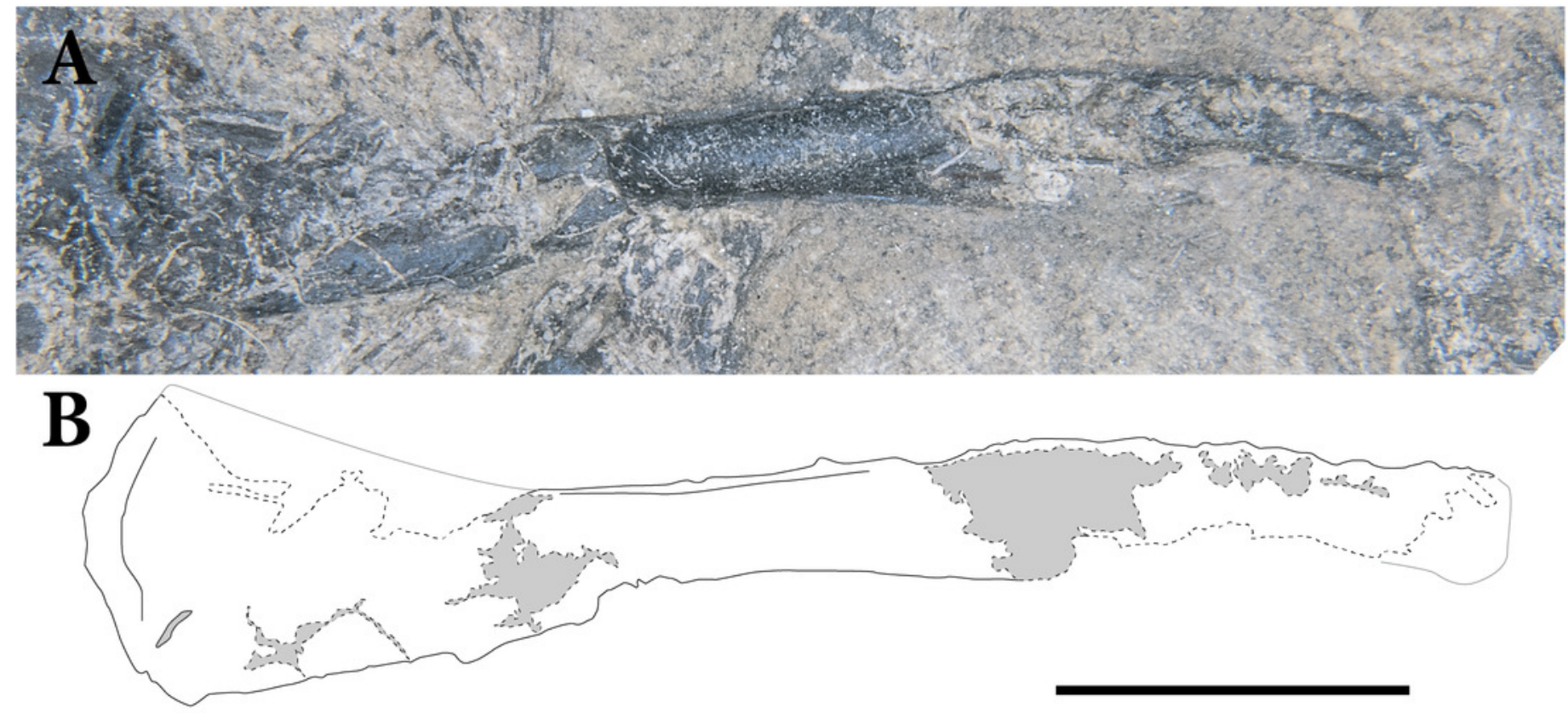


\section{Figure 10}

The right radius and ulna of SMNK-PAL 2882 (Weigeltisaurus jaekeli) in lateral view.

A. photograph of specimen. B. Interpretative drawing demarcating the margins of elements and the cracks and gaps within individual bones and identification callouts. Abbreviations: ol, olecranon process; ra, radius; ul, ulna. Scale bar equals 1 centimeter.
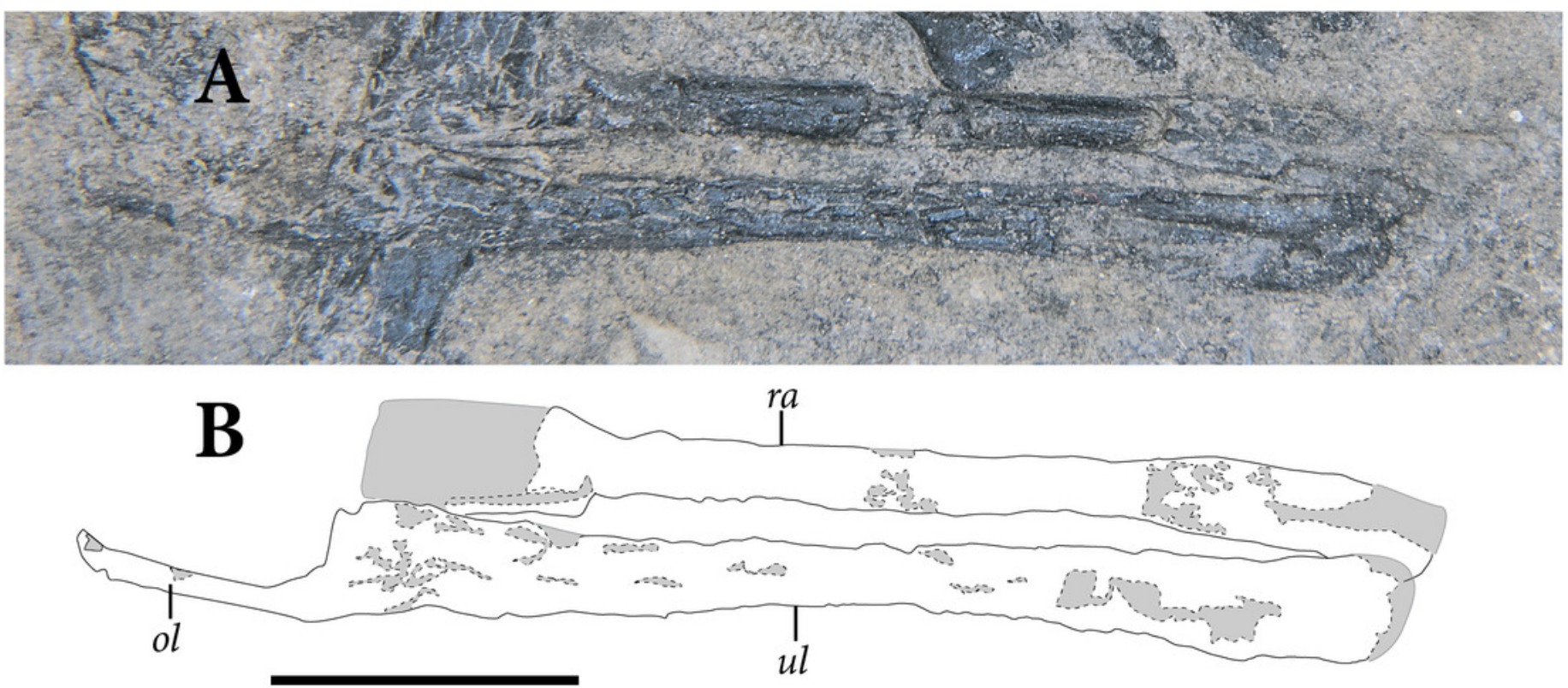


\section{Figure 11}

The left radius and ulna of SMNK-PAL 2882 (Weigeltisaurus jaekeli) in lateral view.

A. photograph of specimen. B. Interpretative drawing demarcating the margins of elements and the cracks and gaps within individual bones and identification callouts. Abbreviations: ol, olecranon process; pa, proximal articular surface; ra, radius; ul, ulna. Scale bar equals 1 centimeter.
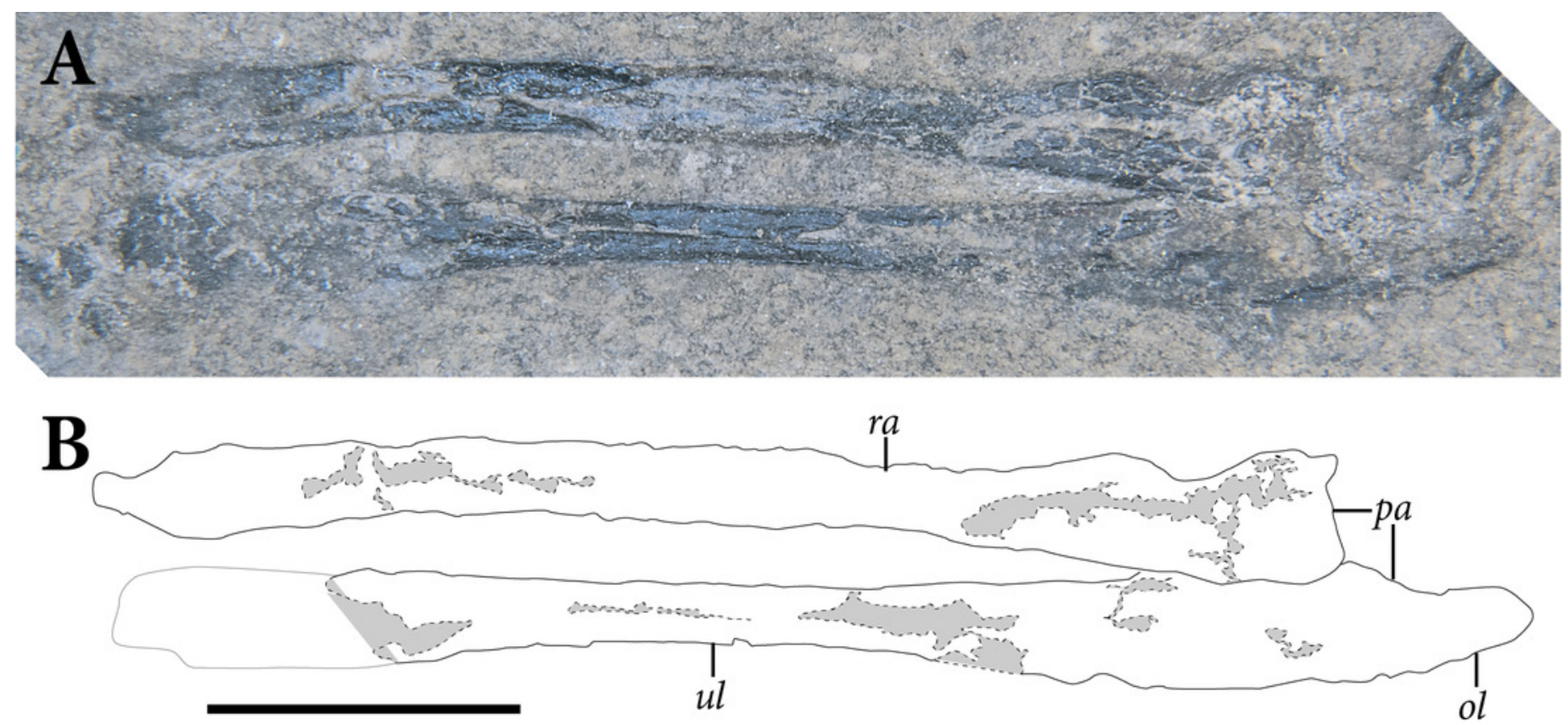


\section{Figure 12}

The left manus of SMNK-PAL 2882 (Weigeltisaurus jaekeli) in dorsal view.

A. photograph of specimen. B. Interpretative drawing demarcating the preserved margins of elements. Abbreviations: cs, preserved bones of carpus, mc, metacarpal. Scale bar equals 1 centimeter.
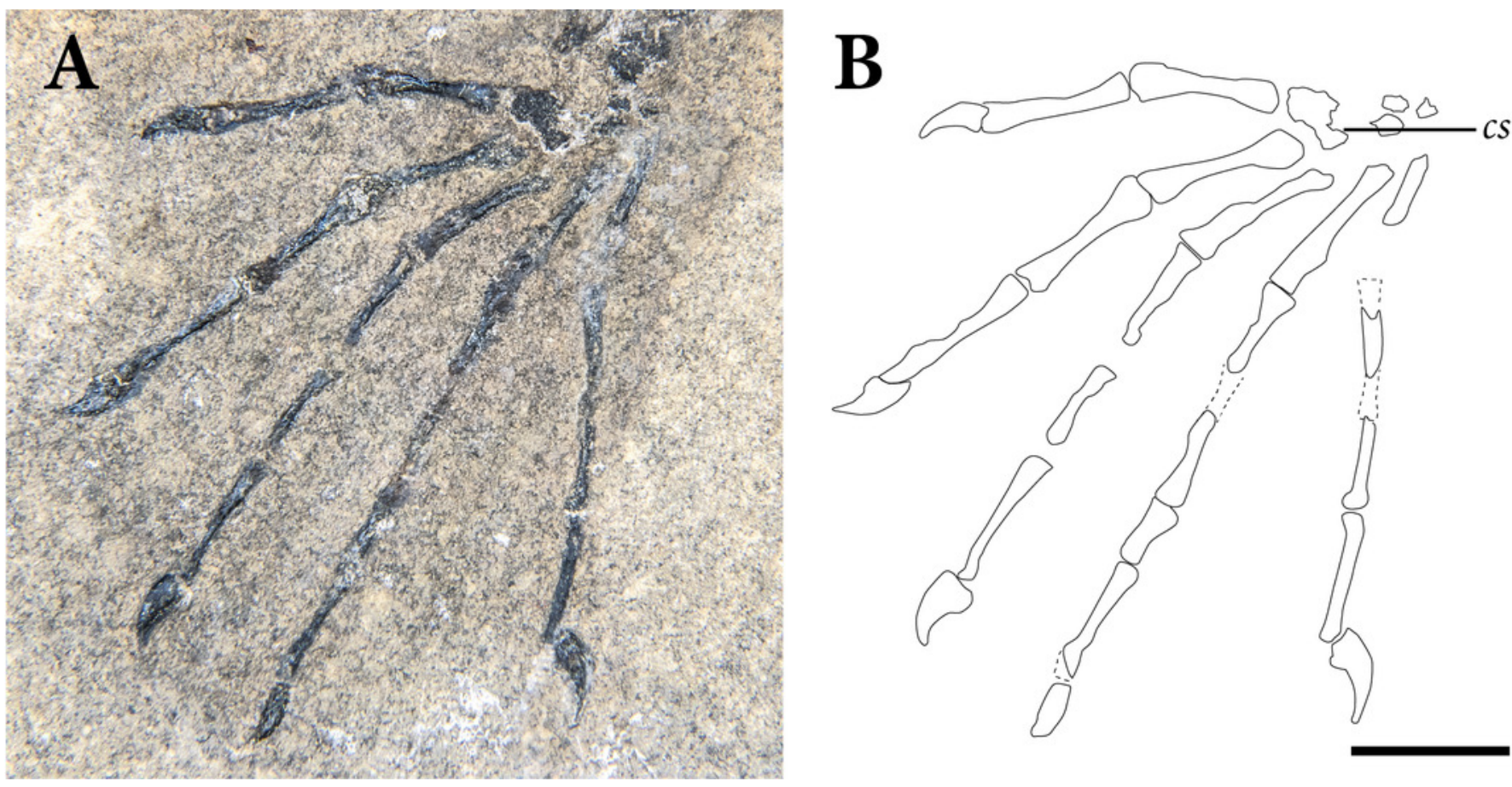
Figure 13

The right manus of SMNK-PAL 2882 (Weigeltisaurus jaekeli) in dorsal view.

A. photograph of specimen. B. Interpretative drawing demarcating the preserved margins of elements. Abbreviations: ft, flexor tubercle of manual ungual, $\mathbf{m c}$, metacarpal. Scale bar equals 1 centimeter.
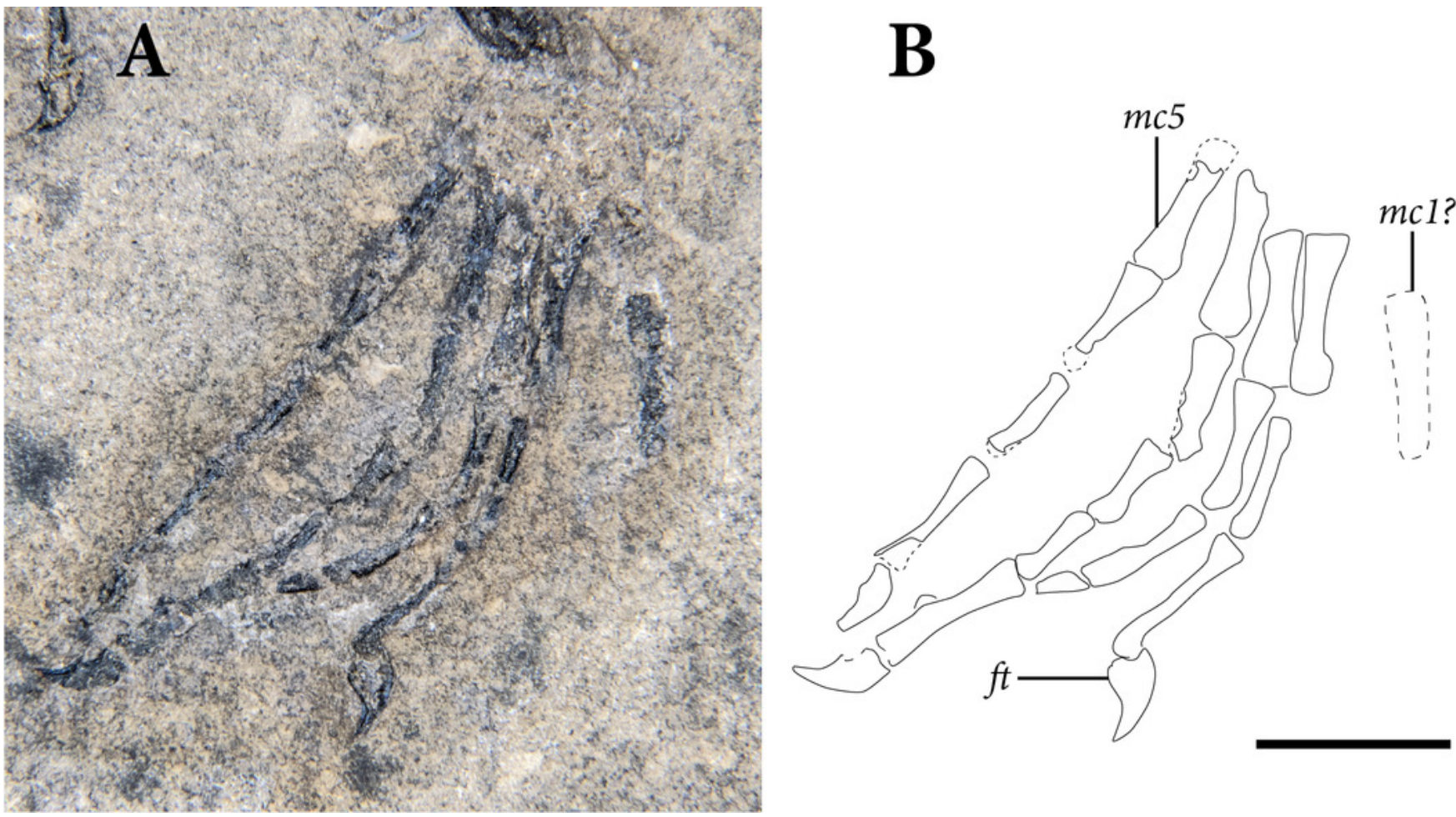


\section{Figure 14}

The pelvic region of SMNK-PAL 2882 (Weigeltisaurus jaekeli) in dorsal view.

A. photograph of specimen. B. Reduced opacity photograph of specimen with interpretive lines demarcating the preserved margins of elements. Abbreviations: dc, dorsal vertebral centrum; il, ilium; ip, posterior process of ischium; is, ischium; le, dorsolateral embayment of iliac blade; pu, pubis. Scale bar equals 1 centimeter.

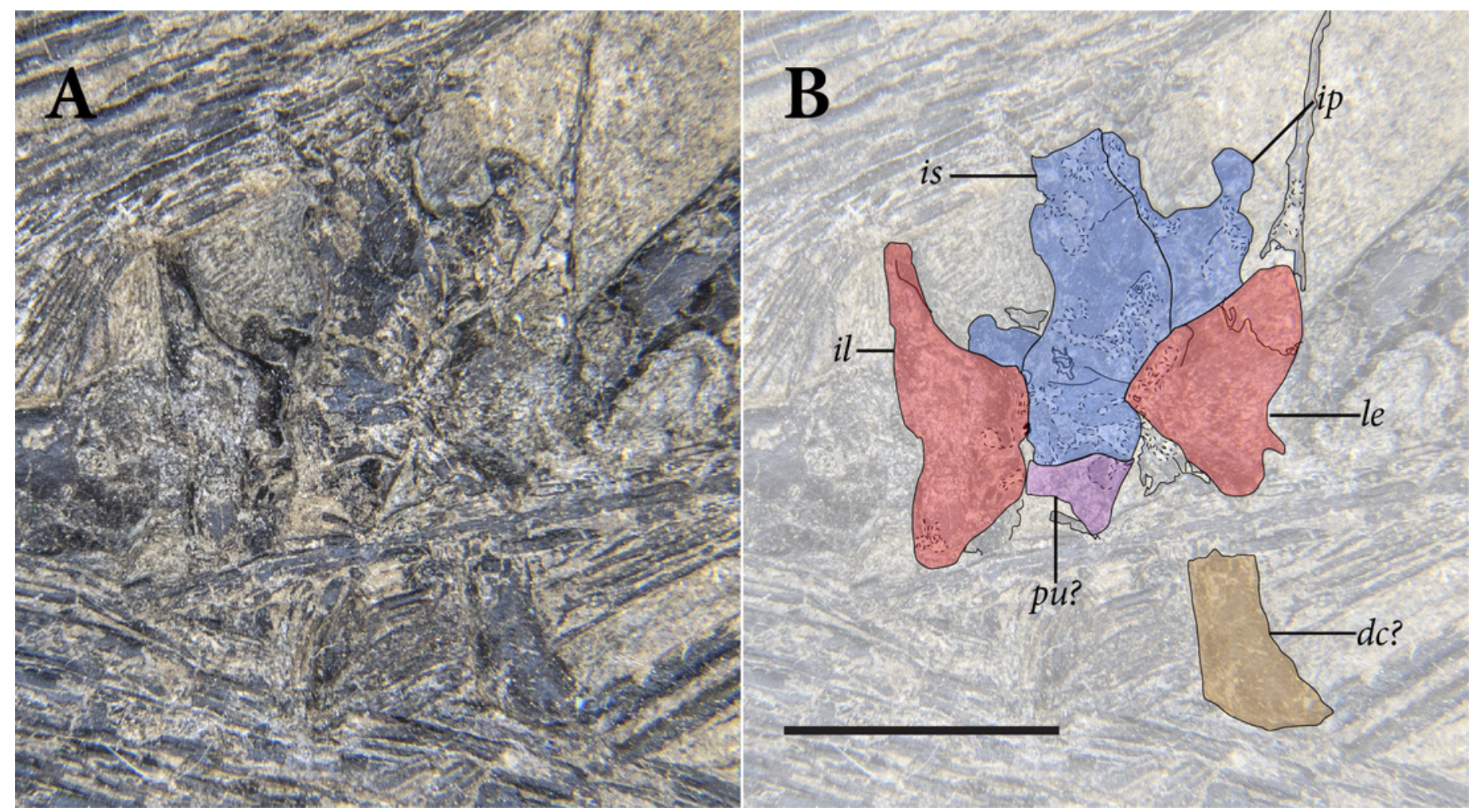




\section{Figure 15}

The left femur of SMNK-PAL 2882 (Weigeltisaurus jaekeli) in extensor view.

A. photograph of specimen. B. Interpretative drawing showing the outline of the femur. Abbreviations: cb, cortical bone of the femoral shaft; $\mathbf{c t}$, crista tibiofibularis/lateral tibial condyle; fc, fibular condyle; it, internal trochanter; $\mathbf{m t}$, medial tibial condyle; we, weathered margin. Scale bar equals 1 centimeter. 


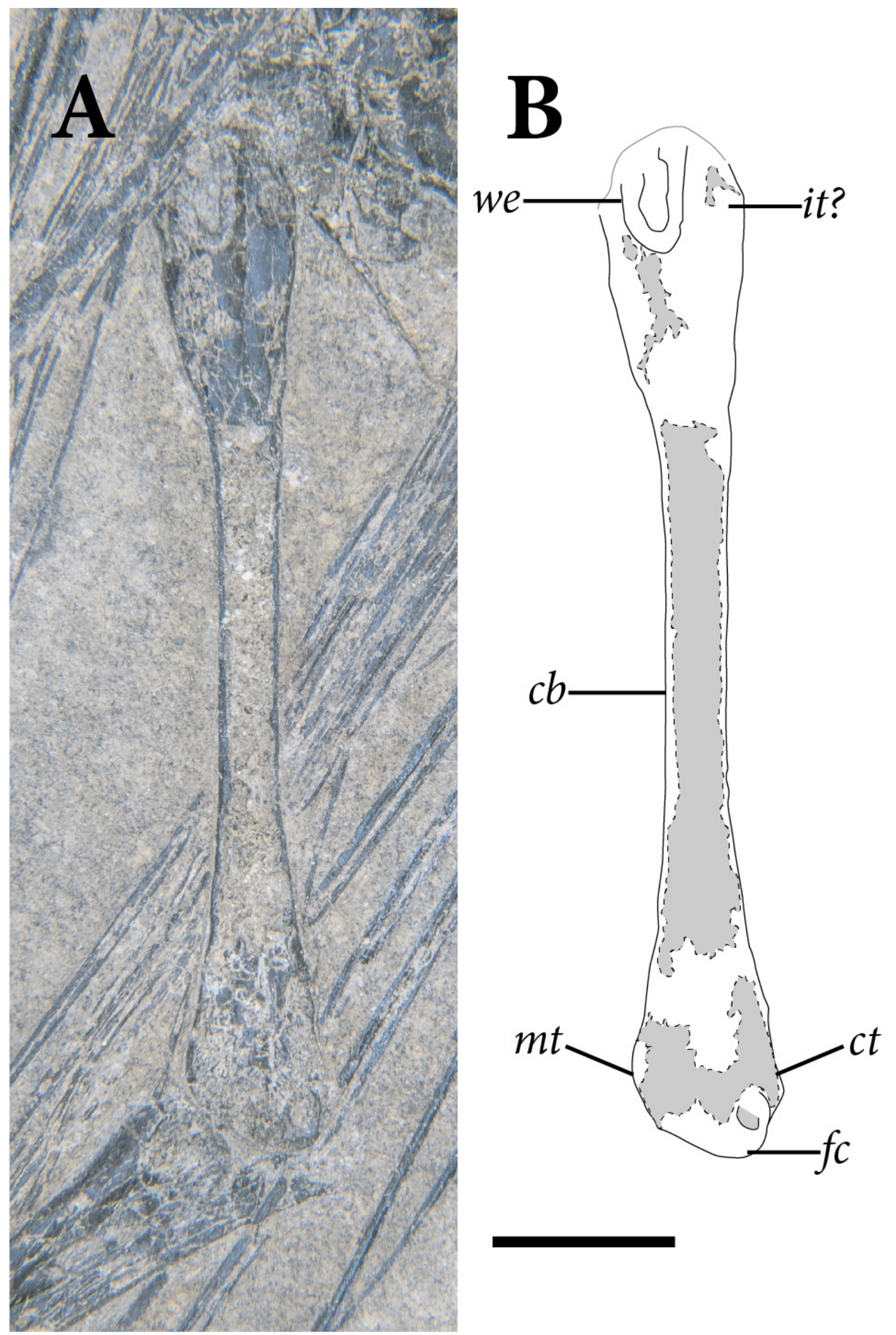

Peer] reviewing PDF | (2020:09:52512:4:0:NEW 8 Apr 2021) 


\section{Figure 16}

The distal portion of the left hindlimb of SMNK-PAL 2882 (Weigeltisaurus jaekeli) in extensor view.

A. photograph of specimen. B. Interpretative drawing demarcating the preserved margins of elements. Abbreviations: cn, cnemial crest; fi, fibula; ti, tibia. Scale bar equals 1 centimeter.
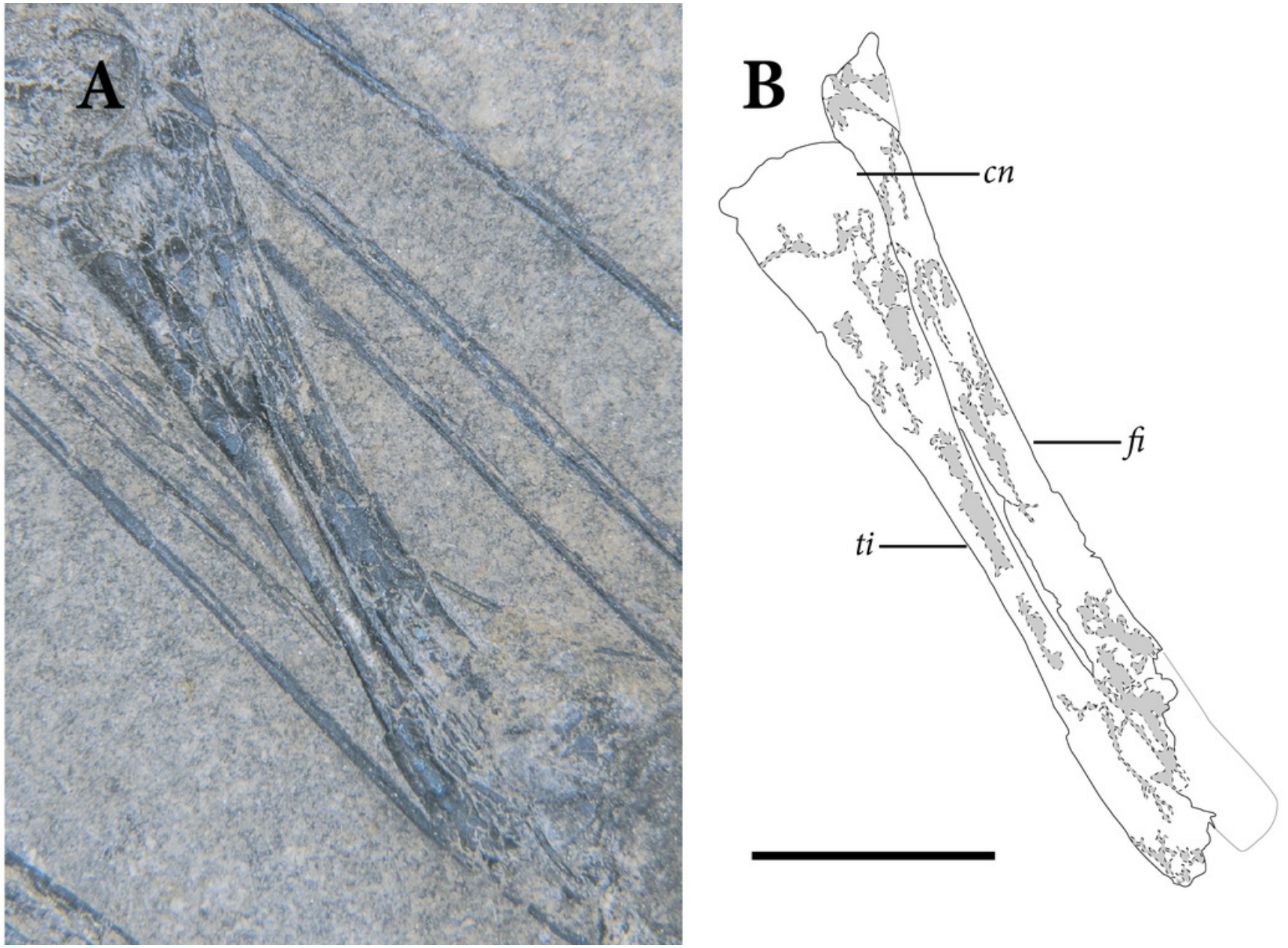


\section{Figure 17}

The right pes of SMNK-PAL 2882 (Weigeltisaurus jaekeli) in dorsal view.

A. photograph of specimen. B. Interpretative drawing demarcating the preserved margins of elements. Abbreviations: ft, flexor tubercle; $\mathbf{m t}$, metatarsal. Scale bar equals 1 centimeter.
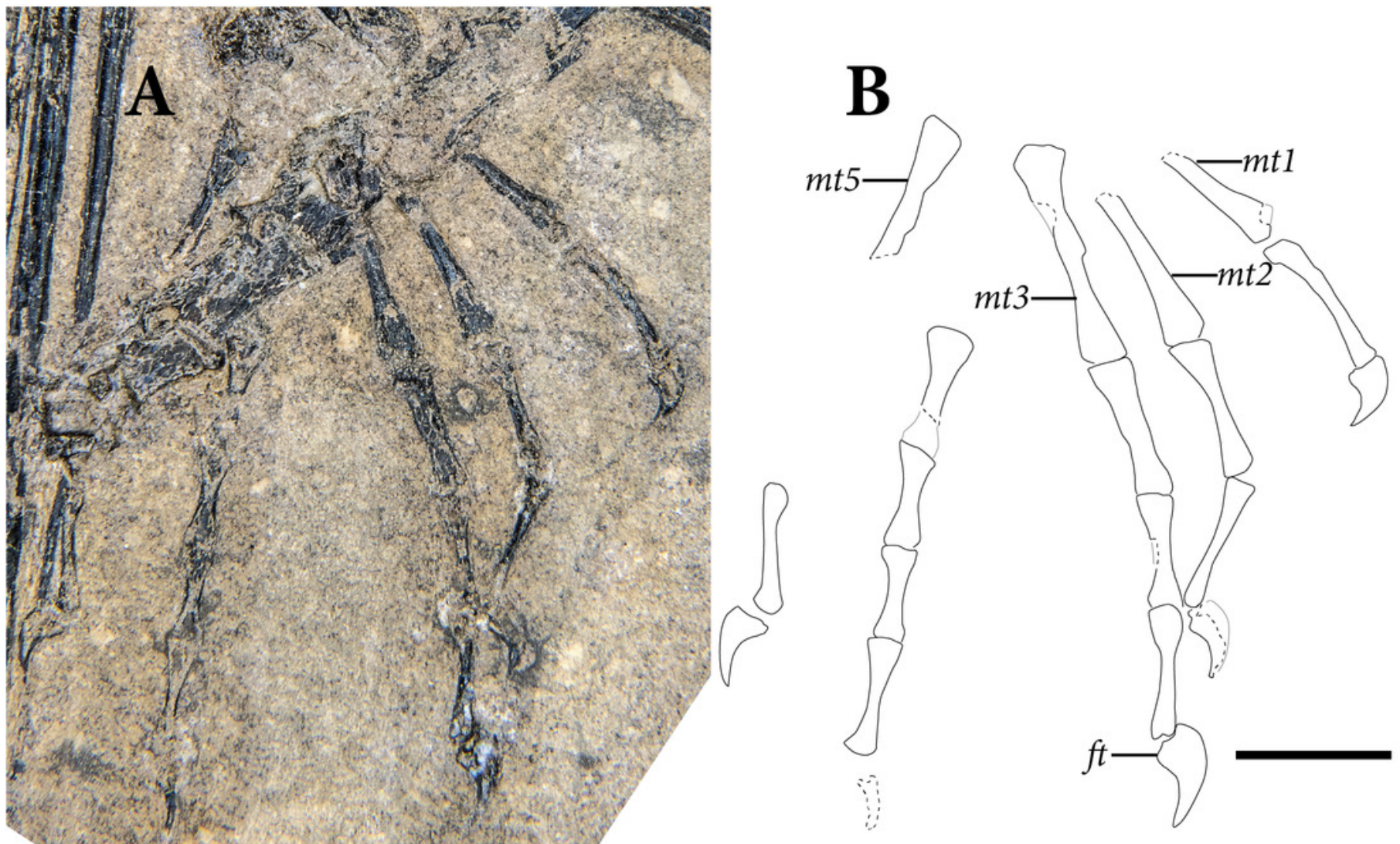
Figure 18

The left pes of SMNK-PAL 2882 (Weigeltisaurus jaekeli) in dorsal view.

A. photograph of specimen. B. Interpretative drawing demarcating the preserved margins of elements. Abbreviations: $\mathbf{f t}$, flexor tubercle; $\mathbf{m t}$, metatarsal. Scale bar equals 1 centimeter.
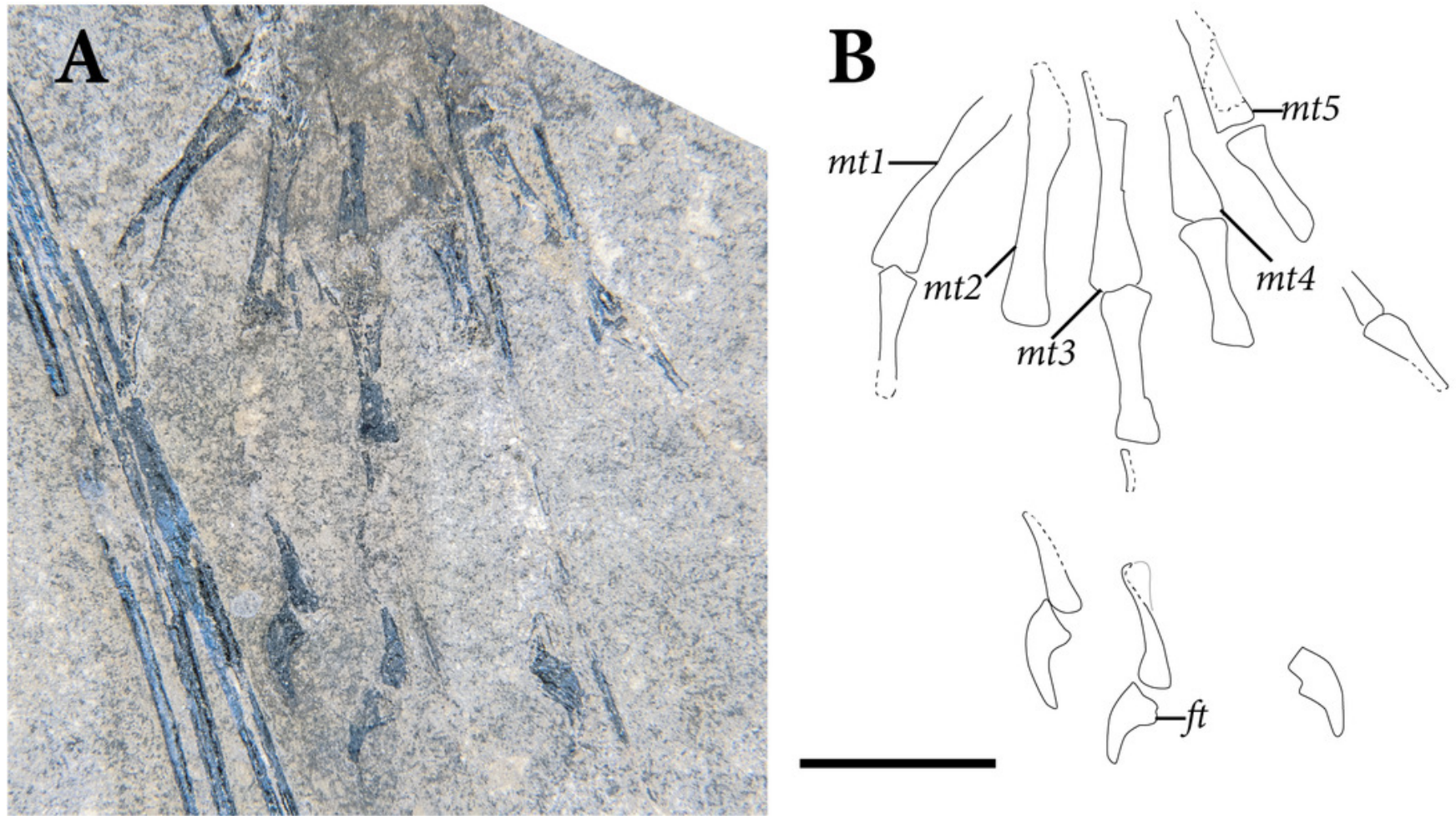


\section{Figure 19}

Patagial spars of SMNK-PAL 2882 (Weigeltisaurus jaekeli) in primarily left lateral view.

The patagial spars have been highlighted with interpretive lines on the reduced opacity image. Hashed lines indicate the positions of broken edges and gaps in the individual patagial elements. Readers may refer to Figure 2 for an unmodified photograph of the SMNKPAL 2882 slab. Scale bar equals 5 centimeters. 


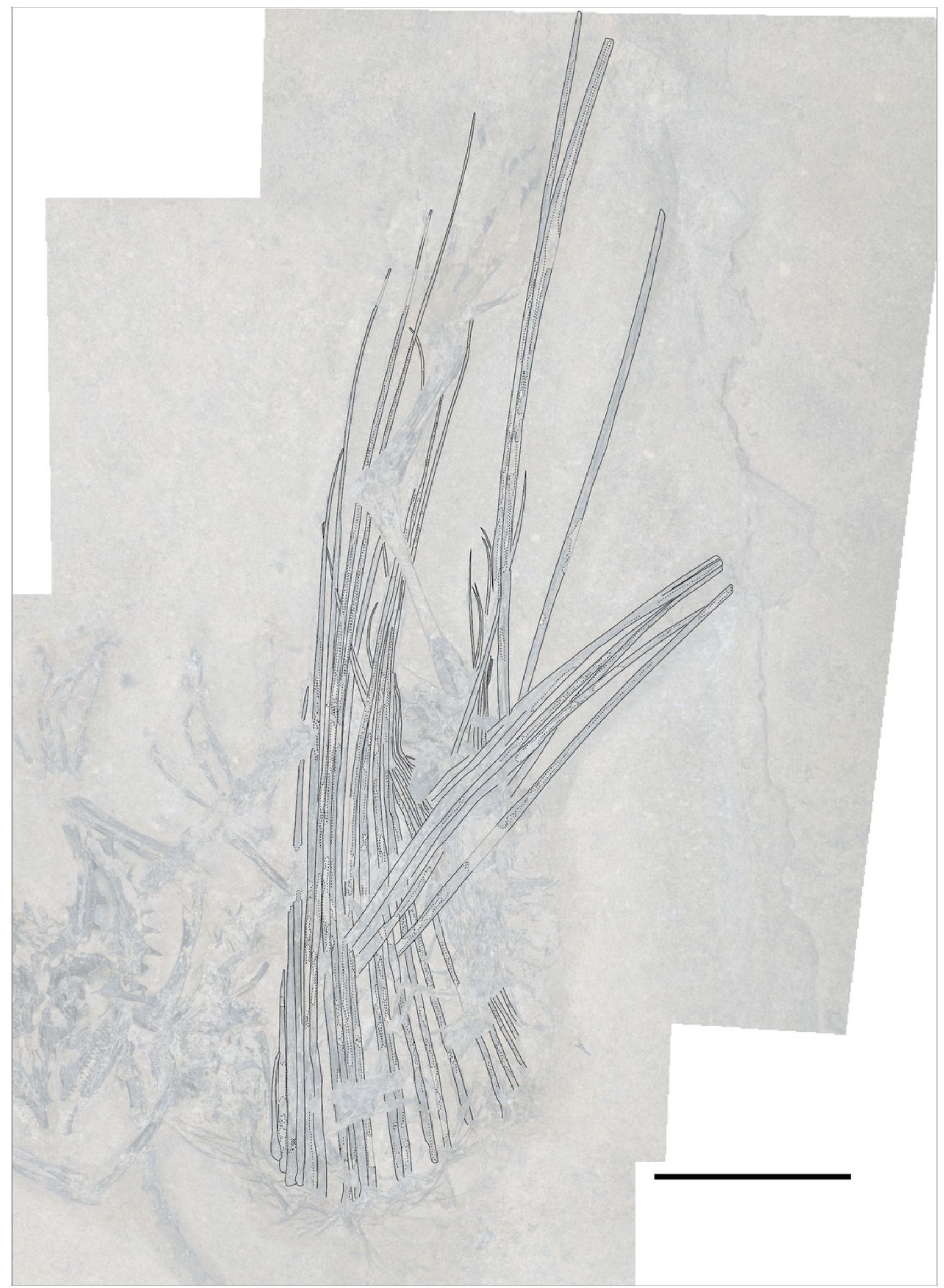




\section{Figure 20}

Schematic reconstruction of the skeleton of Weigeltisaurus jaekeli in primarily dorsal view, based on the proportions of skeletal elements in SMNK-PAL 2882.

Note that this reconstruction is intended to illustrate the proportions of the skeleton rather than a natural posture. The proportions of the mid-posterior dorsal ribs and the posterior patagial elements are based in part on the Eppleton weigeltisaurid skeleton (TWCMS B5937.1). 


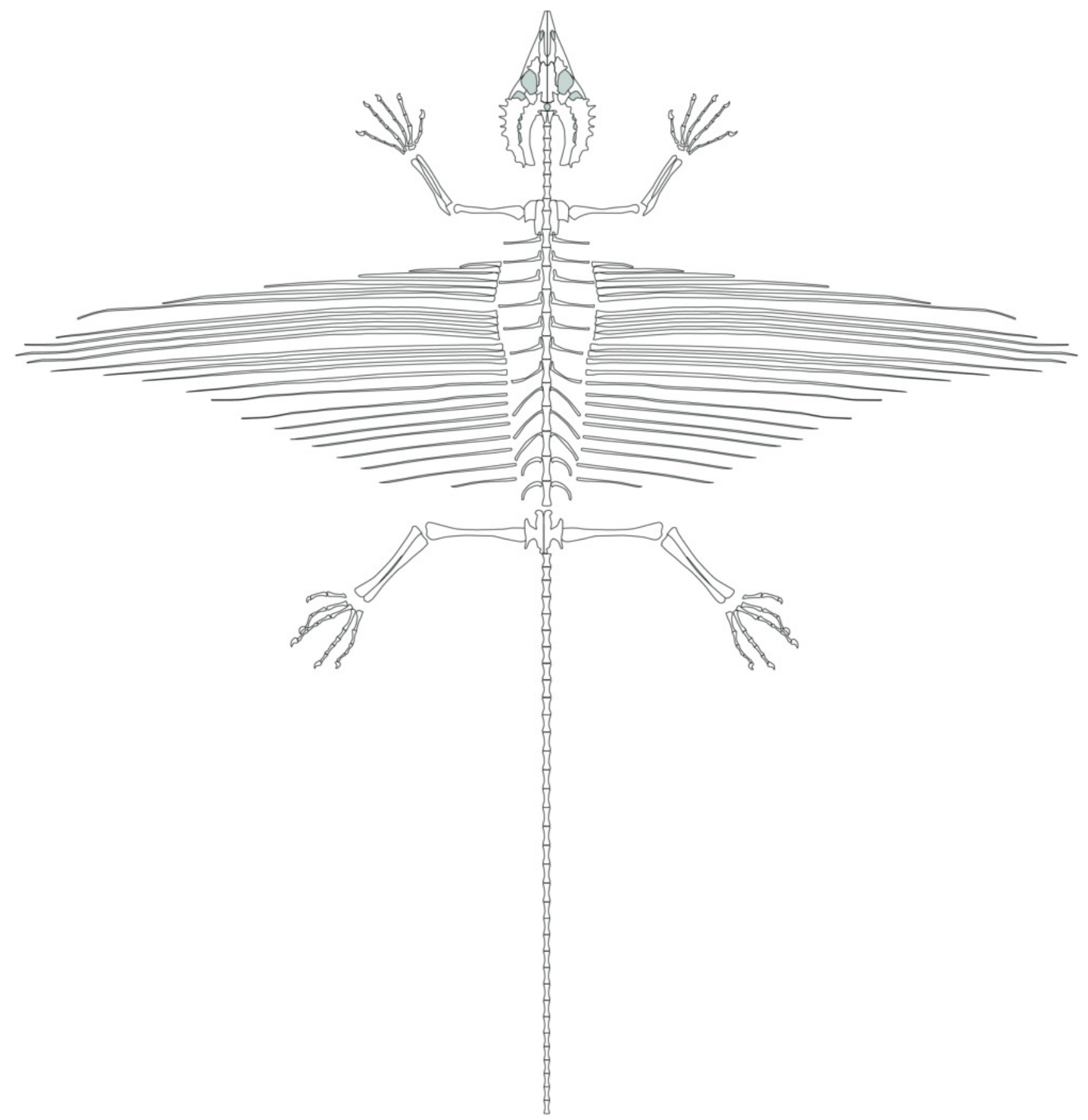




\section{Figure 21}

Simplified strict consensus tree produced by this analysis.

The topologies of Drepanosauromorpha and Sauria are congruent with those recovered by Pritchard and Sues (2019). Numbers above branches represent Bremer Support values whereas numbers below branches represent frequency differences recovered from the Jackknife analysis.

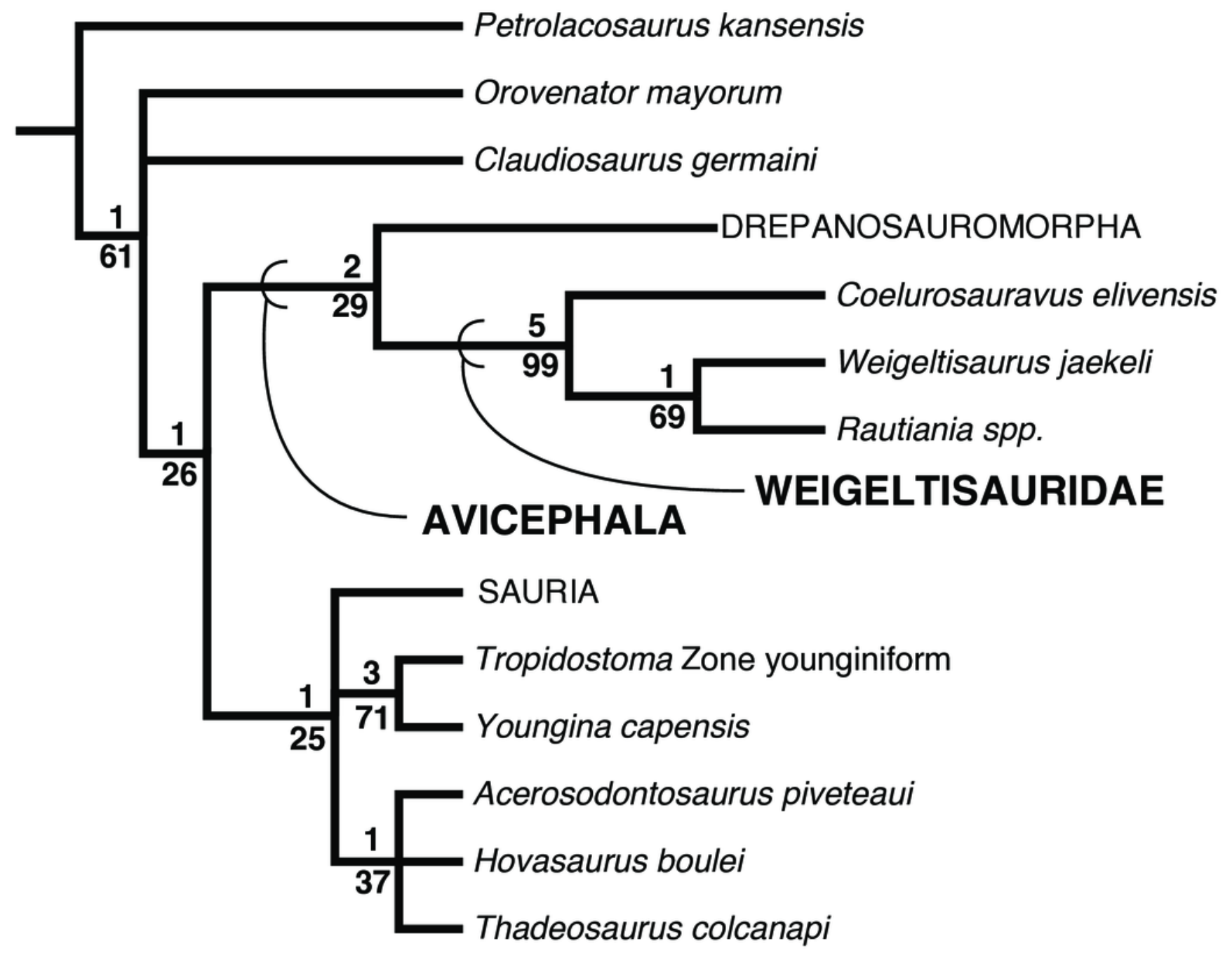




\section{Table $\mathbf{1}$ (on next page)}

Summary of extinct and extant diapsid reptiles that exhibit patagial membranes and/or associated bony support structures for gliding and flight. 
Table 1

\begin{tabular}{|c|c|c|c|c|}
\hline TAXON & Exemplar taxa & $\begin{array}{l}\text { Primary } \\
\text { Patagium } \\
\text { Support }\end{array}$ & $\begin{array}{l}\text { Stratigraphic } \\
\text { Range }\end{array}$ & $\begin{array}{l}\text { General } \\
\text { References }\end{array}$ \\
\hline $\begin{array}{l}\text { Weigeltisauridae } \\
\text { (Neodiapsida) }\end{array}$ & $\begin{array}{l}\text { Weigeltisaurus } \\
\text { jaekeli, } \\
\text { Coelurosauravus } \\
\text { elivensis, Glaurung } \\
\text { schneideri, Rautiania } \\
\text { spp. }\end{array}$ & $\begin{array}{l}\text { Dermal bone } \\
\text { spars along trunk } \\
\text { region }\end{array}$ & Upper Permian & $\begin{array}{l}\text { Schaumberg } \\
(1976,1986, \\
2007), \text { Evans } \\
\text { (1982), Frey et al. } \\
\text { (1997), Bulanov } \\
\text { and Sennikov } \\
(2006,2010 \text {, } \\
\text { 2015a).. }\end{array}$ \\
\hline $\begin{array}{l}\text { Kuehneosauridae } \\
\text { (Neodiapsida, Sauria?) }\end{array}$ & $\begin{array}{l}\text { Kuehneosaurus } \\
\text { latus, } \\
\text { Kuehneosuchus } \\
\text { latissimus, } \\
\text { Icarosaurus siefkeri }\end{array}$ & Dorsal ribs & $\begin{array}{l}\text { Lower?-Upper } \\
\text { Triassic }\end{array}$ & $\begin{array}{l}\text { Robinson (1962, } \\
\text { 1967), Colbert } \\
(1966,1970), \\
\text { Evans (2009), } \\
\text { Pritchard and } \\
\text { Nesbitt (2017) }\end{array}$ \\
\hline $\begin{array}{l}\text { Mecistotrachelos } \\
\text { apeoros } \\
\text { (Archosauromorpha?) }\end{array}$ & Single species & Dorsal ribs & Upper Triassic & $\begin{array}{l}\text { Fraser et al. } \\
(2007)\end{array}$ \\
\hline $\begin{array}{l}\text { Sharovipterygidae } \\
\text { (Archosauromorpha?) }\end{array}$ & $\begin{array}{l}\text { Sharovipteryx } \\
\text { mirabilis, Ozimek } \\
\text { volans? }\end{array}$ & $\begin{array}{l}\text { Hindlimb- } \\
\text { supported } \\
\text { uropatagium }\end{array}$ & $\begin{array}{l}\text { Middle-Upper? } \\
\text { Triassic }\end{array}$ & $\begin{array}{l}\text { Gans et al. (1987), } \\
\text { Unwin et al. } \\
\text { (2000), Dzik and } \\
\text { Sulej (2016). }\end{array}$ \\
\hline $\begin{array}{l}\text { Xianglong zhaoi } \\
\text { (Squamata) }\end{array}$ & Single species & Dorsal ribs & $\begin{array}{l}\text { Lower } \\
\text { Cretaceous }\end{array}$ & Li et al. (2007) \\
\hline $\begin{array}{l}\text { Draco (genus) } \\
\text { (Iguania) }\end{array}$ & $\begin{array}{l}\text { Draco dussumieri, } \\
\text { Draco maculatus, } \\
\text { Draco volans }\end{array}$ & Dorsal ribs & Recent & $\begin{array}{l}\text { John (1970), } \\
\text { McGuire and } \\
\text { Heang (2001), } \\
\text { Russell and } \\
\text { Dijkstra (2001) }\end{array}$ \\
\hline $\begin{array}{l}\text { Chrysopelea (genus) } \\
\text { (Serpentes) }\end{array}$ & $\begin{array}{l}\text { Chrysopelea } \\
\text { paradisi, } \\
\text { Chrysopelea ornata }\end{array}$ & Trunk ribs & Recent & $\begin{array}{l}\text { Heyer and } \\
\text { Pongsapipatana } \\
(1970), \text { Socha } \\
(2002,2006 \text {, } \\
\text { 2011), Holden et } \\
\text { al. }(2014)\end{array}$ \\
\hline $\begin{array}{l}\text { Gekkota (multiple } \\
\text { lineages) }\end{array}$ & $\begin{array}{l}\text { Ptychozoon, } \\
\text { Hemidactylus, } \\
\text { Luperosaurus }\end{array}$ & $\begin{array}{l}\text { Webbing or } \\
\text { dermal fringes } \\
\text { on feet, hands, } \\
\text { trunk, and tail }\end{array}$ & Recent & $\begin{array}{l}\text { Heinicke et al. } \\
\text { (2012) }\end{array}$ \\
\hline $\begin{array}{l}\text { Pterosauria } \\
\text { (Archosauria) }\end{array}$ & $\begin{array}{l}\text { Rhamphorhynchus } \\
\text { muensteri, } \\
\text { Pterodactylus } \\
\text { antiquus, }\end{array}$ & $\begin{array}{l}\text { Elongate } \\
\text { forelimb with } \\
\text { hypertrophied } \\
\text { fourth digit }\end{array}$ & $\begin{array}{l}\text { Upper } \\
\text { Triassic-Upper } \\
\text { Cretaceous }\end{array}$ & $\begin{array}{l}\text { Wellnhofer } \\
(1991), \text { Unwin } \\
(2005) \text {, Witton } \\
(2013)\end{array}$ \\
\hline $\begin{array}{l}\text { Scansoriopterygidae } \\
\text { (Theropoda) }\end{array}$ & $\begin{array}{l}\text { Ambopteryx } \\
\text { longibrachium, Yi qi }\end{array}$ & $\begin{array}{l}\text { Elongate } \\
\text { forelimb with } \\
\text { manual digits } \\
\text { and possible } \\
\text { styliform bone }\end{array}$ & $\begin{array}{l}\text { Upper } \\
\text { Jurassic-Lower } \\
\text { Cretaceous }\end{array}$ & $\begin{array}{l}\text { Xu et al. (2015), } \\
\text { Wang et al. (2019) }\end{array}$ \\
\hline
\end{tabular}

